SEA SURFACE SALINITY AND THE OCEAN STRUCTURE IN THE TROPICAL INDIAN OCEAN 



\title{
SEA SURFACE SALINITY AND THE OCEAN STRUCTURE IN THE TROPICAL INDIAN OCEAN
}

\author{
DISSERTATION
}

to obtain

the degree of doctor at the University of Twente, on the authority of the rector magnificus, prof.dr. T.T.M. Palstra,

on account of the decision of the Doctorate Board, to be publicly defended

on Wednesday 12 February 2020 at 14.45 uur

by

Xu Yuan

born on 13 September 1987

in Ningxia, China 
This thesis has been approved by

Prof.dr. Z. Su, supervisor

ITC dissertation number 377

ITC, P.O. Box 217, 7500 AE Enschede, The Netherlands

ISBN 978-90-365-4959-2

DOI $10.3990 / 1.9789036549592$

Cover designed by Job Duim

Printed by ITC Printing Department

Copyright (c) 2020 by Xu YUAN

\section{UNIVERSITY OF TWENTE.}

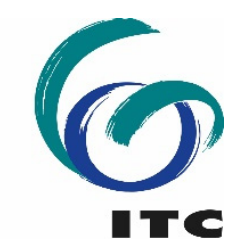


Graduation committee:

\section{Chairman/Secretary}

Prof.dr.ir. A. Veldkamp

\section{Supervisor(s)}

Prof.dr. Z. Su

University of Twente

\section{Members}

Prof.dr. D. Van Der Wa Prof.dr. V.G. Jetten

Prof.dr. W.I. Hazeleger

Prof.dr. L. Jia

niversity of Twente

University of Twente

Utrecht University

Chinese Academy of Sciences 
Little drops of water, little grains of sand, make the mighty ocean and the pleasant land.

—Julia Carney

不积跬步，无以至千里；不积小流，无以成江海。

一《荀子》 
Dedicated to my parents

献给我挚爱的父母 



\section{Acknowledgements}

This Ph.D. thesis was developed with tremendous supports and helps from numerous people, without whom the thesis could have not been completed. I would like to express my sincere gratitude to all of them for making this thesis possible.

First and foremost, I would like to express my heartfelt thanks to Prof. Zhongbo $\mathrm{Su}$, who offered me the opportunity as a Ph.D. candidate at the Faculty of GeoInformation Science and Earth Observation (ITC), University of Twente. It is my great honor to be one of his students and do research under his supervision. His valuable guidance and enthusiastic encouragement helped me overcome all the difficulties and challenges in my research. His positive and creative thinking guided me through both scientific research and daily life in the Netherlands. I am also very grateful for his immense support to fund my many trips to conferences and a three-month exchange at Woods Hole Oceanographic Institute (WHOI), where I was able to broaden my views and thoughts and kept up with the developments in my research field.

I would like to extend my sincere gratitude to Caroline C. Ummenhofer and Hyodae Seo, who co-supervised my research during my stay at WHOI and provided many constructive comments and suggestions for my thesis. Their highly-learned knowledge and patient supervision made my research much earlier and solid. Most importantly, their enthusiastic and rigorous attitude toward research inspired me to do scientific research with passion and dedication. I appreciate it very much of Caroline's honest and straight altitude, which made our communications effective and fruitful. Her useful, instructive, and detailed feedbacks and suggestions also greatly improved the quality of the paper and this thesis. Also, many thanks to Hyodae for always being supportive and helpful, especially for his tremendous efforts in helping me analyze the results and explain the mechanism behind. Without all of their patience, help, and understanding, I doubt I could complete this thesis.

I would also like to thank Dr. ir. Mhd. Suhyb Salama for his patient guidance and continuous encouragement and support at ITC. I appreciate very much for the English writing skills I learned from him. I also thank Dr.ir. C.M.M. Mannaerts for his generous help and support. I appreciate very much for the Dutch summary of my dissertation with his help. I am also in debt to Prof. Liu Xuanfei of Nanjing University of Information Science and Technology, who supervised my postgraduate study on monsoon and precipitation researches and encouraged me to pursue a Ph.D. degree abroad. I am also grateful for the Hong Kong government and Dr. Francis Tam for supporting my stay at the City University of Hong Kong (CITYU) before I went to the Netherlands. Special 
thanks to Frank Selten for the introduction of the EC earth model and many constructive talks that helped me better understand the model.

I would also like to express my sincere thanks to the China Scholarship Council (CSC) for financially supporting my Ph.D. study at the University of Twente. Without the support of CSC, my Ph.D. journey may not even be possible.

There are many other colleagues and friends from ITC and University of Twente, who, directly or indirectly, helped and supported me during the last six years. To them, I would like to express my sincere gratitude and appreciation. Special thanks to the secretaries, J. de Koning (Anke), E.L. Butt - Castro (Tina), L.M. Snijders - Nijkrake (Lindy) and Loes Colenbrander and the Chinese staff, Yijian Zeng, Lichun Wang, and Xuelong Chen for their friendly help and concerns. To my colleagues and friends, Donghai Zheng, Ying Huang, Junping Du, Xiaolong Yu, Hong Zhao, Peiqi Yang, Ruosha Zeng, Lianyu Yu, Binbin Wang, Shaoning Lv, Chenliang Liu, Qiang Wang, Mijun Zou, Yunfei Wang, Yizhe Han, ir. J.G. Hofste (Jan), ir. K.K. Kumah (Kingsley), S.M. Njuki (Sammy), M.L. Blatchford (Megan), H.F. Benninga (Harm-Jan), Bagher Bayat, B. Arabi (Behnaz), Margaret W. Kimani, Cesar Ramiro Cisneros Vaca, Q. Tian (Tina), Linlin Li, Fangyuan Yu, Jing Liu, Xi Zhu, Xiaoling Wang, Yuhang Gu, Zhihui Wang, Chenxiao Tang, Yifang Shi, Yifei Xue, Ling Chang, and many others, thanks very much for the wonderful community and all the joyful moments. May our friendships last forever.

Last, but certainly not least, I am extremely grateful to my beloved family, especially my parents, for their unwavering faith in me and unconditional love, support, and understanding. This thesis is dedicated to them.

The path to the dream is not all roses and the same is for a Ph.D. journey. Although with difficulties and setbacks, my Ph.D. journey was also full of growths and gains for both my knowledge and my personality. The last six years were the most meaningful time for me to become an independent person, not only in research but also in social life. For that, I will always be grateful for the time I spent and the people I met at ITC and the Netherlands. 


\section{Contents}

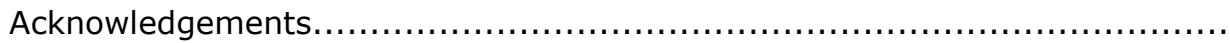

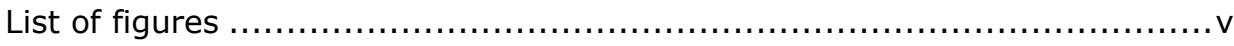

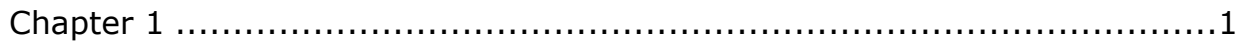

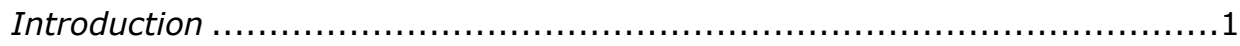

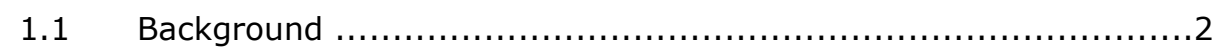

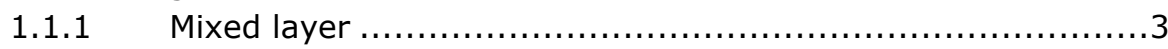

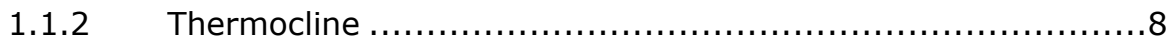

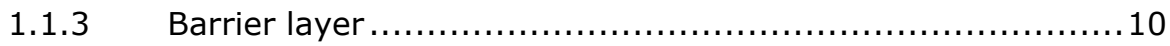

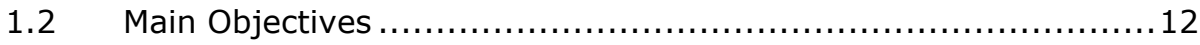

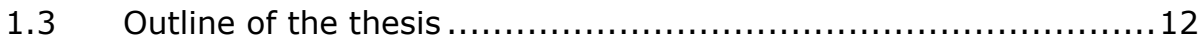

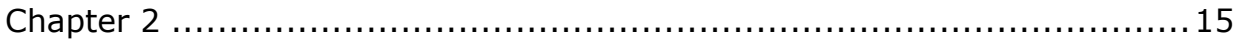

Relative contributions of heat flux and wind stress on the spatiotemporal

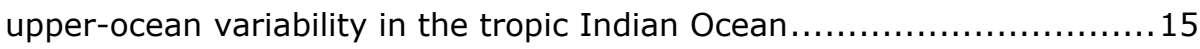

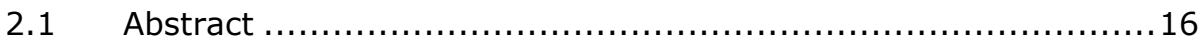

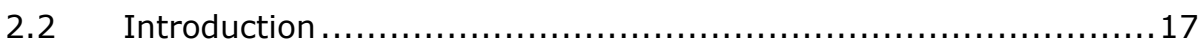

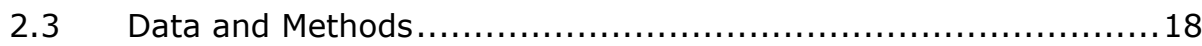

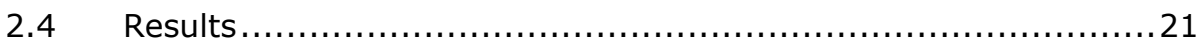

2.4.1 Upper-ocean temperature structure in the TIO $\ldots \ldots \ldots \ldots \ldots \ldots \ldots .21$

2.4.2. Depth-dependent effect of heat flux and wind stress forcing on the interannual variability of the upper-ocean temperature fields............22

2.4.3 Crossing depths: Attribution of the interannual temperature

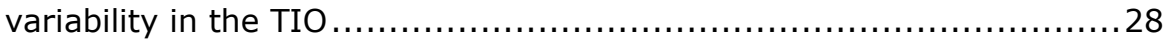

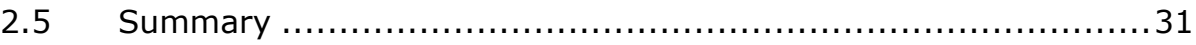

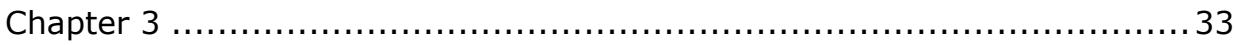

The seasonal and interannual variabilities of barrier layer thickness in the

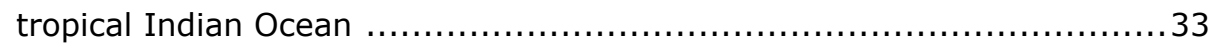

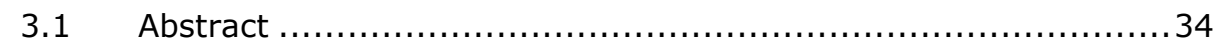

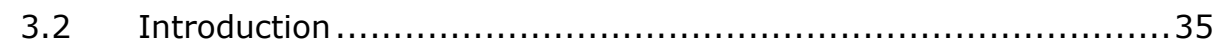

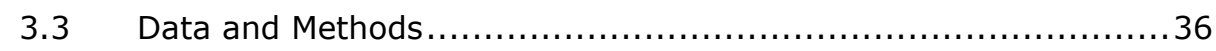

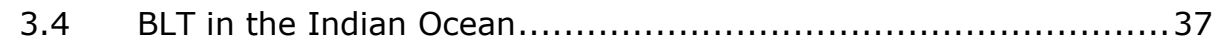

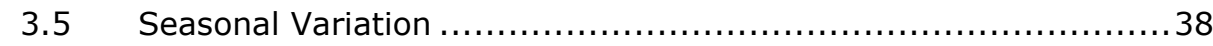

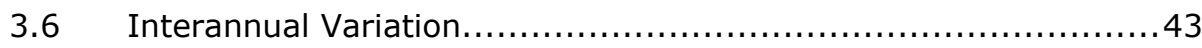

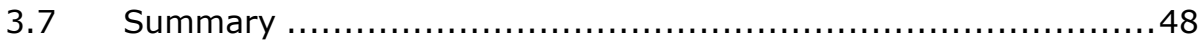

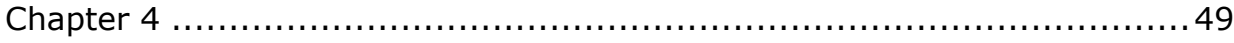

An Observational Perspective of Sea Surface Salinity in the Southwestern Indian Ocean and Its Role in the South Asia Summer Monsoon ...........49

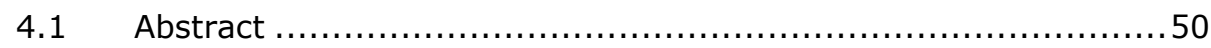

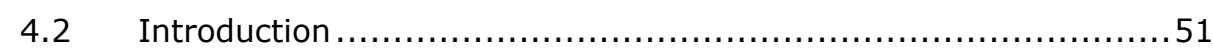

4.3 Data and Methods................................................... 52

4.4 Observed seasonal variability in sea surface salinity anomalies ....53

4.5 The relationship between SSSAs and SSTAs before the onset of SASM 56 
4.6 The external forcing for the SSSAs change ........................ 59

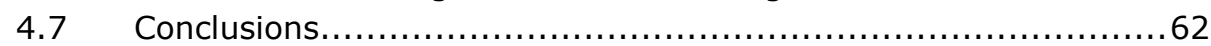

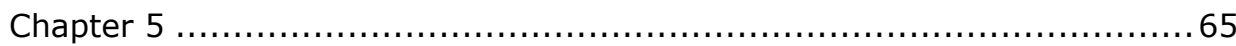

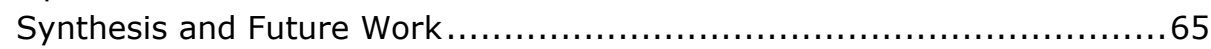

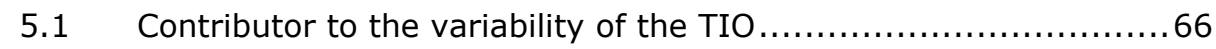

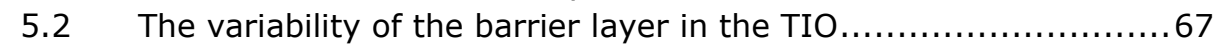

5.3 The seasonal variability of SSS in the southwestern TIO ...........68

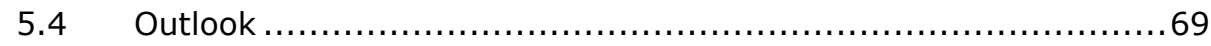

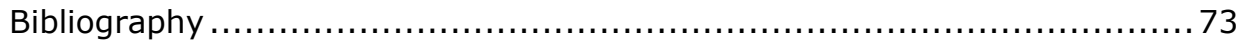

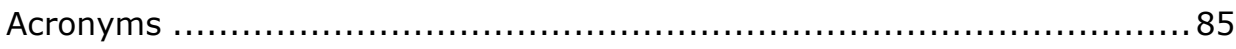

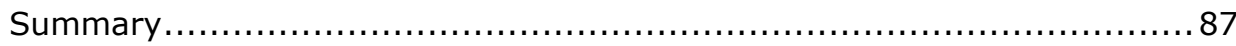

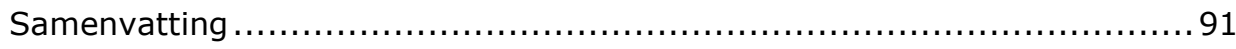




\section{List of figures}

Figure 1. 1. Schematic diagram showing the oceanic stratification in the TIO with the help of the vertical profiles of temperature (black curve) and salinity (green curve). MLD and BLT stand for mixed layer depth (yellow) and barrier layer thickness (light blue), respectively. The thermocline is shaded in red with its top short for ILD. The top layer is the distribution of sea surface temperature (shaded, unit: ${ }^{\circ} \mathrm{C}$ ) and sea surface salinity (contours, units: psu) in the TIO.

Figure 1. 2. The climatological distributions of SSS (left) and SST (right) in the Indian Ocean.

Figure 1. 3. The climatological distribution of thermocline in the Indian Ocean. 10

Figure 1. 4. The profile of temperature (blue), salinity (red) and density (black) averaged the Indian Ocean. The referencing lines are namely mixed layer depth (solid black), isothermal depth (dashed blue) and thermocline (solid red).

Figure 2. 1. Comparison of annual mean ocean temperature in the top $180 \mathrm{~m}$ across the TIO for (a) ORCA025(ALL) (b) SODA reanalysis data and (c) WOA09 averaged along $20^{\circ} \mathrm{S}-20^{\circ} \mathrm{N}$ for the time period 1952-2007. Red line represents the $20^{\circ} \mathrm{C}$ isotherm; Unit: ${ }^{\circ} \mathrm{C} . .21$

Figure 2. 2. The standard deviation of ocean temperature in the top $180 \mathrm{~m}$ across the TIO averaged for $20^{\circ} \mathrm{S}-20^{\circ} \mathrm{N}$ from (a) ORCA025(ALL) and (b) SODA during the years of 1952-2007. Dashed lines represent the isobaths of $60 \mathrm{~m}$ and $150 \mathrm{~m}$ respectively. Unit:

Figure 2. 3. Seasonal upper-ocean temperature in the top $180 \mathrm{~m}$ spatially averaged over the area of the TIO $\left(20^{\circ} \mathrm{S}-20^{\circ} \mathrm{N}, 50^{\circ} \mathrm{E}-100^{\circ} \mathrm{E}\right)$ versus depth in the OGCM simulations for ALL, HF, and WS, from 1952 to 2007 during December-January-February (DJF), March-April-May (MAM), June-July-August (JJA) and September-October-November (SON). Unit: ${ }^{\circ} \mathrm{C}$. The thick black and red lines are the $28^{\circ} \mathrm{C}$ and $20^{\circ} \mathrm{C}$ isotherms, respectively. . 24

Figure 2. 4. Spatial distributions of the standard deviations of interannual (ac) SST $\left[{ }^{\circ} \mathrm{C}\right]$ and $(e-g)$ thermocline $[\mathrm{m}]$ obtained from three sets of model simulations and their corresponding probability distribution functions (PDF) within the TIO $\left(20^{\circ} \mathrm{S}-20^{\circ} \mathrm{N}, 50^{\circ} \mathrm{E}-\right.$ $100^{\circ} \mathrm{E}$ ).In the PDF of (d) SST and (h) thermocline, blue, green, and red curves represent ALL, HF, and WS, respectively.......26

Figure 2. 5. Annual upper-ocean temperature in the top $180 \mathrm{~m}$ spatially averaged over the areas of the TIO $\left(20^{\circ} \mathrm{S}-20^{\circ} \mathrm{N}, 50^{\circ} \mathrm{E}-100^{\circ} \mathrm{E}\right)$, SCTR $\left(12^{\circ} \mathrm{S}-5^{\circ} \mathrm{S}, 50^{\circ} \mathrm{E}-75^{\circ} \mathrm{E}\right)$, WTIO $\left(5^{\circ} \mathrm{S}-5^{\circ} \mathrm{N}, 50^{\circ} \mathrm{E}-75^{\circ} \mathrm{E}\right)$ and ETIO $\left(10^{\circ} \mathrm{S}-\mathrm{EQ}, 80^{\circ} \mathrm{E}-100^{\circ} \mathrm{E}\right)$ versus depth in the OGCM 
simulations for ALL, HF, and WS, from 1952 to 2007 . Unit: ${ }^{\circ} \mathrm{C}$. The thick black and red lines are the $28^{\circ} \mathrm{C}$ and $20^{\circ} \mathrm{C}$ isotherms, respectively. 27

Figure 2. 6. The profiles of the standard deviation of interannual subsurface temperature averaged along $\left(50^{\circ} \mathrm{E}-100^{\circ} \mathrm{E}\right)$ in different latitudes versus depth. Unit: ${ }^{\circ} \mathrm{C}$. Black, blue and red lines represent ALL, $\mathrm{HF}$ and WS separately. The latitudes are $6^{\circ} \mathrm{N}$, equator (EQ), $4^{\circ} \mathrm{S}, 8^{\circ} \mathrm{S}, 12^{\circ} \mathrm{S}, 16^{\circ} \mathrm{S}$, and $20^{\circ} \mathrm{S}$, respectively. 28

Figure 2. 7. The distribution of the crossing depth in the TIO. The boxes represent the locations of SCTR and IODE, respectively........30

Figure 2. 8. The seasonal variations of the crossing depth (a) and the vertical profiles of the standard deviation of interannual ocean temperature during (b),(f) DJF, (c),(g) MAM, (d), (h)JJA and (e),(i) SON averaged in the SCTR and IODE respectively. Blue and orange lines represent the crossing depth of SCTR and IODE separately. Black, red and green lines represent ALL, WS and $\mathrm{HF}$, respectively. The horizontal dashed line represents the depth of $30 \mathrm{~m}$, and the vertical dashed line represents the $1.5^{\circ} \mathrm{C}$ standard deviation.

Figure 3. 1 The distributions of the climatological mean of BLT obtained from Argo (a) and SODA (b) from 2005 to 2015 in the Indian Ocean (Unit: $m$ ).

Figure 3. 2. The seasonal distributions of SSS (unit: psu; a-d) and BLT (units: m; e-h) in the Indian Ocean from 1980 to 2015 (The two black lines represent the latitudes of $12^{\circ} \mathrm{S}$ and $5^{\circ} \mathrm{N}$ respectively).

Figure 3. 3. Simultaneous correlations along the area of $\left(12^{\circ} \mathrm{S}-5^{\circ} \mathrm{N}\right)$ for $(\mathrm{a})$ SST and (b) SSSAs in respect to BLT anomalies [Shaded areas exceed the $95 \%$ significance level; red (blue) shaded areas represent the areas with the positive (negative) correlation coefficients].

Figure 3. 4. Lead - leg crossing correlations between BLT and SSSAs for (a) January, (b) April, (c) July, and (f) October along the area of $\left(12^{\circ} \mathrm{S}-5^{\circ} \mathrm{N}\right.$ ) from 1980 to 2015 (Shaded areas exceed 95\% significance level; Positive lag means SSS leads BLT; blue shaded areas represent the negative correlation; the thick black dashed line represents the in-phase correlation ).......44

Figure 3. 5. Same as Figure 3.4 but for thermocline and BLT anomalies [red (blue) shaded areas represent the positive (negative) correlation; the thick black dashed line represents the in-phase correlation]....

Figure 3. 6. The composting seasonal variations of SSS ( $a, b$; unit: psu), BLT (c, d; unit: $m$ ) and thermocline (e, f; unit: $m$ ) in the IOD events during the period of 1980-2015 averaged by the areas 
of the eastern $\mathrm{TIO}\left(90^{\circ} \mathrm{E}-100^{\circ} \mathrm{E}, 12^{\circ} \mathrm{S}-5^{\circ} \mathrm{N}\right)$ and the western $\operatorname{TIO}\left(50^{\circ} \mathrm{E}-75^{\circ} \mathrm{E}, 12^{\circ} \mathrm{S}-5^{\circ} \mathrm{N}\right)$, separately. The blue line represents compositing in the positive IOD events, and the red one represents that in the negative IOD events, and the green shaded area represents the $95 \%$ Monte-Carlo significance level.

Figure 3. 7. Same as Figure 3.6 but compositing on the El Niño and La Nina years.

Figure 3. 8. Time series of BLT, SSS and thermocline anomalies averaged over the western $\mathrm{TIO}\left(12^{\circ} \mathrm{S}-5^{\circ} \mathrm{N}, 50^{\circ} \mathrm{E}-75^{\circ} \mathrm{E}\right)$ during winter (a) and spring (b) from 1980 to 2010. Red, green, and blue lines represent BLT, SSS, and thermocline, respectively....

Figure 3. 9. Lagged correlations of (a) BLT, (b) thermocline, (c) SSS anomalies, (d) precipitation anomalies, and (e) zonal wind stress anomalies averaged in $\left(12^{\circ} \mathrm{S}-5^{\circ} \mathrm{N}\right)$, with the Nino3.4 index as a function of longitude and calendar month. Shaded areas exceed a $95 \%$ significance level; positive lagging correlations are shaded in red and negative ones are in blue; the thick black dashed line represents the start of the decaying phase of El Niño.

Figure 4. 1. Seasonal variability of sea surface salinity in the Indian Ocean. The annual cycle of sea surface salinity anomalies by (a) Aquarius dataset during 2012-2014 and (b) Argo dataset during 2005-2014. A, B and C (see January) denotes the eastern part ( $\left.A_{E I O}\right)$, the central part ( $\left.B_{C I O}\right)$ and the western part $\left(C_{\text {wio }}\right)$ of the Indian Ocean, respectively. 54

Figure 4. 2. Time-latitude diagrams (a) of SSSAs between $60^{\circ} \mathrm{E}$ and $80^{\circ} \mathrm{E}$ and hovmöller diagrams (b) of SSSAs along the area of $10^{\circ} \mathrm{S}$ and $10^{\circ} \mathrm{N}$ in Argo and Aquarius (Unit: psu, the dashed lines enclose the SSSAs ESF areas).

Figure 4. 3. Seasonal variability and tendency for both SSSAs (obtained from Argo, in blue) and SSTAs (obtained from NOAA; in red) in the areas $\left[(\mathrm{a}, \mathrm{c}) ; 60^{\circ} \mathrm{E}-80^{\circ} \mathrm{E}, 10^{\circ} \mathrm{S}-5^{\circ} \mathrm{S}\right]$ and $\left[(\mathrm{b}, \mathrm{d}) ; 60^{\circ} \mathrm{E}-80^{\circ} \mathrm{E}\right.$, $\left.5^{\circ} \mathrm{N}-10^{\circ} \mathrm{N}\right]$ for 2005 to 2014 . Unit: psu; ${ }^{\circ} \mathrm{C}$

Figure 4. 4. Same as Figure 4.3 but for SSS data obtained from Aquarius... 57

Figure 4. 5. Seasonal variability for both BLT (in blue) and MLD anomalies (in red) in the areas $\left[(\mathrm{a}) ; 60^{\circ} \mathrm{E}-80^{\circ} \mathrm{E}, 10^{\circ} \mathrm{S}-5^{\circ} \mathrm{S}\right]$ and $\left[(\mathrm{b}) ; 60^{\circ} \mathrm{E}-\right.$ $80^{\circ} \mathrm{E}, 5^{\circ} \mathrm{N}-10^{\circ} \mathrm{N}$ ] for 2005 to 2014 (The shaded areas are the standard deviation, the solid black line represents the time that SSSAs change and dotted black line represents the time that the tendency of SSSAs change.). Unit: $\mathrm{m}$. ...

Figure 4. 6. Freshwater flux anomalies. (a) Monthly mean freshwater flux in February (a) and April (b) from 2005 to 2014. (Unit: cm/yr). 
The box (in black line) denotes the SSSAs ESF area $\left(60^{\circ} \mathrm{E}-\right.$

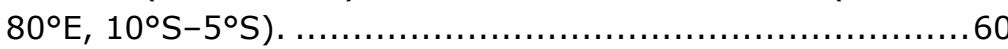

Figure 4. 7. Wind stress and wind stress curl anomalies. (a) Monthly mean wind stress (vector) and wind stress curl anomalies (shaded) in February and April from 2008 to 2014. (b) Differences in wind stress and wind stress curl anomalies as February minus January and April minus February, respectively. (Unit: $\mathrm{N} / \mathrm{m}^{2}$; $\mathrm{N} / \mathrm{m}^{3}$ ). (c) Differences in the surface zonal wind $(10 \mathrm{~m})$ obtained from ERA-interim difference as February minus January and for April minus February, respectively (Unit: m/s). [The boxes in black line are the SSSAs ESF area in the southern Indian Ocean $\left(60^{\circ} \mathrm{E}-80^{\circ} \mathrm{E}, 5^{\circ} \mathrm{S}-10^{\circ} \mathrm{S}\right)$; the green plus mark represents downwelling, and the green closed circle represents upwelling ].

Figure 4. 8. Diagram of the potential mechanism between SSSA and the onset of SASM along $60^{\circ} \mathrm{E}-80^{\circ} \mathrm{E}$ (Gradually increasing red rectangles represent the increasing SSSA, and the blue ones represent the decreasing SSTA; In addition, the orange hollow rectangles represent the increasing SSTA, and the black dotdashed rectangle indicates the period with large SSTA gradient).

Figure 5. 1. The vertical profiles of the standard deviation of interannual ocean temperatures averaged by the area of SCTR (a) and IODE (b), respectively. Red, green and black lines represent the WS, HF and ALL, separately. The upper blue dashed line represents the depth of $30 \mathrm{~m}$ and the lower one represents thermocline. 
Chapter 1

Introduction 


\subsection{Background}

The Indian Ocean, surrounded by three continents, is a semi-open ocean and has unique features compared to other oceans. For example, the absence of stable westerlies along the equator in the Indian Ocean results in warmer water in the east but colder one in the west. Vertically, the isotherms are declining from the west to the east, which is opposite to that observed in the Pacific and Atlantic Ocean (Han et al. 2014; Schott et al. 2009). The variabilities of the Indian Ocean could be determined by different atmospheric circulations for different time scales. Particularly, the prominent seasonal variability of the Indian Ocean is related to the monsoon trade winds (Minoura et al. 2003; Webster and Fasullo 2003), which affects the monsoon precipitation in eastern Africa (Reason 2001; Ummenhofer et al. 2009b), India (Clark et al. 2000; Parthasarathy et al. 1994; Prasanna 2016) and Australia (Ummenhofer et al. 2008). Annamalai et al. (2005) indicated that the seasonal variability of the Indian Ocean could have an impact on the eastern Asian monsoon rainfall. At the interannual time scale, the Indian Ocean, on the one hand, acts as a passive receiver responding to the variability of the Pacific Ocean, such as the El Niño-Southern Oscillation (ENSO) (Alexander et al. 2002; Cherchi and Navarra 2013). On the other hand, it acts as an independent initiator to affect the local and remote atmospheric circulations (Du et al. 2013; Feng et al. 2014). Therefore, well-acknowledging the variabilities of the Indian Ocean will promote the understanding of the air-sea interaction and improve the prediction of the climate variabilities.

Three layers of the oceanic stratification are generally considered, i.e., the mixed layer, the thermocline, and the barrier layer. Figure 1.1 briefly illustrates the oceanic stratification and the relative location of the three layers in the tropical Indian Ocean (TIO). In the following, we introduce in detail the history and the state-of-the-art on the researches of the three layers in global oceans and the TIO. 


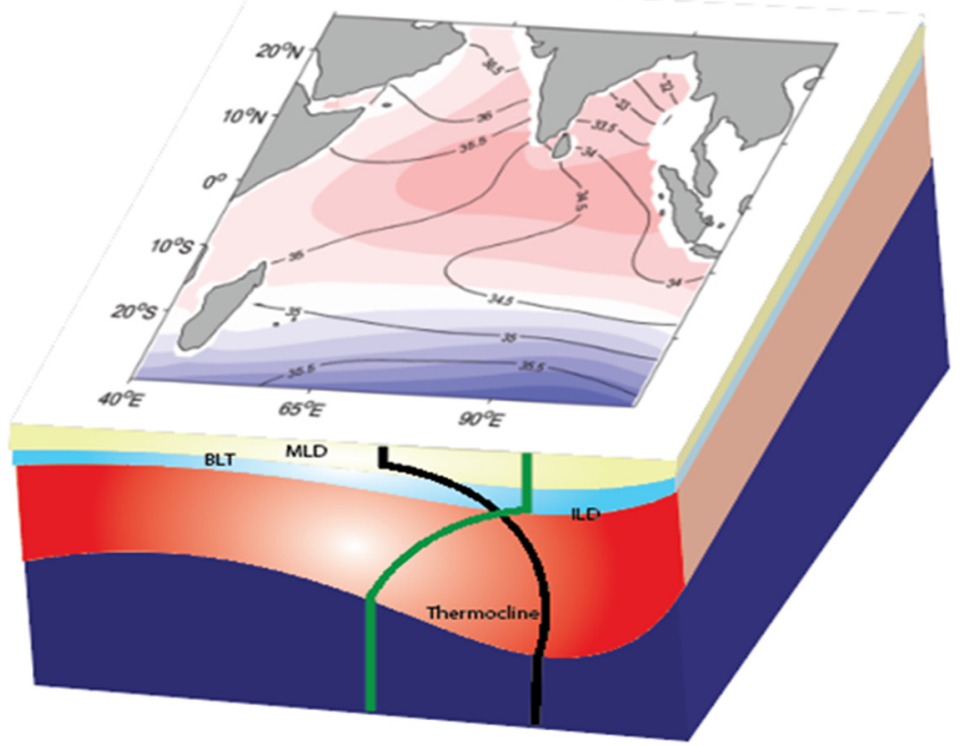

Figure 1. 1. Schematic diagram showing the oceanic stratification in the TIO with the help of the vertical profiles of temperature (green curve) and salinity (black curve). MLD and BLT stand for mixed layer depth (yellow) and barrier layer thickness (light blue), respectively. The thermocline is shaded in red with its top short for ILD. The top layer is the distribution of sea surface temperature (shaded, unit: ${ }^{\circ} \mathrm{C}$ ) and sea surface salinity (contours, units: psu) in the TIO.

\subsubsection{Mixed layer}

The mixed layer is well known as the layer with strong mixing induced by wind stress and heat flux, which is crucial to the air-sea interaction, containing the amount of transaction of mass, momentum, and energy (Lukas and Lindstrom 1991; McCreary Jr et al. 1993; Schiller and Oke 2015). In addition, the thickness of the mixed layer determines the oceanic heat content (Foltz et al. 2003), linking to many spatiotemporal processes, such as internal waves (Garrett and Munk 1972), atmospheric forcing (Anderson et al. 1996) and lateral advection (Armi. 1978).

In this section, we introduce the variability of the mixed layer by giving the background of sea surface temperature (SST) and sea surface salinity (SSS) because of two reasons. One is the oceanic density, which is vital to the oceanic dynamics and is nonlinearly correlated to the temperature and salinity and the other is that the ocean temperature and salinity are treated as vertically uniform in the mixed layer. 


\subsubsection{Sea Surface Temperature}

The spatiotemporal features of SST in the TIO have been intensively investigated in the last few decades. SST in the TIO presents a unique spatial distribution with warmer upper-ocean temperature in the east (Figure 1.2. right), referring to the Indo-Pacific warm pool (Xie et al. 2014). The variabilities of SST in the TIO play vital roles in the global heat budget cycle, mainly interacting with the atmosphere. Therefore, understanding the variabilities of SST in the TIO is desperately demanded.

Three prominent modes of SST in the TIO are studied in previous researches in terms of the interannual time scale, namely the basin warming mode (IOB), the zonal dipole mode (IOD) and the subtropical dipole mode (IOSD), respectively. Firstly, the $\mathrm{IOB}$ is the dominant empirical orthogonal function (EOF) spatial mode of SST in the TIO attributed to the increasing heat flux induced by the El Niño-Southern Oscillation (ENSO) (Du et al. 2009; Yang et al. 2007). The IOB could weaken the land-ocean thermal gradient, leading to a weaker South Asian Summer monsoon (Yang et al. 2007) and even a weaker East Asian Summer Monsoon ( $\mathrm{Li}$ et al. 2008). However, the IOB is not merely a passive phenomenon dominated by $\mathrm{El} \mathrm{Niño.} \mathrm{It} \mathrm{operates} \mathrm{a} \mathrm{negative} \mathrm{feedback}$ mechanism to the ENSO by influencing the atmospheric circulation in the northern TIO (Kug and Kang 2006; Yang et al. 2010; Yang et al. 2009). Secondly, the IOD mode, as the second EOF mode, has become the hotly debated topic since the late $90 \mathrm{~s}$, which is characterized as the zonal SST gradient between the eastern and western TIO. The positive IOD is the pattern with warmer water in the west and colder water in the east, and the negative one is vice versa. Thereby, the intensity of IOD is defined as the anomalous SST gradient between the area of $\left(50^{\circ} \mathrm{E}-70^{\circ} \mathrm{E}, 10^{\circ} \mathrm{S}-10^{\circ} \mathrm{N}\right)$ and $\left(90^{\circ} \mathrm{E}-\right.$ $\left.110^{\circ} \mathrm{E}, 10^{\circ} \mathrm{S}-\mathrm{EQ}\right)$, known as IOD index (Saji et al. 1999). IOD could be triggered by ENSO (Schott et al. 2009). But recent researches pointed out that IOD could be induced by local anomalous monsoon wind (Sun et al. 2015), having an independent forming system from ENSO. Generally, four main differences between IOD and ENSO have been introduced by Li et al. (2003), which include the in-phase cloud-SST relationship, the function of oceanic waves, the thermodynamic air-sea interaction and the monsoon feedback. The effect of IOD on atmospheric circulation is prominent. For example, it could independently influence the variability of the monsoon rainfall through modulating the local atmospheric circulation (Crétat et al. 2016; Pokhrel et al. 2012; Prasanna 2016; Prodhomme et al. 2014; Roxy et al. 2015). And the positive IOD could be an indicator of the rate of the South Asian summer monsoon rainfall associating with ENSO (Ashok et al. 2004; Maity and Nagesh Kumar 2006). Last but not the least, although IOSD is the main SST pattern in the sub-topic, shown as a positive phase characterized by warmer water in the south of Madagascar and colder water off Australia, it could increase the 
rainfall in the Southern Africa via adjusting the moisture transportation (Behera and Yamagata 2001; Reason 1999, 2001). Moreover, these three main SST modes could be combined and result in severe rainfall in the adjacent continents. For instance, the IOD and IOSD joined together and led the rainfall in southeast Africa and southwest Western Australia (Ummenhofer et al. 2008; Ummenhofer et al. 2009b).

Therefore, a better understanding of the variability of SST in the TIO could be beneficial to further study the nearby monsoon rainfall, such as the South Asian Monsoon, the African Monsoon, and the Australia monsoon. Moreover, the remote correlation through atmospheric bridge allows the SST in the TIO to potentially predict the East Asian Monsoon (Yang et al. 2007) and the variability of the Pacific Ocean (Nagura and Konda 2007).

\subsubsection{Sea Surface Salinity}

The impact of SSS is underestimated compared to the SST because it cannot directly interact with the atmosphere and has relatively weaker variabilities. However, SSS, as one important component of the ocean density, not only plays an important role in the ocean dynamical and thermodynamical processes but is also a part of the global hydrological cycle, indicating the intensifying water cycle (Durack et al. 2012).

The primary issue for studying the SSS is to obtain a high-quality SSS dataset. With the development of observing technology, creditable SSS datasets with high-resolution and daily coverage over the global ocean could be obtained. In this thesis, we mainly use three SSS datasets, namely the ocean reanalysis data, the float in situ data, and the satellite data. For the ocean reanalysis data, its most significant merit is that it has the long-term SSS data for the interannual or even decadal time scale study. We use the latest version of the Simple Ocean Data Assimilation (SODA) version 3 from 1980 to 2015 on a grid of $1^{\circ} \times 1^{\circ}$. The major improvement of the latest version is that a high-resolution ocean model with an expanded vertical level is employed compared to the previous version. SODA version 3 has reduced systematic errors in the upper ocean and improved the accuracy of variability in the tropics, along with a reduction in freshwater flux bias (Carton et al. 2018). For the float in situ data, the advantage is that it has continuous observation data in near-real-time. We employ the monthly SSS data obtained from the Argo product. Argo is a compiled dataset with measurements of salinity and temperature profiles from international collaboration, which has uniform geographical distribution in the upper $2000 \mathrm{~m}$ and was firstly launched in 1999 (Roemmich and Gilson 2009). For the satellite data, three products are widely employed in recent times, namely the Aquarius, the Soil Moisture and Ocean Salinity (SMOS) and the Soil Moisture Active Passive (SMAP). Aquarius is designed to observe the global 
SSS for better studying climate change and the global water cycle. Qu et al. (2014) indicated that SSS obtained from Aquarius has the advantage in resolving the zonal displacement along the equator to represent the capacity of warm ocean pool and cold tongue. In addition to this, by using Aquarius SSS data, it was found that faster propagation speed of SSS, distinguishing from that of SST and sea surface height (SSH), could be used to observe the tropical instability waves (Lee et al. 2012; Menezes et al. 2014). SMOS provides the observations of the global soil moisture over lands and sea surface salinity over the oceans for the forecast of weather and climate. In the previous studies, the SMOS SSS data has been validated against the Argo float data with relatively good consistency observed in the world ocean, but the SSS data obtained from SMOS in the northern TIO still contain significant bias (Boutin et al. 2013; Kerr et al. 2001). Although the primary mission of SMAP is to measure soil moisture, it is possible to retrieve salinity. The SSS of SMAP has also been validated with Argo data and presents a quite good agreement, especially in the northern TIO (Tang et al. 2017).

The typical spatial feature of SSS in the TIO presents an east-west contrast with saltier water in the Arabian Sea (AS) and fresher water in the Bay of Bengal (BOB), as shown in Figure 1.2. (left). The fresher water in the BOB is due to the amount of runoff and precipitation (Rao 2003; Subrahmanyam et al. 2011b). SSS could exchange between AS and BOB attributed to the seasonal wind change, such as the Wyrtki Jets (Rao 2003). Thus, the seasonal variability of SSS in the TIO is relatively significant, which even could be captured by a sparse ship dataset, especially during the monsoon period (Donguy and Meyers 1996).

In order to thoroughly understand the seasonal variability of SSS in the TIO, the mixed layer salinity tendency equation is adopted in previous studies (Nyadjro et al. 2012; Rao and Sivakumar 2003), which displays as follows:

$\frac{\partial S}{\partial t}=\underbrace{-\left(\frac{(P-E) S}{h}\right)}_{(1)} \underbrace{-\left(U \frac{\partial S}{\partial x}+V \frac{\partial S}{\partial y}\right)}_{(2)} \underbrace{-W_{e}\left(\frac{S-S_{-h}}{h}\right)}_{(3)} \underbrace{+R}_{(4)}$.

Where $S$ stands for the vertically averaged mixed layer salinity anomalies, $P$ for precipitation, $E$ for evaporation, $h$ for the mixed layer depth (MLD), $U(V)$ for the zonal (meridional) component of velocity, $W_{e}$ for entrainment velocity $\left\{W_{e}=H\left(w_{h}+\frac{d h}{d t}\right), H\right.$ is Heaviside step function and $w_{h}$ is the vertical advection below mixed layer inferred from $20^{\circ} \mathrm{C}$ isotherm topography\}, which is proved to be positive, because of the entrainment upwards from the lower layer to the mixed layer, $S, S_{-h}$ for salinity in and below the mixed layer depth and $R$ for the turbulent term in the mixed layer. Term (1) on the right side of the equation 
represents the influence of the sea surface freshwater flux, the term (2) represents the horizontal advection of salinity, the term (3) describes the entrainment of water from below, and term (4) is the turbulent function.

Accordingly, based on the pure model studies, it has been proven that the first two terms of the tendency equation mainly dominate the seasonal variability of SSS in much of the TIO (Han and McCreary, 2001). The freshwater (Term (1), P, E and river water flows) drives the seasonal variability of SSS in the $\mathrm{BOB}$, and the horizontal advection (Term (2), Indonesia through flow) contributes to the SSS variation during the monsoon seasons in the AS (Rao and Sivakumar 2003). Further, combining the Hybrid Coordinate Ocean Model (HYCOM) simulated data with the Argo float in situ data, the seasonal variability of SSS has also been proven to be affected by the horizontal advection associated with the monsoon currents in the AS and BOB (Zhang and Du, 2012a). Particularly, SSS in the southeastern AS is affected by the east Indian coastal current and winter monsoon current (Subrahmanyam et al., 2011a). Moreover, the annual variability of SSS in the eastern equatorial TIO is characterized as having the semi-annual variability due to the freshwater and zonal currents (Subrahmanyam et al., 2011a). Since satellite becomes more popular as an observational tool, the features of the SSS seasonal variation in the TIO discovered by the model could be observed from the satellite data as well (Bhaskar and Jayaram 2015; Durand et al. 2013; Menezes et al. 2014; Qu et al. 2014).

The interannual variabilities of SSS in the TIO have been studied mostly with the IOD events. In particular, a dipole of sea surface salinity anomalies (SSSAs) was first observed during the positive IOD years obtained from model simulations, with saltier water in the southeastern equatorial TIO and fresher water in the central equatorial TIO (Thompson et al. 2006), and its dynamics were explained by using the oceanic reanalysis data. The positive SSS dipole (saltier water) in the southeastern equatorial TIO is resulted by the upwelling due to the anomalous easterlies and oceanic waves while the negative SSS dipole (fresher water) in the central equatorial TIO is in response to the SSS advection from the BOB (Grunseich et al. 2011b). On the other hand, during the negative IOD events, SSS also presents significant variation. But the anomalous SSS dipole in the negative IOD years moves northward associated with the anomaly easterlies (Subrahmanyam et al. 2011a). Meanwhile, relatively fresher water was revealed in the southeastern TIO attributed to the IOD-induced anomalous westerlies along the equator via reducing the local upwelling and freshening the local water (Du and Zhang 2015).

Furthermore, the intra-seasonal variability of SSS is investigated, accompanying the Madden Julian Oscillation (MJO). In previous studies, many research results have shown that SSS could be an indicator for the MJO 
because of its relationship with the freshwater flux and horizontal advection (Drushka et al. 2012; Horii et al. 2015; Matthews et al. 2010). However, these results are only based on the in situ float data and oceanic reanalysis data. Recently, Grunseich et al. (2011a) indicated that SSS derived from the satellite data was more suitable to investigate the intra-seasonal variability of SSS. For instance, SSSAs could be observed along with the evolution of MJO via convection obtained from Aquarius satellite data (Grunseich et al. 2013), which suggested that there was an in-phase relationship between SSS and MJO in the TIO (Guan et al. 2014). More importantly, this in-phase relationship cannot be explained by the freshwater only, especially in the central TIO during the dry phase of MJO (Guan et al. 2014). Instead, the relationship between SSS and $\mathrm{MJO}$ is led by the anomalous wind stress as well in the central and eastern TIO (Li et al. 2015). In addition to this in-phase relation with MJO, SSS could potentially affect the MJO by adjusting the SST (Guan et al. 2014).
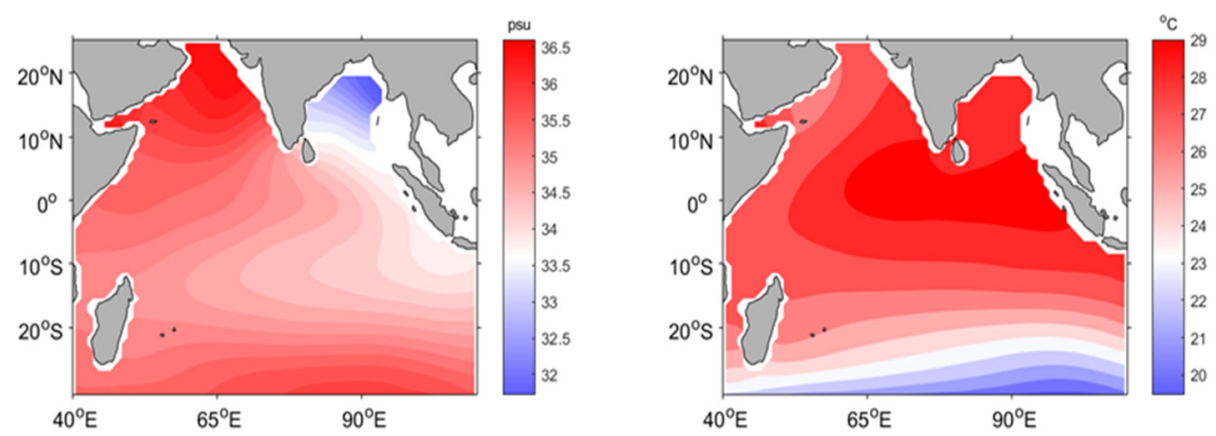

Figure 1. 2. The climatological distributions of SSS (left) and SST (right) in the Indian Ocean.

\subsubsection{Thermocline}

Due to the vertical temperature gradient induced by heat flux, a layer is formed in which the rate of temperature change is much faster than the surrounding water. This layer is called thermocline. The distribution of thermocline in the TIO is unique, with shallower depth in the west and deeper depth in the east (Figure 1.3).

The shallowest thermocline in the western TIO is also known as Seychelles Chagos Thermocline Ridge (SCTR) or Thermocline Ridge of the Indian Ocean (TRIO). Normally, SCTR is defined around the area of $\left(55^{\circ} \mathrm{E}-65^{\circ} \mathrm{E}, 5^{\circ} \mathrm{S}\right.$ $\left.12^{\circ} \mathrm{S}\right)$, noted as a remarkable upwelling region interacting with the atmospheric forcing (Hermes and Reason 2008). The variabilities of the SCTR is relatively prominent, affecting local fishing industries and weather forecast. Therefore, tremendous efforts have been made to investigate the variabilities of the SCTR, including two specialized programs, such as the Vasco-Criene program (Vialard et al. 2009) and the TRIO science plan. 
The multi-time scales variabilities of the thermocline in the SCTR have been studied with different atmospheric forcing. At the seasonal time scale, thermocline in the SCTR is characterized by a semiannual variation, deepening in February and September and shoaling in May and December, in response to the interaction between the remotely forced downwelling Rossby Waves and the local Ekman pumping (Trenary and Han 2012). This local Ekman pumping is mainly resulted by the monsoon wind and southeasterly trade wind (Yokoi et al. 2008, 2009). Meanwhile, the interannual variability of the thermocline in the SCTR is attributed to the ENSO-induced Rossby wave and the local wind stress-induced Ekman pumping (Tozuka et al. 2010). For example, shallower thermocline in the SCTR is associated with the local Ekman downwelling and the remotely excited downwelling Rossby wave while deeper thermocline in the SCTR is induced by the local Ekman upwelling and the upwelling Rossby wave. In addition, the IOD influences the interannual variability of the thermocline in the SCTR as well, but its impact is limited in the north of $10^{\circ} \mathrm{S}$ (Yu et al. 2005). Particularly, during positive IOD years, strengthening anomalous easterlies, caused by positive SST anomalies and zonal wind stress, enhances the local Ekman downwelling, resulting in deeper thermocline; while during negative IOD years, shoaling thermocline led by the remotely upwelling Rossby wave has feedback on SST (Nyadjro et al. 2017).

The thermocline in the SCTR has a remarkable relationship with SST related to the remotely atmospheric forcing. When an El Niño or Sumatra cooling event takes place, the deeper thermocline is induced by the westward downwelling Rossby wave with the anomalous easterlies, which in turn, contributes to the corresponding positive SST anomalies (Xie et al. 2002; Yokoi et al. 2012).

Furthermore, the SSS variation in the SCTR is closely related to the IOD and ENSO. Comparing to the in-phase relationship between the IOD and SSS, the time-lag relationship between ENSO and SSS acts as a more dominant role in the SCTR (Burns and Subrahmanyam 2016).

Here, we use the $20^{\circ} \mathrm{C}$ isothermal depth as a proxy for thermocline depth. 


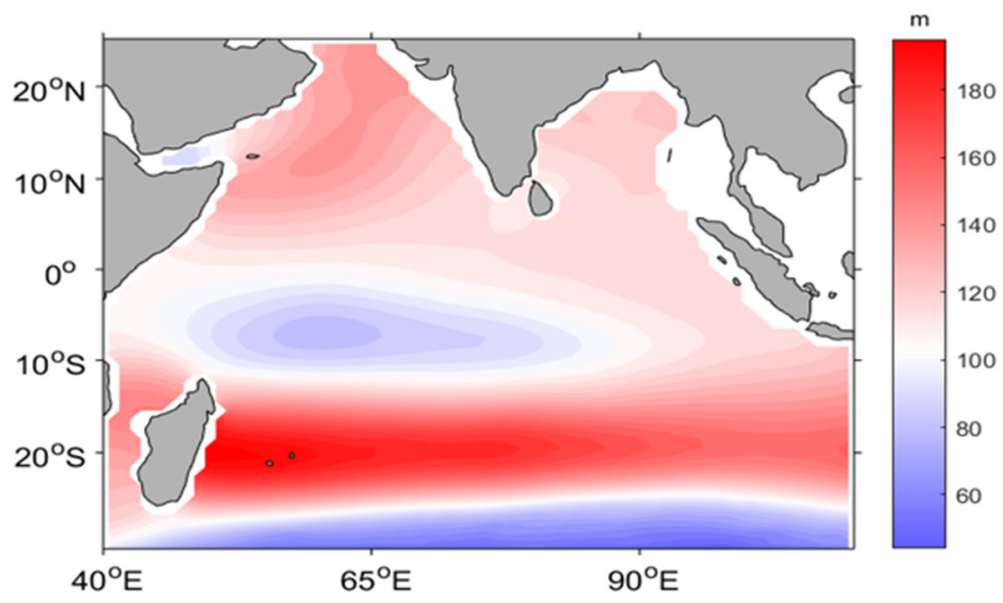

Figure 1. 3. The climatological distribution of thermocline in the Indian Ocean.

\subsubsection{Barrier layer}

Before the 90s, the upper-ocean layer was just divided into the mixed layer and thermocline. With the increasing and more precise in situ data, a thin layer is found between the bottom of the mixed layer (solid black line) and the top of the thermocline (blue dashed line), called the barrier layer (Figure 1.4). Although this layer is relatively thinner, it plays an essential role in sustaining the SST information, especially to prolong the anomalous SST signal affected by remotely atmospheric forcing. In addition to this, the barrier layer even acts as an essential role in the formation of ENSO (Maes 2002; Maes and O'Kane 2014; Maes et al. 2005). 


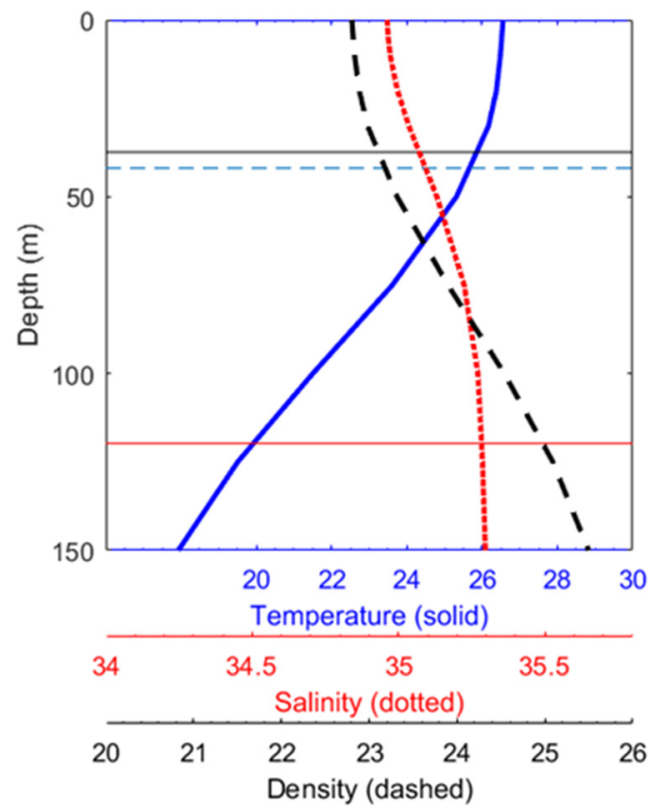

Figure 1. 4. The profile of temperature (blue), salinity (red) and density (black) averaged the Indian Ocean. The referencing lines are namely mixed layer depth (solid black), the top of the thermocline depth(dashed blue) and thermocline depth(solid red).

In the TIO, the seasonal variability of the barrier layer thickness (BLT) almost coincides with the precipitation patterns (Agarwal et al. 2012). For instance, BLT in the southeastern TIO has a clear semiannual variation due to the large excess of precipitation, with its first maximum in April and second maximum in August (Qu and Meyers 2005). BLT in the BOB reaches its maximum between December and February and decreases to its minimum between April and May, associated with the summer and winter monsoon winds (Kumari et al. 2018; Thadathil et al. 2007). A seasonal contrast of BLT has been discovered in the Arabian Sea due to the freshwater forcing and dynamic forcing (Thadathil et al. 2008). Moreover, BLT in the southern TIO is driven by both the freshwater intrusion and the Ekman pumping effect, with its maxima during austral winter and minima during austral summer (Pan et al. 2018).

The interannual variability of BLT has been investigated with IOD events. Particularly, during the positive IOD years, thinner BLT could be observed in the southeastern TIO and the $\mathrm{BOB}$, and vice versa during negative IOD years (Kumari et al. 2018; Qiu et al. 2012). The BLT variability also plays an important role during the developing phase of the positive IOD events (Guo et al. 2013). Equally important, BLT has been proven to be dominated by SSS in the TIO by satellite data and sensitivity experiments (Felton et al. 2014). 


\subsection{Main Objectives}

In this thesis, I mainly focus on studying the variabilities of the tropical Indian Ocean (TIO) at the seasonal and interannual time scale. The main objective can be fulfilled by the three sub-objectives described below.

1) Distinguish the relative influence of heat flux and wind stress on the interannual variability of the upper-ocean temperature in the TIO.

2) Investigate the relationships of the barrier layer thickness (BLT) with the sea surface salinity and thermocline.

3) Understand the seasonal variability of sea surface salinity (SSS) in the TIO and its role in the onset of the South Asian Summer Monsoon (SASM).

\subsection{Outline of the thesis}

This thesis consists of five chapters. A brief background about the variabilities of the TIO is given in the first chapter. The following chapters could be divided into two parts based on the main objectives. On the one hand, the main impactors of the TIO variabilities are diagnosed by using the simulations of a high-resolution model. On the other hand, the variabilities of sea surface salinity (SSS) in the TIO are studied with the observation and reanalysis datasets to understand its relationships with the ocean stratification and the onset of south Asian monsoon respectively. Each core chapter addresses one of the sub-objectives mentioned above and has been prepared as a standalone research paper that has been published in or submitted to the peer-reviewed journal. The five chapters are arranged as follows:

Chapter 1 describes the background of the oceanic structure with detailed introductions and reviews of the three layers of the stratification in the TIO, i.e., the mixed layer, the thermocline, and the barrier layer.

Chapter 2 introduces the relative contribution of heat flux and wind stress to the interannual variability of the upper-ocean temperature in the TIO through adopting a series of high-resolution ocean general circulation models (OGCM) simulations.

Chapter 3 presents the seasonal and interannual variabilities of barrier layer thickness in the TIO with the SSS and thermocline by using the SODA version 3 reanalysis.

In chapter 4, the Aquarius satellite SSS data has been adopted to understand the seasonal variability of SSS in the TIO and its role in the onset of the South Asian Summer Monsoon. The advent of satellite microwave remote sensing has been critical to expanding our understanding of the climate, oceans, and hydrological cycle. 
Chapter 5 is a Synthesis of the results obtained in this dissertation. It includes the main conclusions of Chapters 2, 3, and 4 and recommendations for future efforts in investigating the variabilities of the TIO. 


\section{Chapter 2}

\section{Relative contributions of heat flux and wind stress on the spatiotemporal upper-ocean variability in the tropic Indian Ocean*}

* This chapter is based on:

Xu Yuan, Caroline C. Ummenhofer, Hyodae Seo, Zhongbo Su. Relative contributions of heat flux and wind stress on the spatiotemporal upper-ocean variability in the tropic Indian Ocean. Manuscript has been submitted to Environment Research Letters. 


\subsection{Abstract}

A series of high-resolution ocean general circulation models (OGCM) simulations is employed to investigate interannual variability of the upperocean temperature in the tropical Indian Ocean (TIO). The OGCM hindcast simulation forced both with monthly heat flux and wind stress yields an observed seasonal cycle and interannual variability in the upper-ocean temperature in the TIO that is in good agreement with available observation and reanalysis products. Two further sensitivity OGCM simulations are conducted to separate the relative contributions of heat flux from wind stress. The comparison of the model simulations reveals the depth-dependent influences of heat flux and wind stress on the ocean temperature variability in the TIO $\left(20^{\circ} \mathrm{S}-20^{\circ} \mathrm{N}\right)$. Generally, heat flux dominates the temperature variability in the top $30 \mathrm{~m}$, while wind stress contributes most strongly to the subsurface temperature variability below $30 \mathrm{~m}$. This implies that a transition depth should exist at each location, where the dominant control of the ocean temperature variability switched from heat flux to wind stress. We define the depth of this transition point as the "crossing depth" and make use of this concept to better understand the depth-dependent impacts of the heat flux and wind stress on upper-ocean temperature variability in the TIO. The crossing depth tends to be shallower in the southern TIO $\left(20^{\circ} \mathrm{S}-\mathrm{EQ}\right)$, including the Seychelles-Chagos Thermocline Ridge (SCTR) and the eastern part of the Indian Ocean Dipole (IODE), suggesting the dominance of wind-driven temperature variability in those regions. The crossing depth also shows prominent seasonal variability in the southern TIO. Particularly, in the SCTR, the variability of the subsurface temperature forced by the wind stress dominates largely in boreal winter and spring, resulting in the shallow crossing depth in these seasons. In contrast, the intensified subsurface temperature variability with shallow crossing depth in the IODE is seen during boreal autumn. Overall, our results suggest that the two regions within the TIO, the SCTR and IODE, are the primary locations where the wind-driven ocean dynamics control the upper-ocean temperature variability. 


\subsection{Introduction}

Prominent warming has been observed throughout the global upper-ocean since the 1950s (Levitus et al. 2009; Levitus et al. 2012). Yet, the rate of warming in the tropical Indian Ocean (TIO), the focus of the present study, far exceeds that in the tropical Pacific and Atlantic Oceans (Han et al. 2014). The existing studies have pointed out that the upper-ocean temperature and sea surface temperature (SST) variability in the TIO are closely related to the atmospheric circulation patterns (Annamalai et al. 2005; Ashok et al. 2004; Trenary and Han 2012). Therefore, better understanding the ocean temperature variability in the TIO is of great importance to potentially predict regional rainfall patterns (Reason 2001; Ummenhofer et al. 2008, 2009).

In the tropical oceans, two surface forcing, namely the net heat flux and wind stress are the main drivers of the variability in SST and subsurface ocean temperature on seasonal to interannual timescales (e.g., Behera et al. 2000; Rao and Sivakumar 2000; Sayantani and Gnanaseelan 2015; Schott et al. 2009). The net heat flux, consisting of short and long-wave radiative fluxes and the latent and sensible heat fluxes, is the key term in the upper-ocean temperature equation (Moisan and Niiler 1998). Not only is the net heat flux is the main driver for seasonal variability of upper-ocean temperature in most areas of the TIO (Cyriac et al. 2019; Rao and Sivakumar 2000), but it also plays a vital role in controlling interannual SST variations associated with the El Niño-Southern Oscillation (ENSO) (Behera et al. 2000). In particular, heat flux into the ocean in the TIO is shown to be enhanced during the El Niño years in association with the induced atmospheric circulation changes (i.e., atmospheric bridge) (Alexander et al. 2002; Klein et al. 1999; Lau and Nath 2003; Liu and Alexander 2007), leading to the Indian Ocean Dipole (IOD) and the basin warming mode (Shinoda et al. 2004b; Zhong et al. 2005).

On the other hand, Murtugudde and Busalacchi (1999) suggested that wind stress is an indispensable contributor to interannual warming in some regions within the TIO, such as the Arabian Sea and the southern TIO. In fact, the wellknown IOD mode is a result of the wind-driven response to the upper-ocean circulation, resulting in pronounced interannual SST variability in the TIO through the Bjerknes feedback (Saji et al. 1999).

Behera et al. (2000) pointed out that the interannual variability of upper-ocean temperature within the Seychelles-Chagos Thermocline Ridge (SCTR) region in the southwestern TIO, cannot be fully explained by heat flux alone. The SCTR is unique in that the thermocline depth remains climatologically shallow (Schott et al. 2009). As a result, a strong coupling between the surface and subsurface temperature fields is observed in the SCTR, enabling interannual variability of SST to be sensitive to the subsurface temperature variability driven by the 
local and remote wind stress forcing (Xie et al. 2002). Indeed, Du et al. (2009) suggested that interannual variability of SST in the SCTR is influenced by ocean dynamics within the TIO and the downwelling Rossby wave forced by ENSO (Yamagata et al. 2004; Yu et al. 2005; Zhou et al. 2008).

Moreover, the interannual variability of SST in the eastern TIO also cannot be explained by heat flux variations alone. For instance, while the warming in the eastern TIO during the El Niño mature (boreal winter) and decaying (boreal spring) phases is forced by heat flux (Klein et al. 1999; Murtugudde and Busalacchi 1999), the cooling in the eastern TIO in boreal summer during EI Niño is due to the wind-driven upwelling and horizontal advection of temperature (Shinoda et al. 2004a). In addition, the dominant driver of the SST variability in the eastern TIO is related to the IOD. During the positive IOD years co-occurring with ENSO, the cooling in the eastern TIO results from the negative heat flux (Tanizaki et al. 2017), while during the IOD years independent of ENSO, the cooling is a response to wind-driven upwelling (Chen et al. 2016; Delman et al. 2016).

Despite the apparent simultaneous effects of heat flux and wind stress, their relative contribution to interannual variability of upper-ocean temperature in the TIO has not been systematically quantified. Here, we use the series of highresolution ocean general circulation model (OGCM) simulations to investigate the relative impacts of heat flux and wind stress on the ocean temperature interannual variability in the TIO, focusing on their spatial distribution and vertical structure. In this exploration, we will use the concept of a "crossing depth" to tease apart and diagnose their relative contributions of buoyancy and wind stress forcing.

The remainder of the chapter is structured as follows. In section 2.3, we introduce the OGCM, the reanalysis products, and analysis methods. The performance of the OGCM for simulating the ocean temperature in the TIO is described in section 2.4. Section 2.5 also includes the main result of the study, detailing the relative contribution between heat flux and wind stress to the variability of the TIO. In section 2.6, we provide a brief summary and discussion for our primary findings.

\subsection{Data and Methods}

\section{a. Ocean model simulations}

Numerical experiments are performed on the ORCA025, which is based on the Nucleus for European Modelling of the Ocean (NEMO, version 3.1.1, (Madec 2008)). The ORCA025 is an eddy-permitting global ocean-sea ice configuration with a spatial resolution of $0.25^{\circ}$ latitude/longitude. The model uses the tripolar grid that has a $21-28 \mathrm{~km}$ effective resolution in the TIO. Its vertical coordinate 
is discretized with 46 height ( $\mathrm{z}$ ) levels, ranging from $6 \mathrm{~m}$ at the surface to 250 $\mathrm{m}$ in bottom layers. The lowest grid cells apply a partial step topography (Bernard et al. 2006). Vertical mixing and boundary layer mixing are parameterized by a turbulent kinetic energy scheme (Blanke and Delecluse 1993). The lateral diffusion is performed along isopycnal surfaces.

The initial conditions of the model for temperature and salinity are obtained from climatology data of (Levitus et al. 1998). The atmospheric forcing fields of heat fluxes and wind stress follow are adapted from corrected global observational dataset based on the National Centers for Environmental Prediction (NCEP)-National Center for Atmospheric Research (NCAR) reanalysis products (Large and Yeager 2009). Atmospheric variables, such as 6-hourly wind, air temperature, and humidity; daily shortwave and longwave radiation; monthly precipitation and runoff, are set according to the Coordinated Ocean Reference Experiments 2 (CORE2) protocol (Griffies et al. 2009). The model was employed in previous work to study the Indian Ocean variability on seasonal, interannual, to multidecadal time scale and was found to be adequate to reproduce the upper structure of the Indian Ocean (Jin et al. 2018; Schwarzkopf and Böning 2011; Ummenhofer et al. 2017).

Here, we use three long-term hindcast simulations (1952-2007) to examine the role of wind stress and heat flux on interannual variability of upper-ocean temperature in the TIO. All three runs are started after spin-up cycles in accordance with the CORE2 protocol. The reference run is forced with full interannual forcing in both heat flux and wind stress and will be hereafter referred to as ALL. The second run is forced with interannually varying heat flux, but wind stress is kept at seasonal climatology (HF), thereby lacking interannual variability in the wind stress field. Conversely, the third experiment is integrated with interannually varying wind stress at the surface, while heat flux is kept at seasonal climatology (WS). To correct for spurious model drift, linear trends for the period 1952-2007 in a climatological simulation were removed from all interannually forced simulations (Ummenhofer et al. 2017). However, linear trends in upper ocean temperatures are very small.

A caveat in the relative contributions of heat flux and wind stress to upperocean variability needs to be kept in mind: The experimental set-up with the OGCM forced by atmospheric fields does not allow for feedback from the ocean to the atmosphere and interactive response of the atmosphere to any resultant anomalies at the ocean surface. Similarly, heat fluxes are applied through bulk formulae, which represents essentially a damping on timescales of about a month, to atmospheric surface air temperatures; in ALL and HF this is applied to interannually varying air temperatures, for WS to climatological surface conditions. This could partially account for the subdued ocean temperature variability in the near-surface layers in WS compared to ALL and HF. 


\section{b. Datasets}

To evaluate the performance of the model, we use the monthly ocean temperature reanalysis data from the Simple Ocean Data Assimilation (SODA) version 2.2.3 for the years between 1952 and 2007 (Carton and Giese 2008) and the World Ocean Atlas 2009 (WOA09) climatological annual mean ocean temperature data (Levitus et al. 1998).

SODA version 2.2.4 is based on Parallel Ocean Program physics with an average horizontal resolution of $0.25^{\circ} \times 0.4^{\circ}$ and 40 vertical levels, representing their first assimilation run of over 100 years. The model is continuously corrected by direct observations including virtually all available hydrographic profile data as well as ocean station data, moored temperature and nighttime infrared satellite SST data. The upper-ocean temperature of SODA fields is made available monthly at a uniform $0.5^{\circ} \times 0.5^{\circ}$ and 40 level grid.

WOA09 is a set of objectively analysed climatology of in situ temperature on a grid of $1^{\circ} \times 1^{\circ}$, which is interpolated mean fields for an oceanographic temperature at standard depth levels for the World Ocean (https://www.nodc.noaa.gov/OC5/WOA09/pr_woa09.html).

\section{c. Methods}

To investigate the spatiotemporal upper-ocean temperature variability in TIO, a concept of "crossing depth" is introduced. We define it based on the standard deviation of interannual ocean temperature obtained from the three model outputs such that,

$$
\text { Depth }_{c d}=\operatorname{Depth}_{\text {Minimum }\left(T_{H F}-T_{W S}\right)}
$$

where, Depth $c$ id is the crossing depth and Depth ${\text { minimum }\left(T_{H F}-T_{W S}\right)}_{\text {indicates the }}$ depth at which the difference between $T_{H F}$ and $T_{W S}$ reaches the minimum. $T_{H F}$ and $T_{W S}$ represent the ocean temperature variability forced by heat flux and wind stress, respectively.

Monthly mean datasets are averaged over different three months periods for different seasons, such as December-January-February (DJF) for boreal winter, March-April-May (MAM) for boreal spring, June-July-August (JJA) for boreal summer and September-October-November (SON) for boreal autumn. 


\subsection{Results}

\subsubsection{Upper-ocean temperature structure in the TIO}

The skill of ORCA025 in representing the observed upper-ocean temperature fields is assessed against the WOA annual climatology and the SODA ocean reanalysis. Figure 1 shows the longitude-depth diagrams of upper-ocean temperature averaged in the TIO $\left(20^{\circ} \mathrm{S}-20^{\circ} \mathrm{N}\right)$. All the depth-longitude profiles and area averages shown in this study are weighted by the cosine of the latitude. In general, the temperature distribution simulated by the ORCA025 ALL (Figure 2.1a) is consistent compared to the observational product and reanalysis (Figures $2.1 \mathrm{~b}$ and $2.1 \mathrm{c}$ ). For example, the climatology of temperature fields exhibits a realistic zonal gradient of the upper-ocean temperature that is in the opposite direction to the what is observed in the tropical Pacific and Atlantic oceans (Schott et al. 2009) with the warmer water up to $28{ }^{\circ} \mathrm{C}$ above $60 \mathrm{~m}$ depth in the eastern TIO while the upwelling and cold near-surface temperature is in the western TIO. However, the ORCA025 simulation has also shown a warm bias of $0.2{ }^{\circ} \mathrm{C}$ in the top $60 \mathrm{~m}$ depth, most pronounced into the east of $70^{\circ} \mathrm{E}$ in the TIO. This warm bias also extends to a deeper depth, resulting in thermocline depth (red line) that is biased to deep (Figure 2.1a). When defined as the depth of $20{ }^{\circ} \mathrm{C}$ isotherm, the thermocline depth in ORCA ALL is located at $130 \mathrm{~m}$ depth, compared to an average $115 \mathrm{~m}$ depth and $117 \mathrm{~m}$ depth in WOA and SODA, respectively.

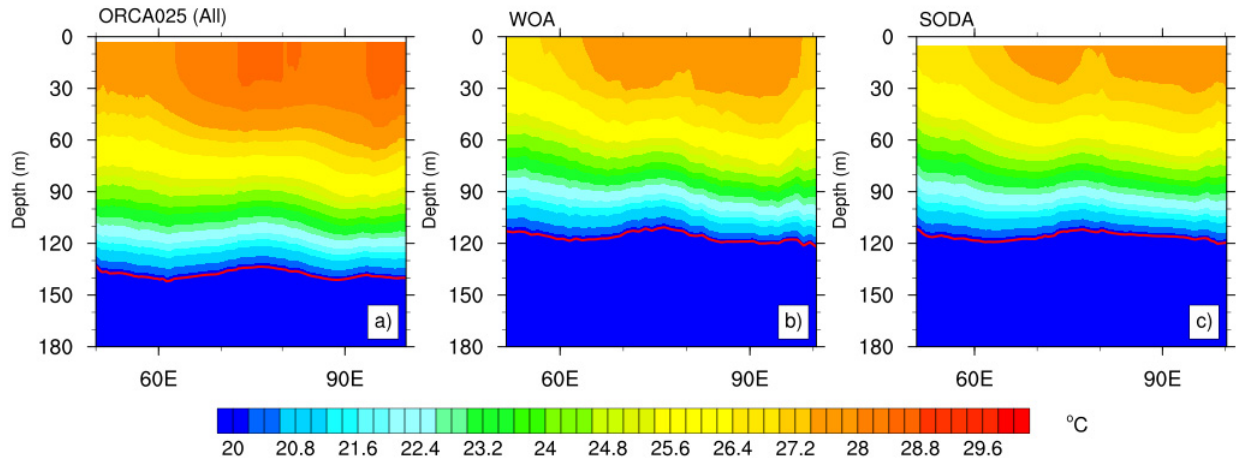

Figure 2. 1. Comparison of annual mean ocean temperature in the top $180 \mathrm{~m}$ across the TIO for (a) ORCA025(ALL) (b) SODA reanalysis data and (c) WOA09 averaged along $20^{\circ} \mathrm{S}-20^{\circ} \mathrm{N}$ for the time period $1952-2007$. Red line represents the $20^{\circ} \mathrm{C}$ isotherm; Unit: ${ }^{\circ} \mathrm{C}$.

Next, the interannual variability of ocean temperature simulated by the ORCA025 is examined in comparison to SODA reanalysis data. A weak interannual variability can be seen in both ORCA025 (ALL) and SODA hindcast in the top $60 \mathrm{~m}$ in the eastern TIO (Figures 2.2a and 2.2b). Also apparent in both the OGCM and SODA is the enhanced interannual variability of the 
temperature at $60-150 \mathrm{~m}$ in the $\mathrm{TIO}\left(20^{\circ} \mathrm{S}-20^{\circ} \mathrm{N}, 50^{\circ} \mathrm{E}-100^{\circ} \mathrm{E}\right)$. However, we also note that the too weak (strong) variability in the simulated temperature in the top $60 \mathrm{~m}(60-150 \mathrm{~m})$ of the TIO from the ORCA025 (ALL) compared to SODA.

Despite the biases in the spatial feature and interannual variability of upperocean temperature, ORCA025 (ALL) is deemed to overall reasonably well reproduce the main characteristics of the upper-ocean temperature climatology and variability in the TIO, and thus it has merits for further exploration of the interannual variability of the upper ocean temperature in the TIO.

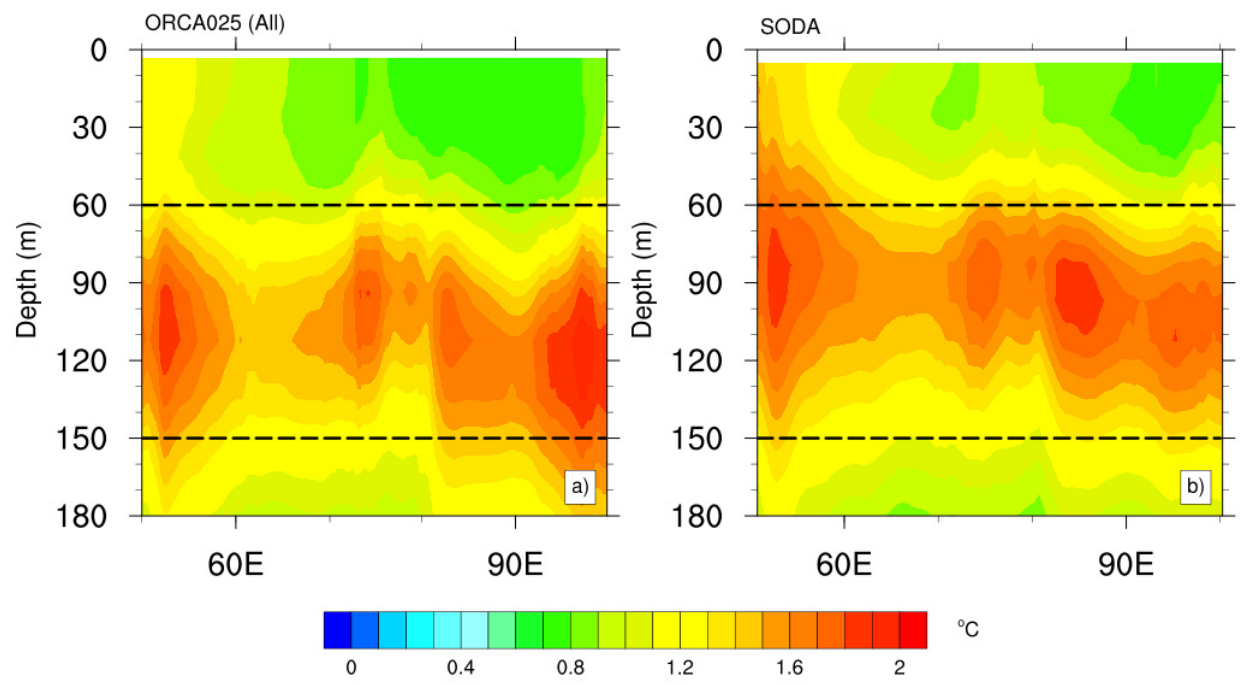

Figure 2. 2. The standard deviation of ocean temperature in the top $180 \mathrm{~m}$ across the TIO averaged for $20^{\circ} \mathrm{S}-20^{\circ} \mathrm{N}$ from (a) ORCA025(ALL) and (b) SODA during the years of 1952-2007. Dashed lines represent the isobaths of $60 \mathrm{~m}$ and $150 \mathrm{~m}$ respectively. Unit: ${ }^{\circ} \mathrm{C}$.

\subsubsection{Depth-dependent effect of heat flux and wind stress forcing on the interannual variability of the upper-ocean temperature fields}

Previous studies have shown that interannual variability of the upper-ocean temperature in the TIO features a significant seasonal locking phase related to ENSO and IOD (e.g., Behera et al. 2000; Huang and Kinter III 2002). Thus, we compare the seasonal averages of interannual variability of ocean temperature in the top $180 \mathrm{~m}$ averaged as $20^{\circ} \mathrm{S}-20^{\circ} \mathrm{N}, 50^{\circ} \mathrm{E}-100^{\circ} \mathrm{E}$ (the whole TIO) from ALL, HF and WS. In four seasons, the interannual variability of the whole TIO from ALL (Figure 2.3a, d, $g, j$ ) is similar to that of HF (Figure $2.3 \mathrm{~b}, \mathrm{e}, \mathrm{h}, \mathrm{k}$ ) in the top $30 \mathrm{~m}$, while its variability is greatly reduced at 
increasing depth. On the other hand, WS underestimates the variability seen in ALL in the surface layer, only to become comparable to ALL in the deeper ocean. This highlights the depth-dependent role of wind stress and heat flux forcing in determining interannual variability of upper-ocean temperature in the TIO. Taking the $28^{\circ} \mathrm{C}$ isotherm as an example, HF well captures the cold and warm events shown in ALL during all seasons, suggesting the year-round effect of heat flux on interannual variability of ocean temperature above the $28^{\circ} \mathrm{C}$ isotherm. On the other hand, interannual variability of ocean temperature below $28{ }^{\circ} \mathrm{C}$ in WS presents good agreement with that in ALL for four seasons, as shown by the thermocline depth (red line). Thus, the relative impact of heat flux and wind stress on interannual variability of upper-ocean temperature in the TIO is depth-dependent and this feature is independent of the seasonal change. 

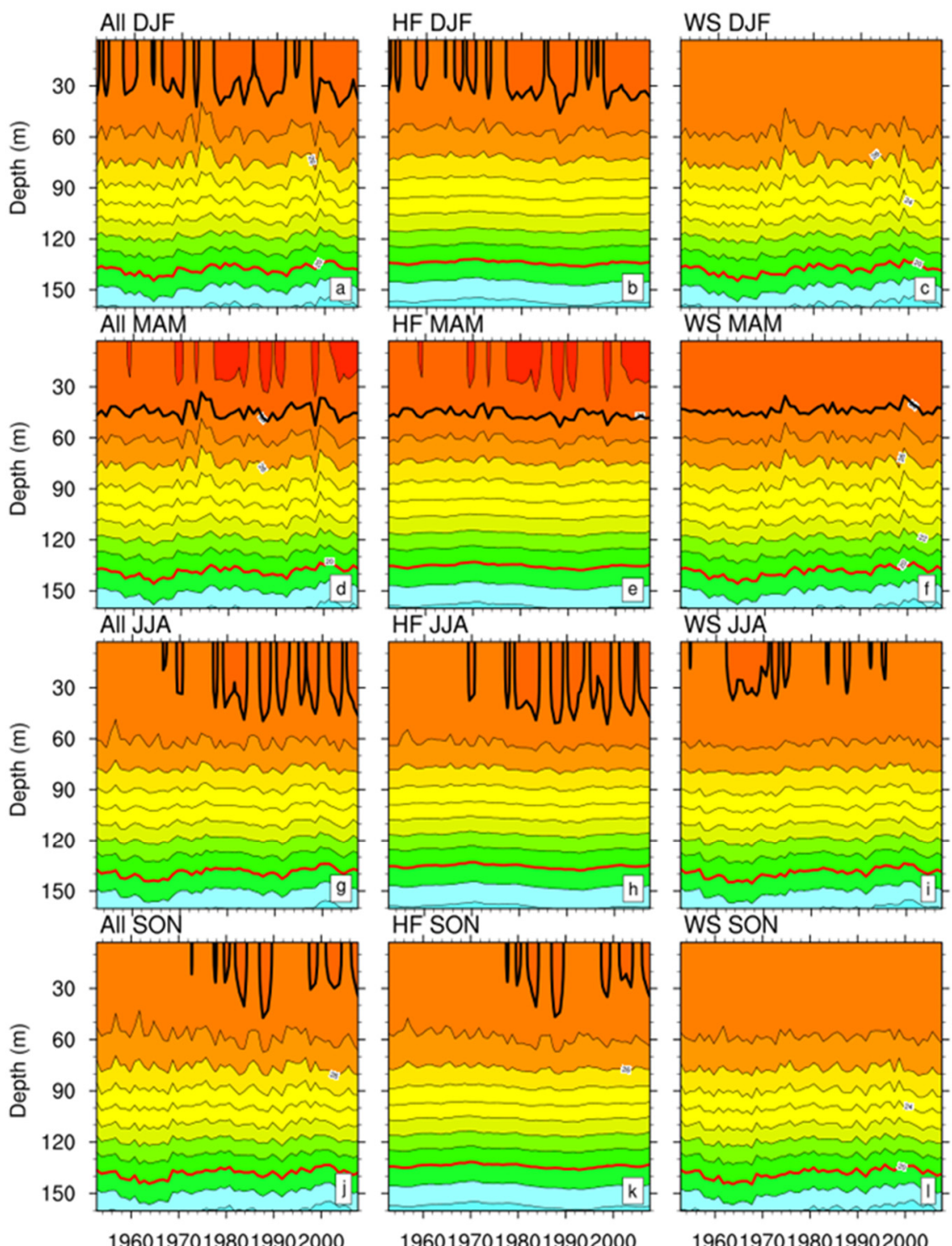

WS JJA'
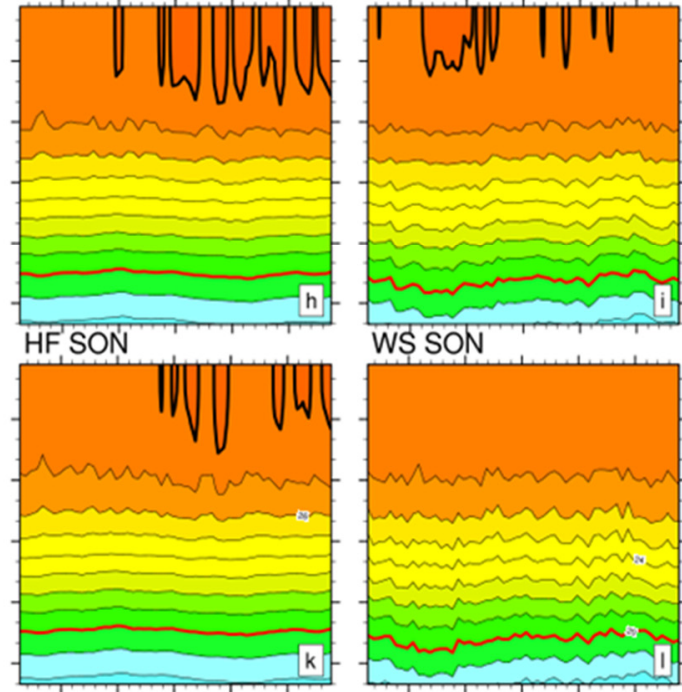

WS SON

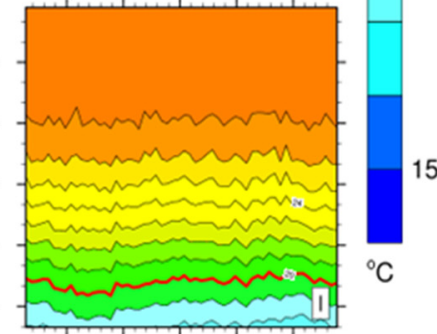

19601970198019902000

19601970198019902000

Figure 2. 3. Seasonal upper-ocean temperature in the top $180 \mathrm{~m}$ spatially averaged over the area of the TIO $\left(20^{\circ} \mathrm{S}-20^{\circ} \mathrm{N}, 50^{\circ} \mathrm{E}-100^{\circ} \mathrm{E}\right)$ versus depth in the OGCM simulations for $A L L, H F$, and WS, from 1952 to 2007 during December-January-February (DJF), MarchApril-May (MAM), June-July-August (JJA) and September-October-November (SON). Unit: ${ }^{\circ} \mathrm{C}$. The thick black and red lines are the $28^{\circ} \mathrm{C}$ and $20^{\circ} \mathrm{C}$ isotherms, respectively.

To further quantify the contributions of wind stress and heat flux to the ocean temperature variability, the spatial distributions of the standard deviation of SST and thermocline depth obtained from three simulations are shown in Figure 2.4. Although the largest values of SST standard deviation near the $30^{\circ} \mathrm{S}$ can be detected in all three simulations (Figure $4 a, b$ ), which is consistent 
with the previous study (Baquero-Bernal et al. 2002), the values near the equatorial TIO $\left(5^{\circ} \mathrm{S}-5^{\circ} \mathrm{N}, 70^{\circ} \mathrm{E}-90^{\circ} \mathrm{E}\right)$ in WS is relatively weaker compared to ALL and HF. At depth, in contrast, the distributions of the standard deviations of thermocline depth in both ALL and WS present strong SST variability in the southwestern $\mathrm{TIO}\left(5^{\circ} \mathrm{S}-15^{\circ} \mathrm{S}, 50^{\circ} \mathrm{E}-70^{\circ} \mathrm{E}\right)$ [Figure $2.4 \mathrm{e}, \mathrm{f}$ ], while the one simulated by HF fails to reproduce this signal.

We also calculate the probability distribution functions of the interannual variability of SST and thermocline depth within the TIO. The distributions are calculated for SST and thermocline obtained from the three model simulations to further illustrate the relative contributions of heat flux and wind stress on the interannual variability in the TIO (Figure $2.4 \mathrm{~d}, \mathrm{~h}$ ). All three experiments exhibit a similar unimodal pattern of SST variability distribution in the TIO. However, a closer examination shows that the SST variability distribution in WS is shifted to the left by about $0.2{ }^{\circ} \mathrm{C}$ compared to that in ALL in both the entire TIO. On the other hand, the distribution of the SST variability in HF is nearly identical to that of ALL. This indicates that heat flux exerts a stronger control on the interannual SST variability in the TIO. As for the thermocline depth, in contrast, wind stress is the main driver since the thermocline depth variability in both ALL and WS features the bimodal distribution in the TIO, which is in stark contrast to a unimodal distribution seen in HF. From this analysis, it is clear that the influence of heat flux and wind stress on the upperocean temperature variability in the whole TIO is distinct with depth and potentially separable. 
SST

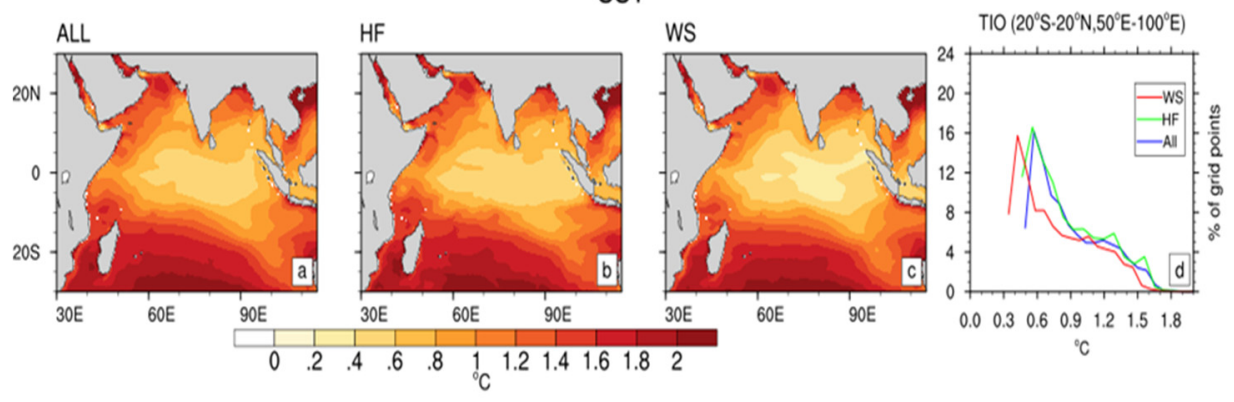

Thermocline
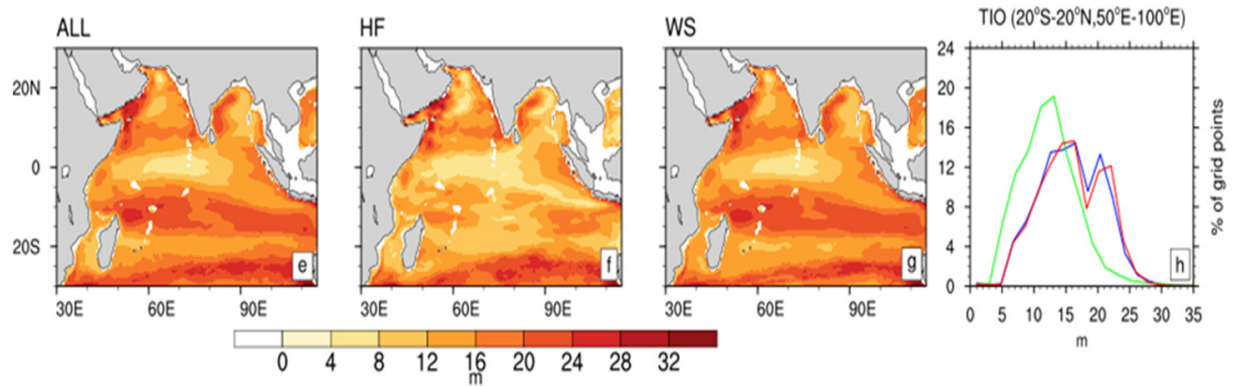

Figure 2. 4. Spatial distributions of the standard deviations of interannual (a-c) SST $\left[{ }^{\circ} \mathrm{C}\right]$ and $(\mathrm{e}-\mathrm{g})$ thermocline $[\mathrm{m}]$ obtained from three sets of model simulations and their corresponding probability distribution functions (PDF) within the TIO $\left(20^{\circ} \mathrm{S}-20^{\circ} \mathrm{N}, 50^{\circ} \mathrm{E}-\right.$ $100^{\circ} \mathrm{E}$ ). In the PDF of (d) SST and (h) thermocline, blue, green, and red curves represent $A L L, H F$, and WS, respectively.

We also compare the depth-time diagrams of the ocean temperature from ALL, $\mathrm{HF}$ and WS within the TIO $\left(20^{\circ} \mathrm{S}-20^{\circ} \mathrm{N}\right)$ in Figure 2.5 . Taking the $28^{\circ} \mathrm{Cisotherm}$ (thick black line) as an example, HF captures the two cold events in the 1950s and 1970 s when the $28^{\circ} \mathrm{C}$ isotherm outcrops, while WS fails to reproduce such strong events. However, the variability of ocean temperature from WS is almost identical to ALL below the $28^{\circ} \mathrm{C}$ isotherm, indicating that the wind stress is the main driver of the interannual temperature variability at the subsurface. This finding is consistent with previous studies showing that interannual variability of the thermocline $\left(20^{\circ} \mathrm{C}\right.$; thick red line in Figure 2.5) was found to be entirely attributed to wind stress (Rao and Behera 2005; Yu et al. 2005). The pronounced spatial differences of SST and thermocline standard deviations in Figure 4 also motivate us to examine the depth-dependent influence of heat flux and wind stress in sub-areas of the TIO, including the SCTR $\left(12^{\circ} \mathrm{S}-5^{\circ} \mathrm{S}\right.$, $50^{\circ} \mathrm{E}-75^{\circ} \mathrm{E}$ ), the western TIO (WTIO, $5^{\circ} \mathrm{S}-5^{\circ} \mathrm{N}, 50^{\circ} \mathrm{E}-75^{\circ} \mathrm{E}$ ), and the eastern TIO (ETIO, $10^{\circ} \mathrm{S}-5^{\circ} \mathrm{N}, 80^{\circ} \mathrm{E}-100^{\circ} \mathrm{E}$ ). , and In the SCTR (Figure $2.5 \mathrm{~d}-\mathrm{f}$ ), interannual variability of ocean temperature above the $28^{\circ} \mathrm{C}$ isotherm in ALL is better reproduced by $\mathrm{HF}$, while the stronger interannual variability of the subsurface temperature is in good agreement between ALL and WS. In the WTIO (Figure $2.5 \mathrm{~g}-\mathrm{i}$ ) and ETIO (Figure $2.5 \mathrm{j}-\mathrm{I}$ ), although the impact of heat flux 
on interannual variability of ocean temperature does not reach down the depth of $28^{\circ} \mathrm{C}$ isotherm, the simulated interannual variability of ocean temperature between HF and ALL is reasonably consistent in the top of $30 \mathrm{~m}$. Interannual variability of ocean temperature below the depth of $28^{\circ} \mathrm{C}$ isotherm in WS is entirely consistent with that in ALL.

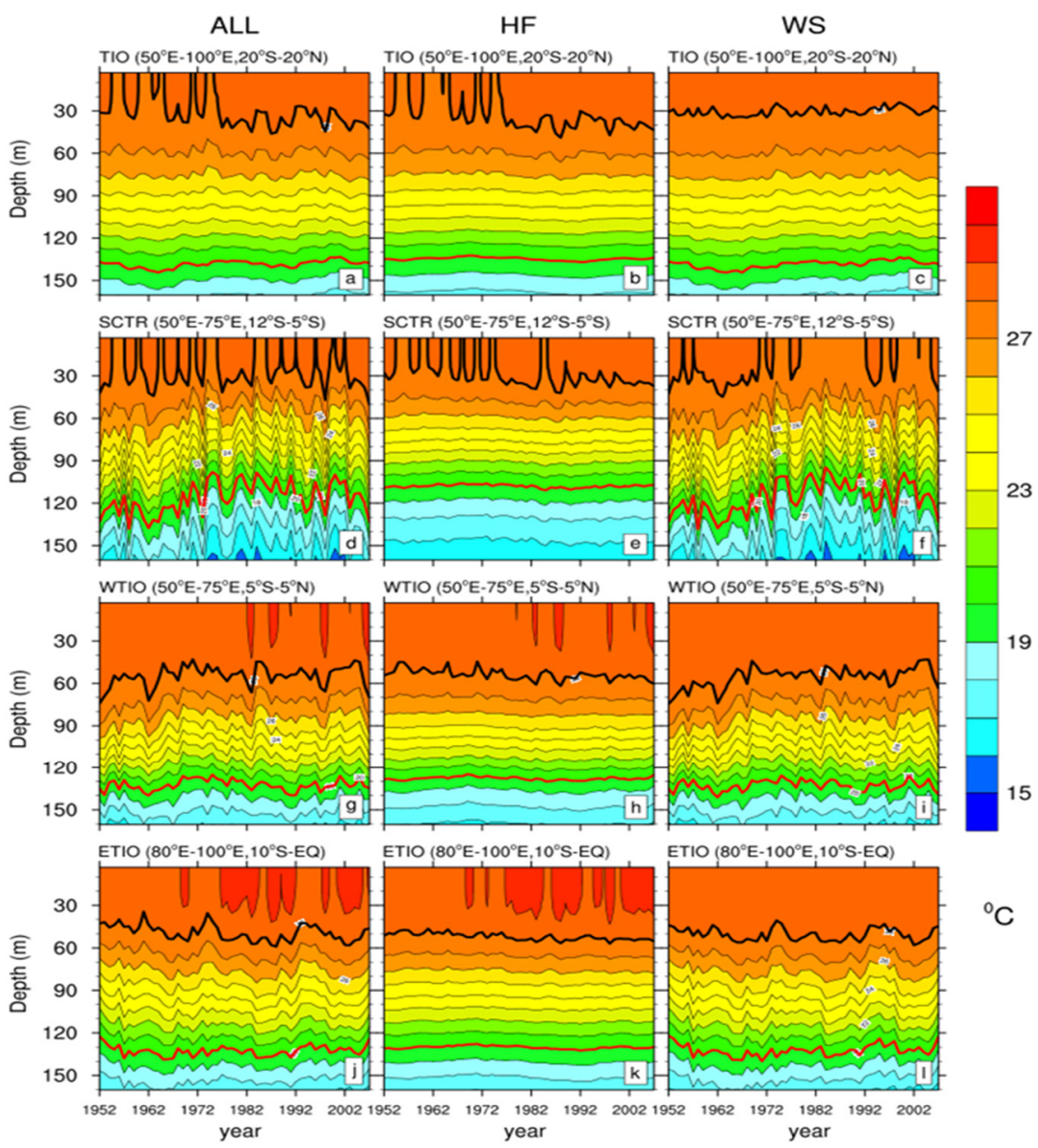

Figure 2. 5. Annual upper-ocean temperature in the top $180 \mathrm{~m}$ spatially averaged over the areas of the TIO $\left(20^{\circ} \mathrm{S}-20^{\circ} \mathrm{N}, 50^{\circ} \mathrm{E}-100^{\circ} \mathrm{E}\right)$, SCTR $\left(12^{\circ} \mathrm{S}-5^{\circ} \mathrm{S}, 50^{\circ} \mathrm{E}-75^{\circ} \mathrm{E}\right)$, WTIO $\left(5^{\circ} \mathrm{S}-5^{\circ} \mathrm{N}, 50^{\circ} \mathrm{E}-75^{\circ} \mathrm{E}\right)$ and $\mathrm{ETIO}\left(10^{\circ} \mathrm{S}-\mathrm{EQ}, 80^{\circ} \mathrm{E}-100^{\circ} \mathrm{E}\right)$ versus depth in the OGCM simulations for $A L L, H F$, and WS, from 1952 to 2007 . Unit: ${ }^{\circ} \mathrm{C}$. The thick black and red lines are the $28^{\circ} \mathrm{C}$ and $20^{\circ} \mathrm{C}$ isotherms, respectively.

This depth-dependent influences of heat flux and wind stress are further illustrated in the vertical profiles of the standard deviation of interannual ocean temperature averaged along $50^{\circ} \mathrm{E}-100^{\circ} \mathrm{E}$ as a function of latitude (Figure 2.6). The consistency of the ocean temperature variability between HF and ALL can only be identified in the top $30 \mathrm{~m}$, which confirms that the effect of heat flux 
on the ocean temperature variability is limited to the near-surface. In contrast, the comparable ocean temperature variability between WS and ALL is observed in the deeper ocean, indicating that the impact of wind stress is crucial to the subsurface temperature variability. Particularly, WS accurately captures the observed level of the subsurface temperature variability in the SCTR within $4^{\circ} \mathrm{S}-12^{\circ} \mathrm{S}$ (Vialard et al. 2009).

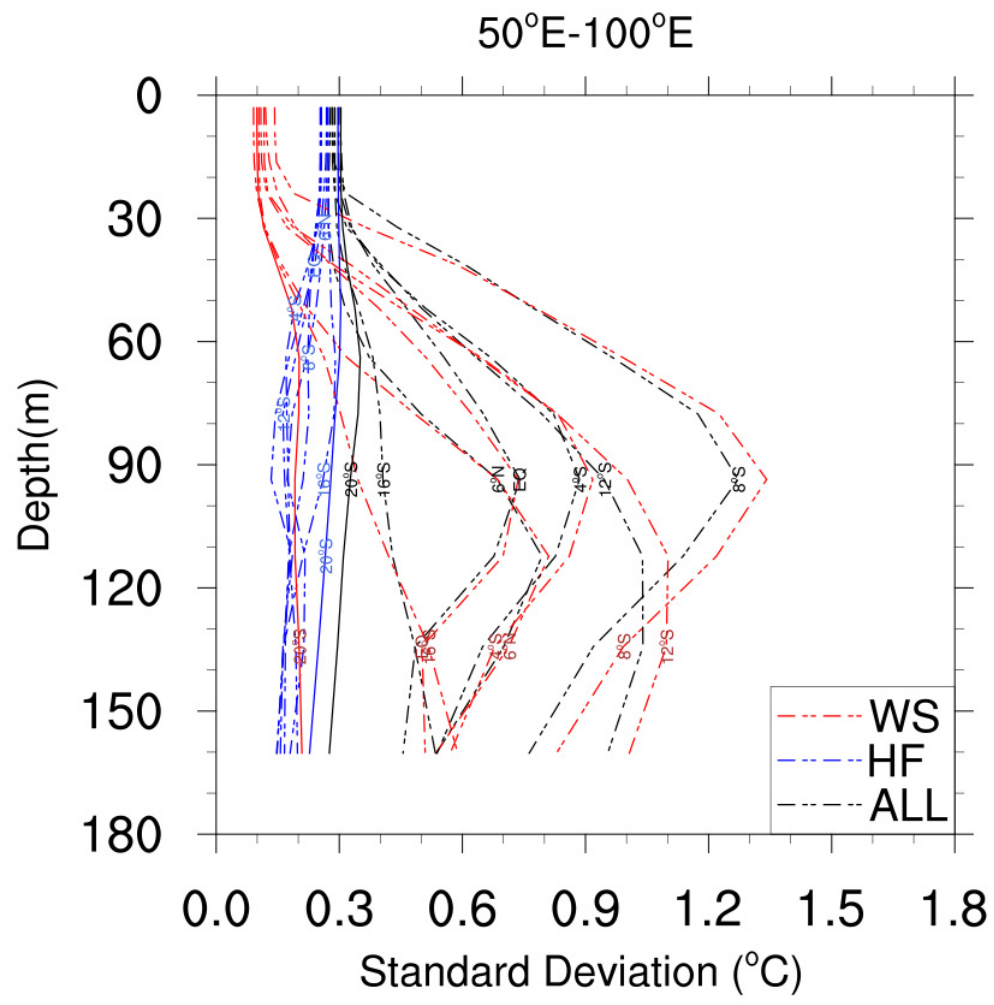

Figure 2. 6. The profiles of the standard deviation of interannual subsurface temperature averaged along $\left(50^{\circ} \mathrm{E}-100^{\circ} \mathrm{E}\right)$ in different latitudes versus depth. Unit: ${ }^{\circ} \mathrm{C}$. Black, blue and red lines represent $A L L, H F$ and WS separately. The latitudes are $6^{\circ} \mathrm{N}$, equator (EQ), $4^{\circ} \mathrm{S}, 8^{\circ} \mathrm{S}, 12^{\circ} \mathrm{S}, 16^{\circ} \mathrm{S}$, and $20^{\circ} \mathrm{S}$, respectively.

\subsubsection{Crossing depths: Attribution of the interannual temperature variability in the $\mathrm{TIO}$}

Note that the idea of a crossing depth is meaningful only in regions where the effects of wind stress and heat flux can be quasi-linearly separable such as in the tropics and where the thermocline remains relatively shallow. We expect that it does not offer particularly useful information in regions where wind stress also drives significant mixing to affect superficial layer as in the subtropics. For example, Figure 2.7 shows the distribution of crossing depth in the TIO. As expected, the shallower crossing depths are located in the southern equatorial TIO associated with a shallower thermocline depth. However, the 
crossing depth becomes very deep in the south of $15^{\circ} \mathrm{S}$ where the wind stress impacts both the SST through wind-driven vertical mixing. Thus, we focus our analysis based on the crossing-depth in two regions, the SCTR and the eastern part of IOD (IODE). These two regions are interesting because SCTR has the shallowest crossing depth and the IODE supports the most significant interannual ocean temperature variability in the TIO (Chen et al. 2016; Qu and Meyers 2005).

Figure 2.8a presents the seasonal variations of the crossing depth in the SCTR and IODE. The crossing depth in the SCTR has a clear annual cycle, peaking in September up to $58 \mathrm{~m}$ and reaching the minimum $23 \mathrm{~m}$ in March. This seasonal variation is very similar to the climatological SST seasonal change in the SCTR (Yuan et al. 2018). The peaking time of the crossing depth in the SCTR is in good agreement with the seasonal phase locking impact of ENSO on the SCTR when the SST variability in the SCTR is affected by the subsurface variability due to ENSO induced anomalous wind stress (Burns and Subrahmanyam 2016; Nagura and Konda 2007; Shinoda et al. 2004b). In contrast, the seasonal variation of the crossing depth in the IODE is relatively weak ranging between $30 \mathrm{~m}$ and $48 \mathrm{~m}$.

To further study the crossing depth, Figure $2.8 \mathrm{~b}-\mathrm{i}$ present the seasonally averaged vertical profiles of the standard deviations of interannual ocean temperature averaged in the SCTR and IODE. In particular, in the SCTR, the depth of the crossing point between HF and WS is in the top of $30 \mathrm{~m}$ during winter and spring while it drops below 30 m during summer and autumn. In the IODE, the transition depth is below 30 m during winter, spring and summer but rise to above $30 \mathrm{~m}$ in autumn. Furthermore, corresponding to the shallower crossing depth in winter and spring, the interannual variability of the subsurface temperature affected by wind stress is significant within the SCTR with its standard deviations reaching $2^{\circ} \mathrm{C}$ (Figure $2.8 \mathrm{~b}, \mathrm{c}$ ). Similarly, the large interannual variability of the subsurface in the IODE is seen along with the shallower crossing depth in winter and autumn, but its intensity is weaker (1.5 ${ }^{\circ} \mathrm{C}$ standard deviation, Figure $\left.2.8 \mathrm{f}, \mathrm{i}\right)$. Therefore, the crossing depth can separate the relative role of heat flux from wind stress in the ocean temperature variability, as well as potentially be an indicator for the intensity of the subsurface variability. 


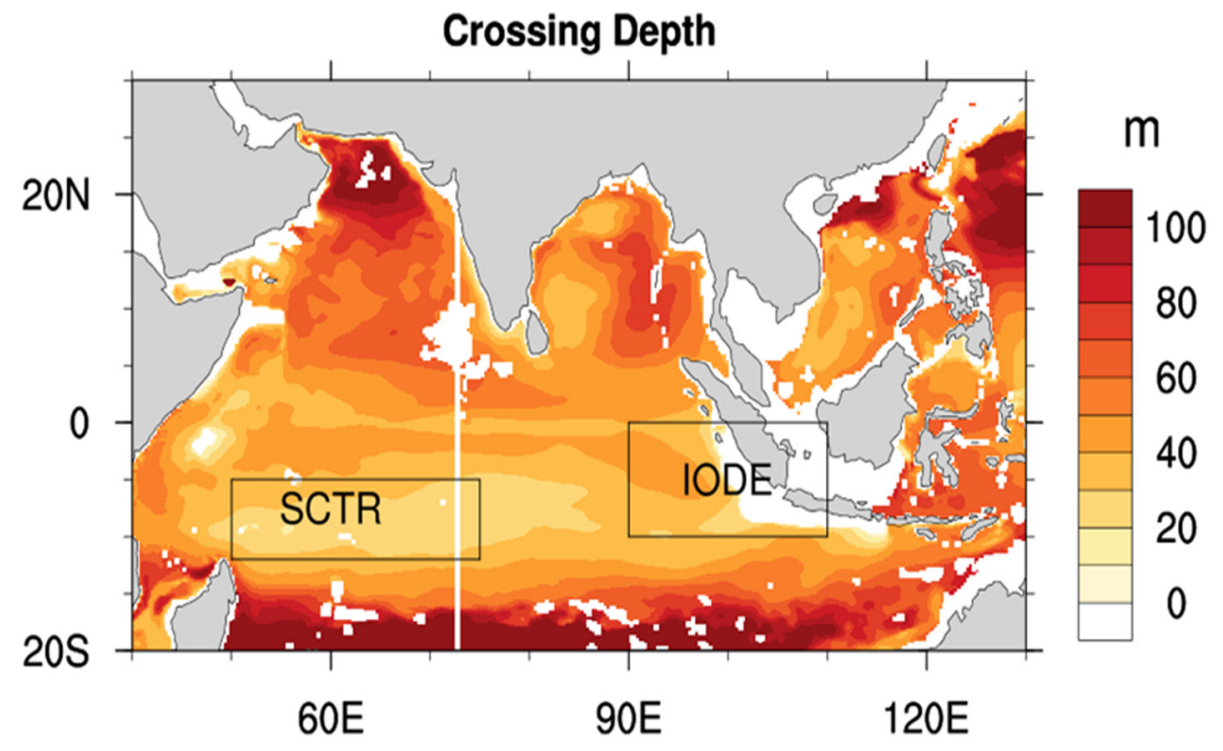

Figure 2. 7. The distribution of the crossing depth in the TIO. The boxes represent the locations of SCTR and IODE, respectively. 

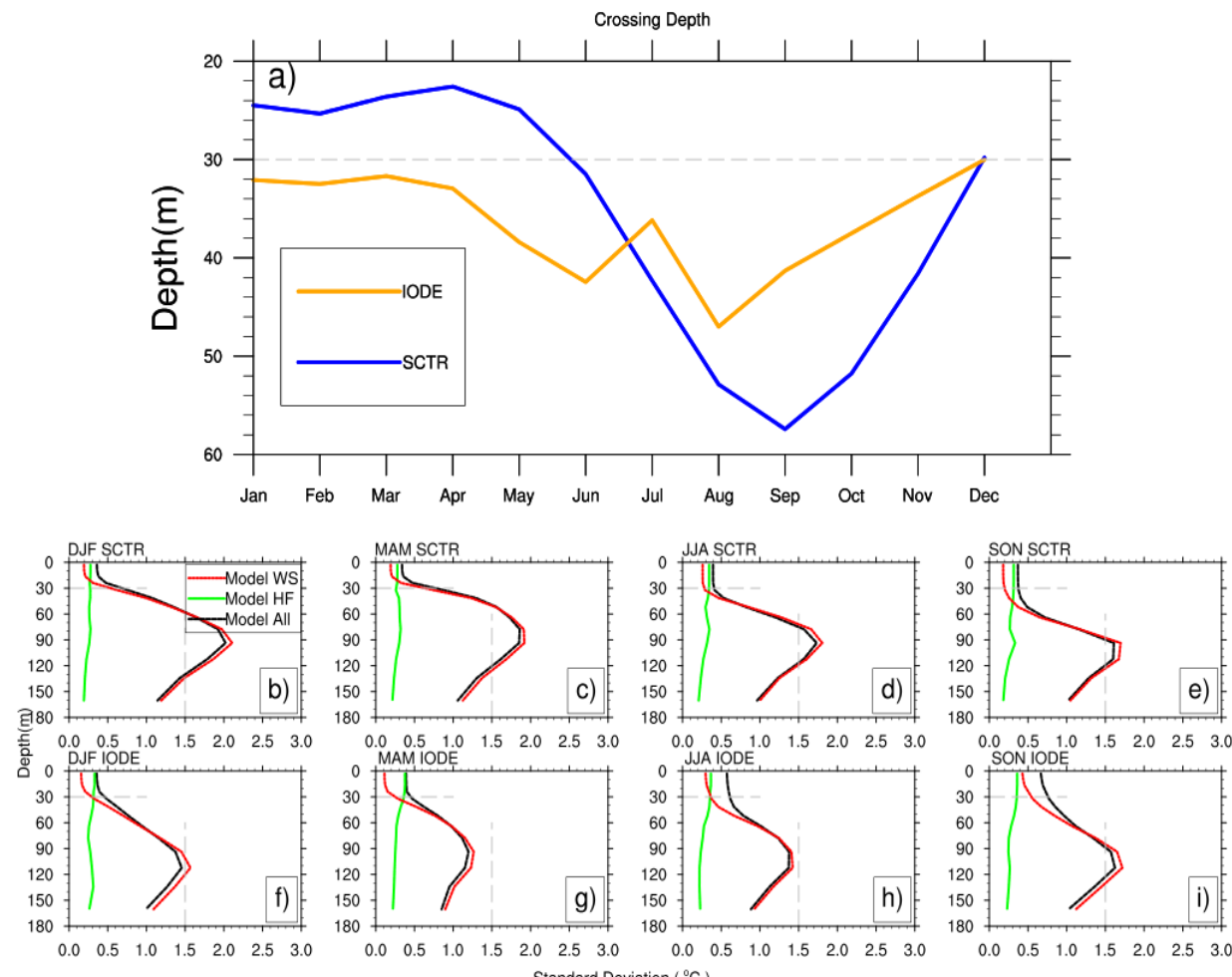

Figure 2. 8. The seasonal variations of the crossing depth (a) and the vertical profiles of the standard deviation of interannual ocean temperature during (b), (f) DJF, (c), (g) MAM, (d), (h)JJA and (e),(i) SON averaged in the SCTR and IODE respectively. Blue and orange lines represent the crossing depth of SCTR and IODE separately. Black, red and green lines represent ALL, WS and HF, respectively. The horizontal dashed line represents the depth of $30 \mathrm{~m}$, and the vertical dashed line represents the $1.5^{\circ} \mathrm{C}$ standard deviation.

\subsection{Summary}

In this Chapter, we diagnose the relative contributions of heat flux and wind stress to the interannual upper-ocean temperature variability in the Tropical Indian Ocean (TIO) by analyzing three sets of high-resolution OGCM simulations that differ only in their surface forcings. ALL, forced by both interannually varying heat flux and wind stress, reasonably well reproduces the observed mean and variability of the vertical structure of ocean temperature in the TIO when compared to the WOA climatology and SODA reanalysis data.

Comparison of the sensitivity simulations, HF and WS, against the ALL reveals the depth-dependent impacts of heat flux and wind stress on the ocean temperature variability in the TIO. In general, heat flux dominates the variability of ocean temperature in the upper $30 \mathrm{~m}$ in much of the TIO, while 
its impact is quickly subdued below $30 \mathrm{~m}$. On the contrary, wind stress is the decisive driver of temperature variability below $30 \mathrm{~m}$. This suggests that there be a transition depth at which the main driver of the upper-ocean interannual temperature variability is shifted from heat flux to wind stress. We investigated this crossing depth to better understand the driving forces of the spatial pattern and seasonality of the upper-ocean interannual temperature variability.

Our results show that the variability of ocean temperature above the crossing depth is deemed mainly a response to heat flux while the one below is induced by wind stress either locally or remotely. The shallowest crossing depth is found in the southern TIO, including the SCTR and IODE, indicating that these are the regions of the strong control of the wind-driven circulation in the upperocean interannual temperature variability. The SCTR is characterized by a shallower crossing depth along with intensified variability of the subsurface temperatures driven by wind stress, because of the anomalous wind stress and Rossby wave-induced upwelling forced by ENSO (Burns and Subrahmanyam 2016; Xie et al. 2002; Yokoi et al. 2012; Zhou et al. 2008) and the Interdecadal Pacific Oscillation (Jin et al. 2018). On the other hand, the crossing depth in the IODE shoals during boreal autumn and winter while it deepens in late boreal spring and summer. However, the annual cycle of the crossing depth in the IODE region is relatively smaller.

The crossing depth in the SCTR also exhibits a clear seasonal variability with shoaling during boreal winter and spring and deepening during boreal summer and autumn.

The strong annual cycle in the crossing depth in the SCTR is in agreement with the result from previous studies (Hermes and Reason 2008; Yokoi et al. 2008, 2009), which associated the strong annual cycle in the upper-ocean temperature in the SCTR to the wind-driven upwelling related to trade winds and Rossby waves.

In this study, we have demonstrated that, at least in the TIO, the crossing depth can be a useful diagnostic to examine the relative role of heat flux and wind stress in the ocean temperature variability. As Doi et al. (2017) stressed, the prediction of interannual variability associated with IOD events can be improved by including the subsurface temperature. 


\section{Chapter 3}

The seasonal and interannual variabilities of barrier layer thickness in the tropical Indian Ocean *

\footnotetext{
* This chapter is based on:

Yuan, X. and Su, Z.: The seasonal and interannual variabilities of the barrier layer thickness in the tropical Indian Ocean, Ocean Sci. Discuss.,

https://doi.org/10.5194/os-2019-12, under review, 2019.
} 


\subsection{Abstract}

The seasonal and interannual variations of the barrier layer thickness (BLT) in the tropical Indian Ocean (TIO) is investigated in this study using the Simple Ocean Data Assimilation (SODA) version 3 reanalysis dataset from 1980 to 2015. BLT presents a significant seasonal variation in the TIO, mainly attributed to the variations of the sea surface salinity (SSS) and the thermocline. In particular, BLT anomalies are negatively correlated to SSS anomalies (SSSAs) in the western TIO, except in summer. In the eastern TIO, the thermocline anomalies positively impact BLT anomalies in all seasons. However, the dependency of BLT anomalies on thermocline in the western TIO is only observed in winter.

Furthermore, it is found that BLT could feedback on SSS, as BLT of the springtime can negatively affect the SSS of the summer-time in the western TIO. In terms of the interannual BLT variation, we found that both the Indian Ocean Dipole (IOD) and EI Niño Southern Oscillation (ENSO) events could impact the variation of BLT by affecting the thermocline, especially in the eastern TIO. In addition, BLT in the western TIO presents remarkable seasonal phase locking feature during the El Niño years. During the developing and mature phases of EI Niño, thicker BLT is due to the change of thermocline, while during the decaying phase of El Niño, BLT anomalies opposing to the weakened thermocline change, become more significant because of the change of SSS. 


\subsection{Introduction}

The upper-ocean variability, particularly the formation and variability of the mixed layer, can provide a broad perspective to better understand the air-sea interaction and the impacts of climate events on the marine ecosystem. The tropic Indian Ocean (TIO) with a shallower thermocline in the west (Yokoi et al., 2012, 2008; Yu et al., 2005) and stronger interannual variation in the east (Li et al., 2003; Saji et al., 1999) comparing to the tropic Pacific and the Atlantic Ocean, provides a unique study region to investigate the variability of upper ocean.

Traditionally, the mixed layer depth was defined by the temperature where the temperature within the layer is $0.2^{\circ} \mathrm{C}$ lower than that of the surface (de Boyer Montégut et al., 2004). However, the definition of the mixed layer has recently been changed by using the oceanic density with assuming the density within the layer is $0.03 \mathrm{~kg} / \mathrm{m} 3$ smaller than the surface (Mignot et al., 2007). The new definition results in novel terminology, the barrier layer. The barrier layer thickness (BLT) is defined as the depth from the mixed layer bottom to the top of the thermocline (Lukas and Lindstrom, 1991; Masson et al., 2002; Sprintall and Tomczak, 1992). BLT plays a key role in oceanic dynamics and air-sea interaction. For example, BLT isolates the density of the mixed layer from the cooling entrainment, helping to sustain the heat for the formation of the El Niño Southern Oscillation (ENSO) (Maes, 2002; Maes et al., 2006; Maes et al., 2005), as well as contributing to the formation of the different ENSO types (conventional ENSO and ENSO Modoki) (Singh et al., 2011). The spatial structure of BLT led by different Ekman drift (Thadathil et al., 2007; Vinayachandran et al., 2002) is crucial for the formation of monsoon cyclone in the pre-monsoon season (Masson et al., 2005; Neetu et al., 2012).

The variability of BLT is attributed to various mechanisms, such as heavy precipitation, oceanic currents, wind stress and oceanic waves (Bosc et al., 2009; Mignot et al., 2007). For instance, thicker BLT mainly locates in the areas beneath the Inter-Tropical Cyclone Zone (ITCZ) due to abundant rainfall (Vialard and Delecluse, 1998) or regions with large river runoff (Pailler et al., 1999). The strong wind stress anomalies could also contribute to thickening the BLT (Seo et al., 2009).

In the TIO, the features of BLT variation have been found very similar to the variation of sea surface salinity (SSS). Firstly, the southeastern Arabian Sea, the Bay of Bengal, and the southeastern TIO, characterized by significant seasonal variability of SSS due to different hydrological processes, are also observed with the strong BLT variations (Schott et al., 2009). Secondly, it is reported that the seasonal variability of SSS in the TIO is mainly attributed to the freshwater (precipitation and runoff) and the horizontal advection (Rao, 
2003; Subrahmanyam et al., 2011; Zhang et al., 2016; Zhang and Du, 2012), whereas the BLT annual variation could also be affected by the freshwater (Masson et al., 2002; Qu and Meyers, 2005). Moreover, the Indian Ocean Dipole (IOD) and ENSO have been intensively reported to have impacts on the interannual variability of SSS in the TIO (Grunseich et al., 2011; Rao and Sivakumar, 2003; Subrahmanyam et al., 2011; Yuhong et al., 2013), while the IOD events can also partly explain the interannual variability of BLT in the southeastern TIO (Qiu et al., 2012). In general, in the positive IOD year (e.g., 2006), the isothermal layer is lifted by the upwelling Kelvin wave and the mixed layer becomes shallower due to salinity decrease, which results in a thinner barrier. In the negative IOD year (e.g., 2010), a thicker BLT is expected due to the extending of the isothermal layer. Furthermore, the tight relationship between BLT and zonal SSS gradient was also reported in the TIO at the subseasonal time scale (Bosc et al., 2009).

However, existing studies on the interannual variability of BLT were mainly for specific years and lack of the long-term verification and the co-varying between the BLT and SSS variation is not always hold in the TIO (Qiu et al., 2012). Also, the relationship between BLT and the thermocline anomaly is less documented in the TIO. As a result, further investigations of BLT seasonal and interannual variabilities and its relationship with SSS and thermocline anomalies are still highly desired. The Simple Ocean Data Assimilation (SODA) version 3 reanalysis dataset with observations from 1980 to 2015 could be adequate for such purpose.

The remainder of this paper is arranged as follows. After a description of the datasets and methods in section 3.3, we compare the variability features of BLT obtained from observed and reanalysis datasets in the Indian Ocean in section 3.4. Section 3.5 presents the seasonal variation of the BLT anomalies in the TIO. Its interannual variability is shown in section 3.6. A summary and discussion are given in section 3.7.

\subsection{Data and Methods}

A series of monthly global gridded observation and reanalysis products were used to assess the variability of BLT in the Indian Ocean. At 10 horizontal resolution, this includes the Argo profiles products provided by the French Research Institute for Exploration of the Sea (Ifremer: http://www.ifremer.fr/cerweb/deboyer/mld/Subsurface_Barrier_Layer_Thickn ess.php) from 2005 to 2015. BLT is calculated as the difference between $T T D_{D T m 02}$ and $M L D_{\text {DReqDT02 }}$.

$$
B L T=T T D_{D T m 02}-M L D_{D R e q D T 02}
$$


where $T T D_{D T m 02}$ is the top of thermocline depth defined as the depth at which the surface temperature cooled by $0.2{ }^{\circ} \mathrm{C}$ and $M L D_{D R e q D T 02}$ is the mixed layer depth defined in density with a variable threshold criterion (de Boyer Montégut et al., 2007; Mignot et al., 2007).

At $0.5^{\circ}$ horizontal resolution, the latest released version 3 Simple Ocean Data Assimilation (SODA) ocean reanalysis data (1980-2015) provided by the Asiapacific data-research center (APDRC: http://apdrc.soest.hawaii.edu/datadoc/soda_3.3.1.php) is employed, which has reduced systematic errors to a level in the upper ocean and improve the accuracy of poleward variability in the tropic (Carton et al. 2018). It has 26 vertical levels with a $15-\mathrm{m}$ resolution near the sea surface. We adopt the same Ifremer equation to calculate SODA BLT by using the mixed layer depth defined by both density and temperature.

We take the salinity and temperature in the first level as the SODA SSS and SST, respectively. The thermocline is defined as the depth of $20{ }^{\circ} \mathrm{C}$ isotherm.

Monthly sea surface temperature (SST) obtained from Hadley Center Global Sea Ice and Sea Surface Temperature (HadISST: https://climatedataguide.ucar.edu/climate-data/sst-data-hadisst-v11) for $1980-2015$ on a grid of $1^{\circ} \times 1^{\circ}$ is also used as validation and to calculate the Nino3.4 index $\left(5^{\circ} \mathrm{N}-5^{\circ} \mathrm{S}, 170^{\circ} \mathrm{W}-120^{\circ} \mathrm{W}\right)$.

In all the datasets, we removed the annual cycle before proceeding with correlation. The simultaneous and lead-lag correlations are used in this study with the t-student significance test. The composition analysis is employed in studying the interannual variability of BLT with Monte-Carlo significance test. The positive and negative IOD years are provided by the Bureau of Meteorology (http://www.bom.gov.au/climate/iod/) and the El Niño and La Nina years are obtained from Golden weather gate service (https://ggweather.com/enso/oni.htm). In our study period, there are seven positive IOD years, including 1982, 1983, 1994, 1997, 2006, 2012 and 2015, and seven negative IOD years, including 1981, 1989, 1992, 1996, 1998, 2010 and 2014, while four El Niño and five La Nina years are 1982, 1987,1991,1997 and 1988, 1998, 1999, 2007, 2010, respectively.

\subsection{BLT in the Indian Ocean}

BLT calculated by SODA version 3 reanalysis data is briefly assessed against Argo float observation from 2005 to 2015. Figure 3.1 shows the distributions of the climatological mean of BLT in the TIO. A clear east-west contrasting distribution of the climatological mean BLT can be observed in both Argo and SODA in the TIO, with thick BLT in the east and thin BLT in the west. BLT 
calculated by SODA in the Bay of Bengal is underestimated compared to that by Argo. This weakened BLT maybe because of lacking the runoff data in the Bay of Bengal (Carton et al., 2018; Carton and Giese, 2008, 2006). With this in mind, we focus on using SODA version 3 data for analysing the seasonal and interannual variability of BLT in the TIO from 1980 to 2015.

The seasonal and interannual variations of the mixed layer depth (MLD) and the top of the thermocline depth (TTD) averaged over the $\mathrm{TIO}\left(50^{\circ} \mathrm{E}-100^{\circ} \mathrm{E}\right.$, $20^{\circ} \mathrm{N}-20^{\circ} \mathrm{S}$ ) have also been calculated (Figures are not shown) to see which is the dominant role for the BLT variability. However, it is hard to define whether MLD or TTD is the main dominator. In particular, in terms of the seasonal time scale, both MLD and TTD have clear annual variations while BLT has a semi-annual variation, reaching maxima in February and September. Thus, the impacts of MLD and TTD on the BLT is dependent on the seasons. In terms of the interannual time scale, the contribution of MLD and TTD to the BLT variability is more complicated to be defined. To further study the seasonal and interannual variations of BLT, we choose the observed variables in MLD, such as SST and SSS, and thermocline, which has prominent variations in the deeper ocean.

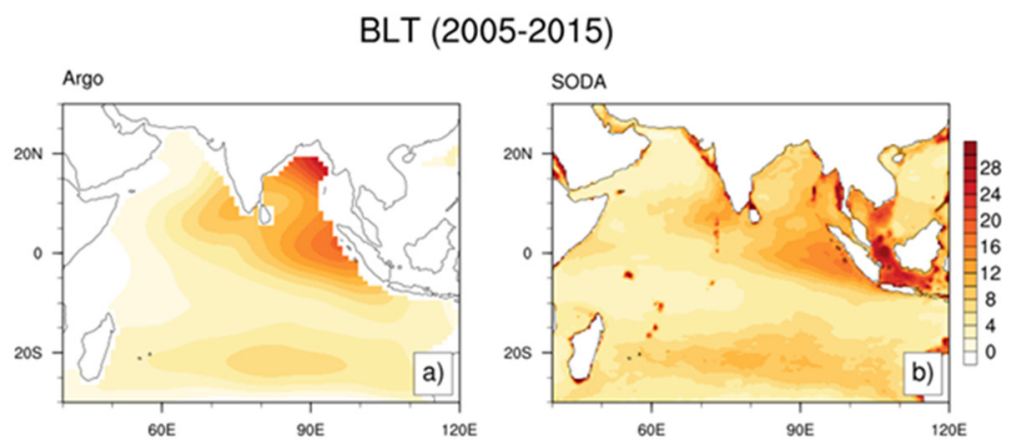

Figure 3. 1 The distributions of the climatological mean of BLT obtained from Argo (a) and SODA (b) from 2005 to 2015 in the Indian Ocean (Unit: m).

\subsection{Seasonal Variation}

To understand the seasonal variability of BLT in the TIO, Figure 3.2 presents the distributions of SSS and BLT during winter (December-January-February, DJF), spring (March-April-May, MAM), summer (June-July-August, JJA) and autumn (September-October-November, SON). The BLT distribution pattern is inversely correlated to the SSS distribution, where thick BLT is observed with fresh water in the eastern TIO, and vice versa in the western TIO. This is consistent with previous studies (Agarwal et al., 2012; Felton et al., 2014; Han and McCreary, 2001; Vinayachandran and Nanjundiah, 2009). Although both SSS and BLT have a similar distribution in the TIO, their seasonal variabilities do not co-vary with each other, especially near the equator. For example, 
saltwater in the western $\operatorname{TIO}\left(40^{\circ} \mathrm{E}-90^{\circ} \mathrm{E}, 5^{\circ} \mathrm{N}-12^{\circ} \mathrm{S}\right)$ elongates to the east during winter and spring and retreats during summer and autumn, while the corresponding thin BLT does not vary accordingly. In contrast, there is significant seasonal variability of BLT in the eastern $\operatorname{TIO}\left(90^{\circ} \mathrm{E}-100^{\circ} \mathrm{E}, 5^{\circ} \mathrm{N}\right.$ $12^{\circ} \mathrm{S}$ ), with its maxima occurred in autumn. Besides, there is a weak seasonal variability of the east-west SSS gradient along the equator $\left(5^{\circ} \mathrm{N}-12^{\circ} \mathrm{S}\right)$ while the zonal BLT gradient becomes more significant in spring and strongest during autumn. Thus, the seasonal variability of BLT in the TIO is not always covarying with SSS.

To do more detailed correlation analysis, we choose the area of $\left(12^{\circ} \mathrm{S}-5^{\circ} \mathrm{N}\right.$, $\left.40^{\circ} \mathrm{E}-100^{\circ} \mathrm{E}\right)$ as the TIO. This area is selected because it is adequate to demonstrate the difference in the seasonal variability between SSS and BLT. In addition, the well-known area of Seychelles Chicago Thermocline Ridge [SCTR, $\left(60^{\circ} \mathrm{E}-80^{\circ} \mathrm{E}, 12^{\circ} \mathrm{S}-5^{\circ} \mathrm{S}\right)$ ] (Manola et al., 2015; Yokoi et al., 2012, 2008) and the eastern IOD area $\left[\mathrm{IODE},\left(90^{\circ} \mathrm{E}-110^{\circ} \mathrm{E}, 10^{\circ} \mathrm{S}-\mathrm{EQ}\right)\right]$ are also within the selected regions.

BLT anomalies were obtained from SODA version 3 reanalysis data averaged along the TIO $\left(12^{\circ} \mathrm{S}-5^{\circ} \mathrm{N}\right)$ as a function of longitude vs. time. Figure 3.3 displays the correlation coefficients of SST anomalies and SSS anomalies (SSSAs) with BLT anomalies, respectively. In the previous study, it has been proven that SST has a tight relationship with thermocline in the western TIO at the seasonal time scale (Yokoi et al., 2012). However, from Figure 3.3a, a significant relationship cannot be found between SST and BLT anomalies in the western TIO. Instead, a short-term (less than two months) negative relationship between BLT and SST anomalies can be observed in the eastern TIO during winter, with colder water connecting to thicker BLT and vice versa (Figure 3.3a). This SST-BLT relationship in the TIO can also be found by correlating the BLT anomalies with SST anomalies obtained from the HadISST (Figure not shown), except their negative correlated area is smaller. On the contrary, in the western TIO, a remarkable negative SSS-BLT (blue shaded) relationship, shows during winter and spring with saltier (fresher) water corresponding to thinner (thicker) BLT (Figure 3.3b), while there is no significant relationship between SSS and BLT anomalies in the east. 


\section{(1980-2015)}
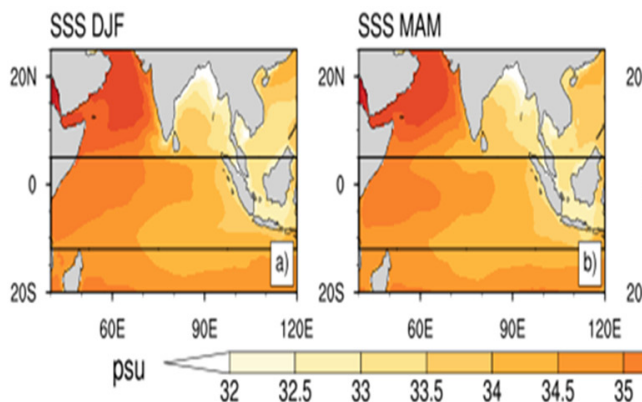

SSS JJA
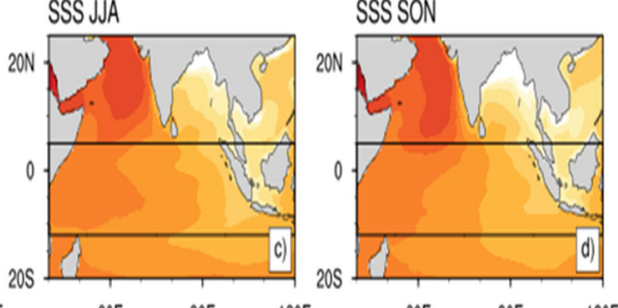
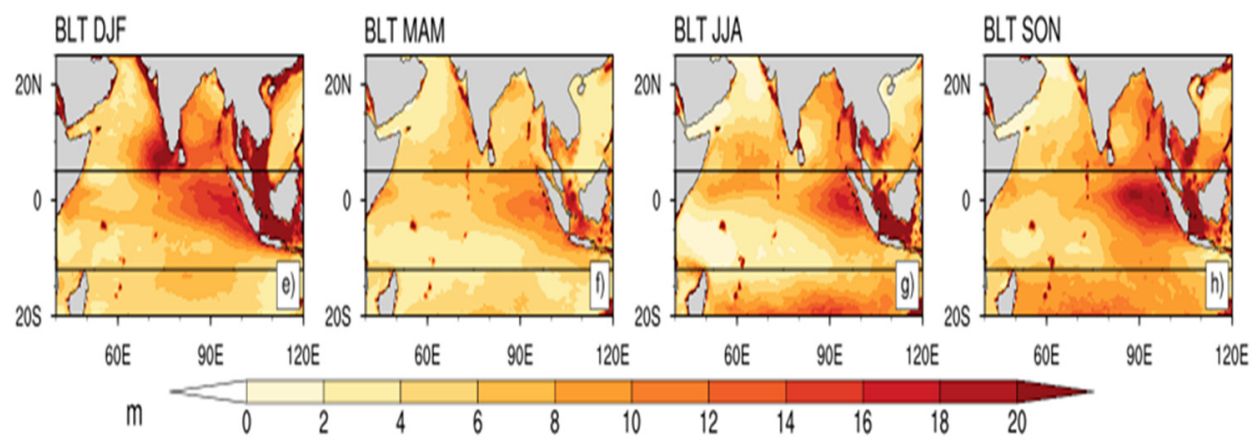

Figure 3. 2. The seasonal distributions of SSS (unit: psu; a-d) and BLT (units: m; e-h) in the Indian Ocean from 1980 to 2015 (The two black lines represent the latitudes of $12^{\circ} \mathrm{S}$ and $5^{\circ} \mathrm{N}$ respectively).
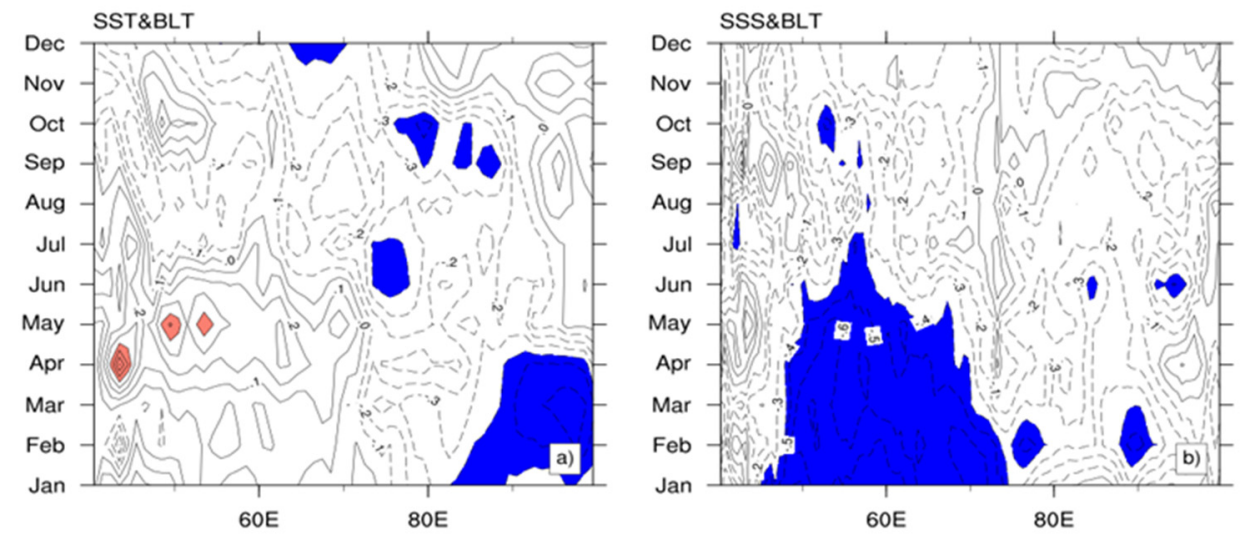

Figure 3. 3. Simultaneous correlations along the area of $\left(12^{\circ} \mathrm{S}-5^{\circ} \mathrm{N}\right)$ for (a) SST and (b) SSSAs in respect to BLT anomalies [Shaded areas exceed the $95 \%$ significance level; red (blue) shaded areas represent the areas with the positive (negative) correlation coefficients]. 
To further understand the seasonal variability of BLT anomalies, we use the lagged correlations for BLT anomalies in respect to SSSAs in January (JAN), April (APR), July (JUL) and October (OCT). The significant lagged correlation between SSSAs and BLT anomalies mainly locates in the western TIO (Figure 3.4), as shown in Figure 3.3b. SSSAs in winter and autumn not only have a specific in-phase relationship with BLT anomalies but could also affect the change of the corresponding BLT anomalies at least two months later (Figure $3.4 a$,d). For example, in the western TIO, saltier water in October can result in thinner BLT in following November and December; saltier water in January could lead to thinner BLT until May. This leading relationship of SSSAs on BLT anomalies is also found in April, but associated with a weaker negative BLT feedback (Figure 3.4b). In July, it is only found the BLT feedback in the western TIO, implying that the spring-time BLT anomalies could have a negative impact on the summer-time SSSAs (Figure 3.4c).
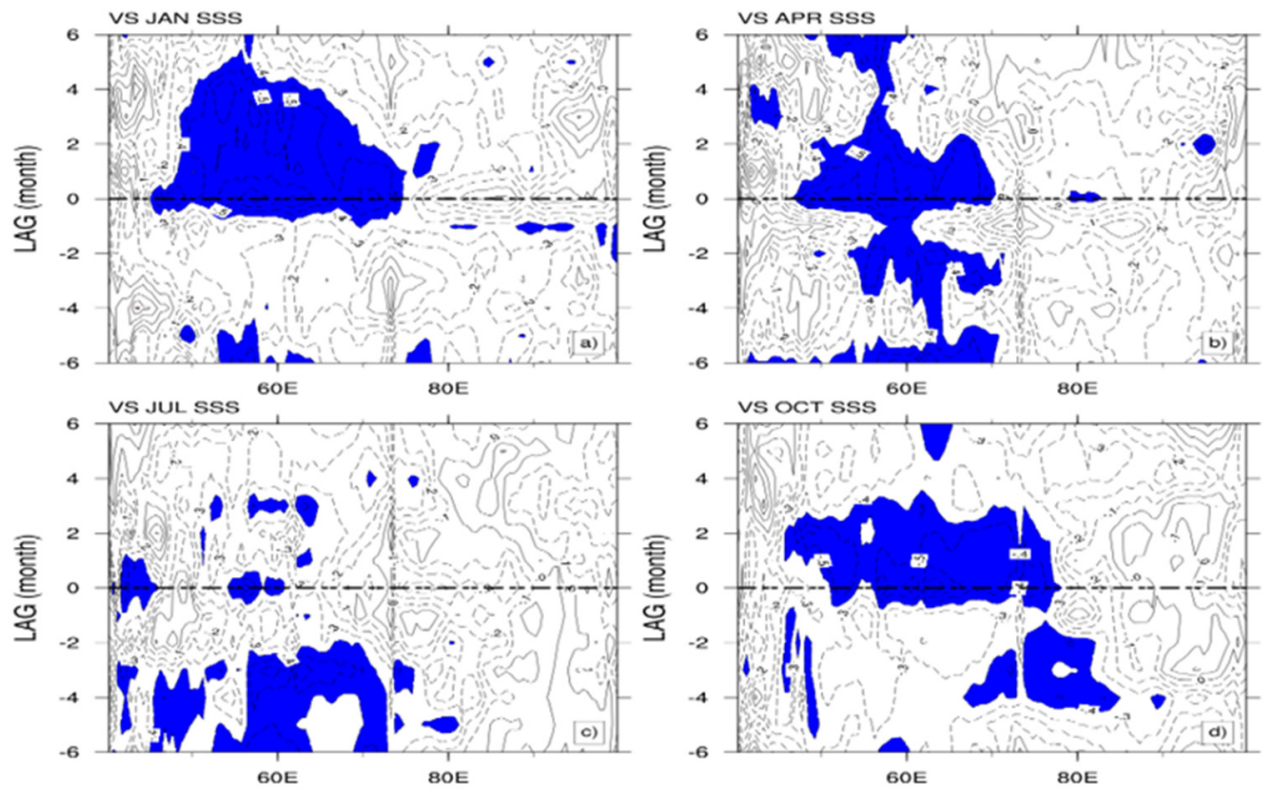

Figure 3. 4. Lead - leg crossing correlations between BLT and SSSAs for (a) January, (b) April, (c) July, and (f) October along the area of $\left(12^{\circ} \mathrm{S}-5^{\circ} \mathrm{N}\right)$ from 1980 to 2015 (Shaded areas exceed $95 \%$ significance level; Positive lag means SSS leads BLT; blue shaded areas represent the negative correlation; the thick black dashed line represents the in phase correlation ).

Figure 3.5 shows the lagged correlations between BLT and thermocline anomalies. Deeper thermocline in October is along with thicker BLT in the central and the eastern TIO and has a positive leading effect on the BLT anomalies in following November and December. Deeper thermocline in January is associated with thicker BLT in the eastern TIO, without leading impact on the BLT anomalies in the following months. In contrast, in the 
western TIO, both the in-phase and leading impacts of thermocline anomalies on the BLT could be observed since January and weakened in April. In July, there is little correlation between thermocline and BLT anomalies in the whole TIO.

In summary, during autumn, BLT anomalies in the eastern TIO is determined by the subsurface oceanic process while SSSAs drive BLT anomalies in the western TIO with the negative in-phase and leading impacts. During winter, due to strong wind convergence induced by both the winter monsoon wind and the southeasterlies (Yokoi et al., 2012), BLT anomalies is affected by both SSS and thermocline anomalies in the western TIO. SSSAs have a negative influence on BLT anomalies while thermocline anomalies have a positive impact. This negative SSS-BLT relationship sustains until spring with weaker negative feedback of the BLT anomalies on the surface. A relatively weaker thermocline-BLT relationship is observed in the eastern TIO. SSS in summer is affected by the spring-time BLT in the western TIO without the BLTthermocline relationship.
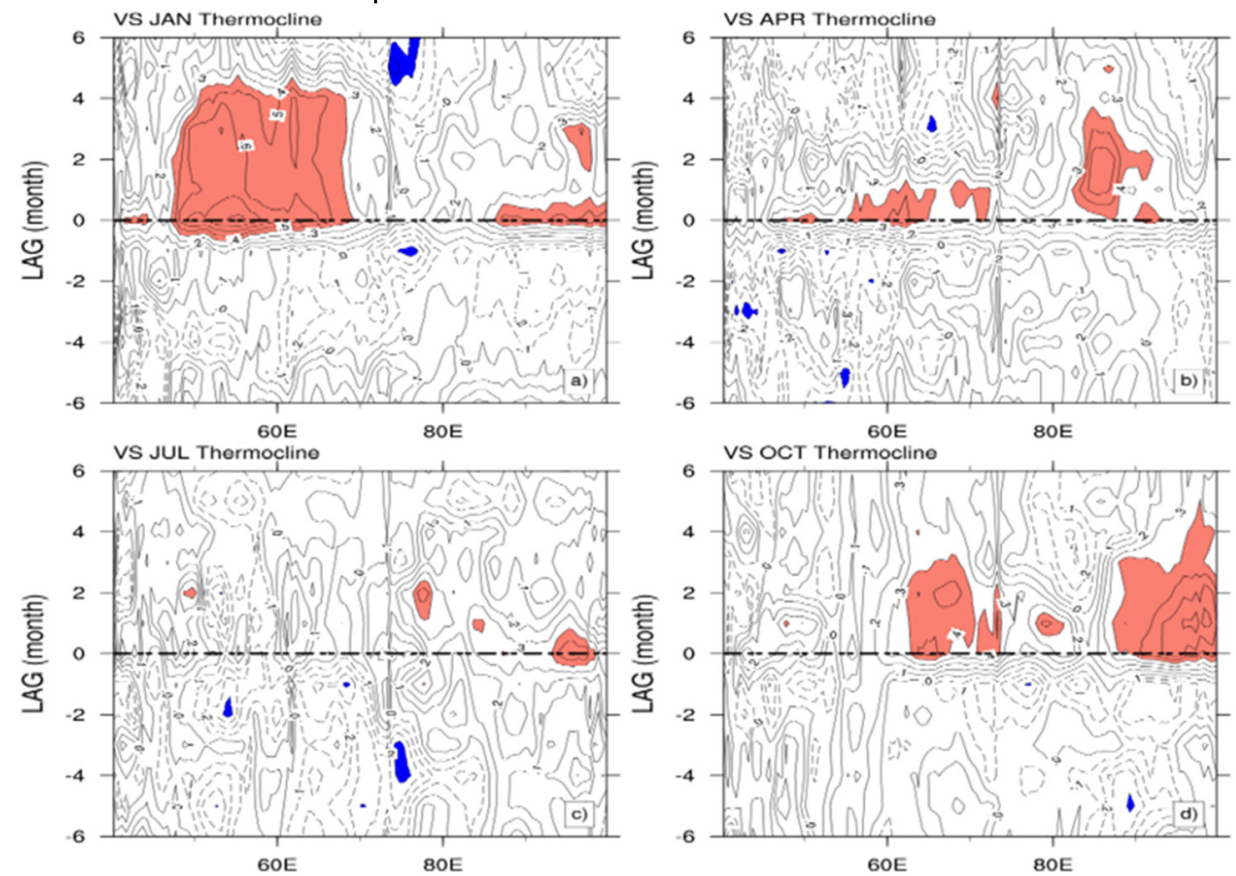

Figure 3. 5. Same as Figure 3.4 but for thermocline and BLT anomalies [red (blue) shaded areas represent the positive (negative) correlation; the thick black dashed line represents the in-phase correlation].

To further understand the seasonal variability of BLT anomalies, we use the lead-lag crossing correlation for BLT anomalies in respect to SSSAs in January $(\mathrm{JAN})$, April (APR), July (JUL) and October (OCT). The significant lead-lag 
relationship between SSS and BLT anomalies mainly locates in the western TIO (Figure 3.4), as their in-phase relationship shows (Figure 3.3b). SSSAs in winter and autumn not only have a specific in-phase relationship with BLT anomalies but could also lead to the change of the corresponding BLT anomalies at least two months earlier (Figure 3.4a,d). For example, in the western TIO, saltier water in October is presented with thinner BLT and can result in thinner BLT in November and December; saltier water in January associated with thinner BLT could lead to thinner BLT until May. This leading relationship of SSSAs on BLT anomalies is also found in April, but with a weaker negative BLT feedback from January and February (Figure 3.4b). In July, it is only found the BLT feedback in the western TIO, implying that the spring-time BLT anomalies can give a negative impact on the summer-time SSSAs (Figure 3.4c).

\subsection{Interannual Variation}

In regard to the different mechanisms of BLT variation between the western TIO and the eastern TIO, we have since investigated the interannual variability of BLT by averaging the western $\operatorname{TIO}\left(12^{\circ} \mathrm{S}-5^{\circ} \mathrm{N}, 50^{\circ} \mathrm{E}-75^{\circ} \mathrm{E}\right)$ and the eastern TIO $\left(12^{\circ} \mathrm{S}-5^{\circ} \mathrm{N}, 90^{\circ} \mathrm{E}-100^{\circ} \mathrm{E}\right)$ separately. Figure 6 presents the compositing seasonal variations of SSS, BLT, and thermocline based on the positive and negative IOD events during the period of 1980-2015. In the eastern TIO (Figure $3.6 a, c, e)$, there is no significant signal of SSS during the IOD events while thermocline accompanying with BLT displays the prominent seasonal phase locking feature. Both thin BLT and shallow thermocline appear during the mature and decaying phases of the positive IOD events due to the reduced precipitation and the strong upwelling (Thompson et al., 2006), which in turn, contributes to intensifying the positive IOD events coupled with SST (Deshpande et al., 2014). Thicker BLT can be found in the mature phase of the negative IOD events along with deeper thermocline. In the western TIO (Figure $3.6 b, d, f), S S S, B L T$, and thermocline only respond well to the positive IOD events. BLT has been thickened due to deeper thermocline and fresher water, providing favorable circumstance to sustain warmer water. 

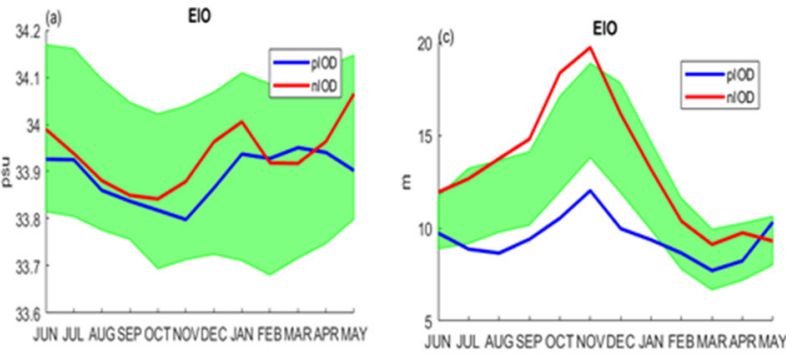

wo
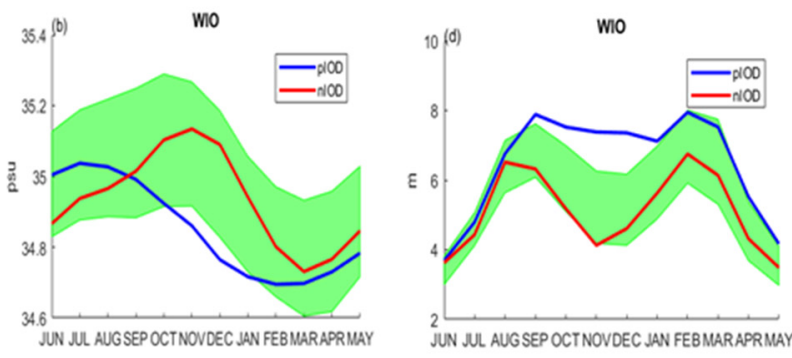

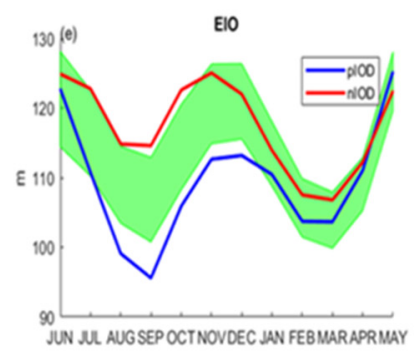

wo

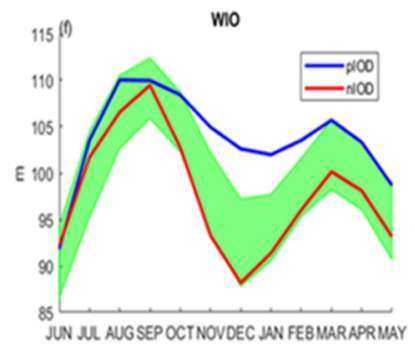

Figure 3. 6. The composting seasonal variations of SSS ( $a, b$; unit: psu), BLT (c, d; unit: $\mathrm{m})$ and thermocline (e, f; unit: $\mathrm{m}$ ) in the IOD events during the period of 1980-2015 averaged by the areas of the eastern TIO $\left(90^{\circ} \mathrm{E}-100^{\circ} \mathrm{E}, 12^{\circ} \mathrm{S}-5^{\circ} \mathrm{N}\right)$ and the western TIO $\left(50^{\circ} \mathrm{E}-75^{\circ} \mathrm{E}, 12^{\circ} \mathrm{S}-5^{\circ} \mathrm{N}\right)$, separately. The blue line represents compositing in the positive IOD events, and the red one represents that in the negative IOD events, and the green shaded area represents the $95 \%$ Monte-Carlo significance level.

The compositing seasonal variations of SSS, BLT, and thermocline are also shown in Figure 3.7 but based on the ENSO events. In the eastern TIO (Figure 3.7a,c,e), the thinner BLT mainly connects to the shallower thermocline during the developing and mature phases of El Niño (Figure 3.7c, e), due to the anomalous easterlies along the equator invoked by the adjusted Walker Circulation (Alexander et al., 2002; Kug and Kang, 2006). In the western TIO (Figure $3.7 b, d, f)$, the deepening thermocline, due to the westward downwelling Rossby wave and the anomalous wind stress induced by El Niño (Kug and Kang, 2006; Xie et al., 2002), peaks in the El Niño developing phase. A following weak peak of thermocline anomalies appears during the decaying phase of El Niño events. The corresponding BLT has a similar semi-annual variation in the El Niño years, but with the intensified second peak after the mature phase of El Niño attributed to the fresher surface water.

The seasonal phase locking of BLT is prominent in the eastern TIO mainly induced by the corresponding thermocline in both the IOD and the ENSO years. In the western TIO, the variation of BLT is influenced by thermocline during the developing and mature phases of the positive IOD or El Niño events. Then, it is affected by SSS during the decaying phase of the positive IOD or El Niño events. 

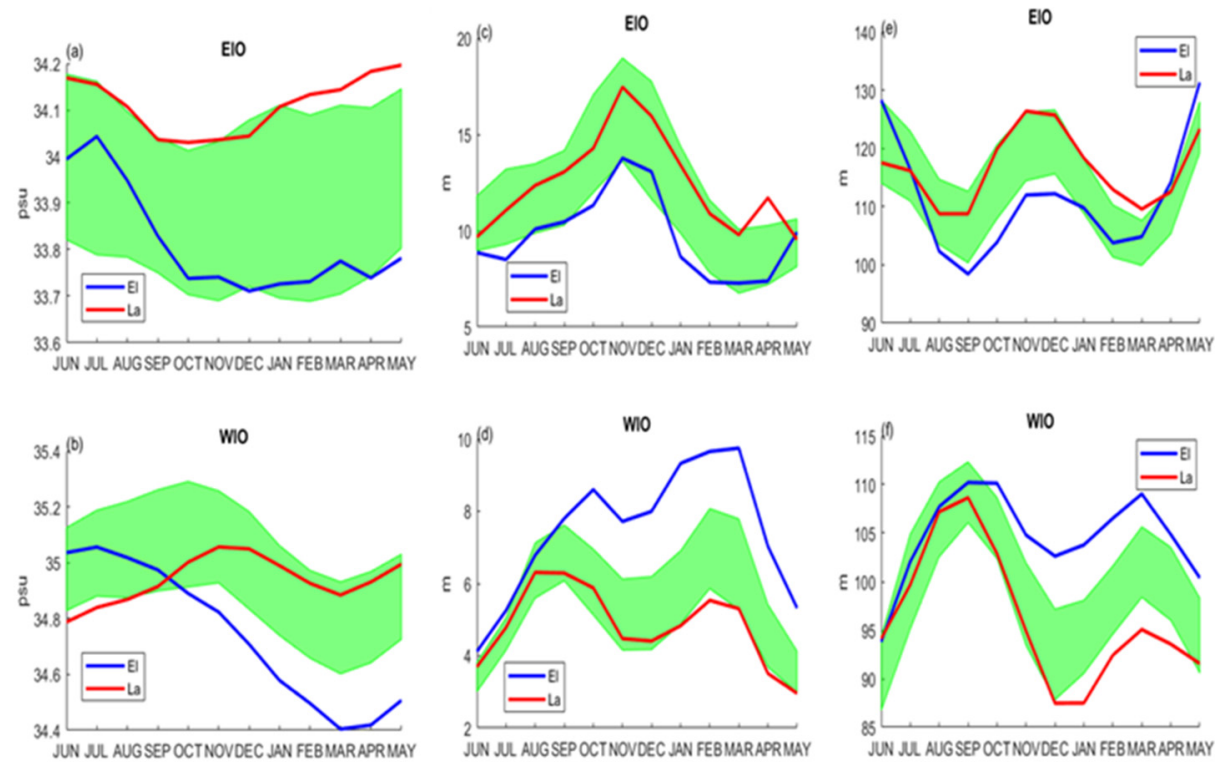

Figure 3. 7. Same as Figure 3.6 but compositing on the El Niño and La Nina years.

The relationship between BLT and El Niño could also be detected in the time series of BLT, SSS and thermocline anomalies averaged over the western TIO during winter and spring from 1980 to 2015 (Figure 3.8). During winter (Figure 3.8a), deeper BLT and thermocline could be found in 1983, 1992, 1998, corresponding to the mature phase of El Niño. During spring (Figure 3.8b), deeper BLT and thermocline could also be observed in these El Niño decaying years, accompanying with fresher water. On the other hand, the effect of IOD on the interannual variability of BLT could be observed in specific years as well, such as 1983,1998, and 2006.
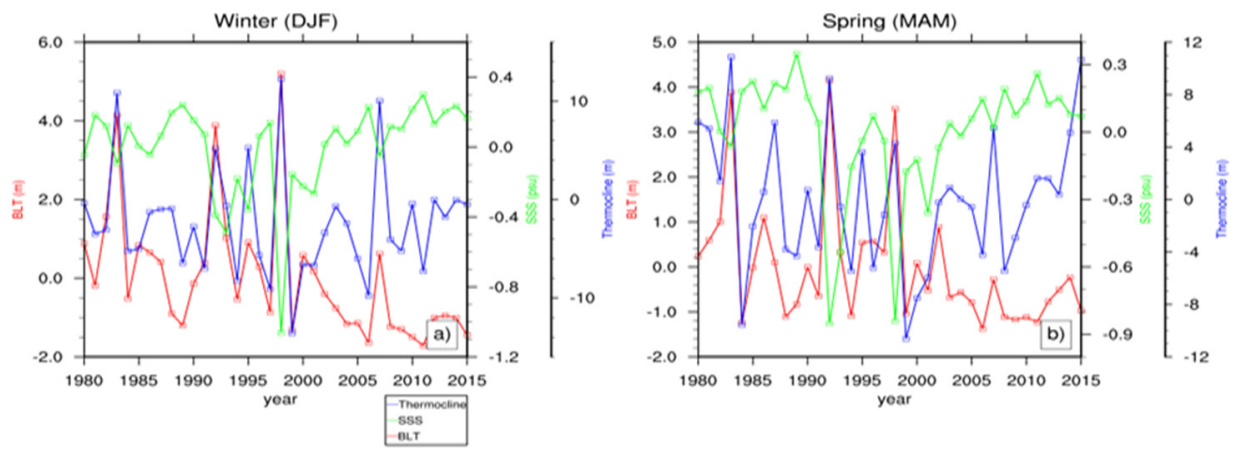

Figure 3. 8. Time series of BLT, SSS and thermocline anomalies averaged over the western TIO $\left(12^{\circ} \mathrm{S}-5^{\circ} \mathrm{N}, 50^{\circ} \mathrm{E}-75^{\circ} \mathrm{E}\right)$ during winter (a) and spring (b) from 1980 to 2010. Red, green, and blue lines represent BLT, SSS, and thermocline, respectively. 
Next, we calculate the lagged correlations of BLT, thermocline, and SSSAs with the Nino3.4 index from 1980 to 2015. The BLT-EI Niño relationship experiences two phases (Figure 3.9a) linking to the subsurface and surface effects. In particular, the correlation coefficients between the thermocline anomalies and the Nino3.4 index reach the noticeable values during the mature period of $\mathrm{El}$ Niño (Figure 3.9b), and their correlation has a longitude-dependent time-delay, which is consistent with the result of Xie et al., (2002). This deeper thermocline resulted by El Niño via the westward downwelling Rossby wave affects the corresponding BLT anomalies, shown as the remarkably positive correlation between BLT anomalies and the Nino3.4 index appearing in one month later (Figure 3.9a). Then, the correlation between the thermocline anomalies and El Niño becomes weaker during the decaying period of El Niño. However, there is an enlarged correlation between BLT and ENSO, corresponding to the intensifying second peak of BLT shown in Figure 3.7d. This enlarged pattern accompanies with the appearance of a negative correlation between SSS and ENSO (Figure 3.9c). The negative SSSAs, induced by EI Niño via the adjusting Walker circulation and the westward Rossby wave, thicken the BLT anomalies in the western TIO. 

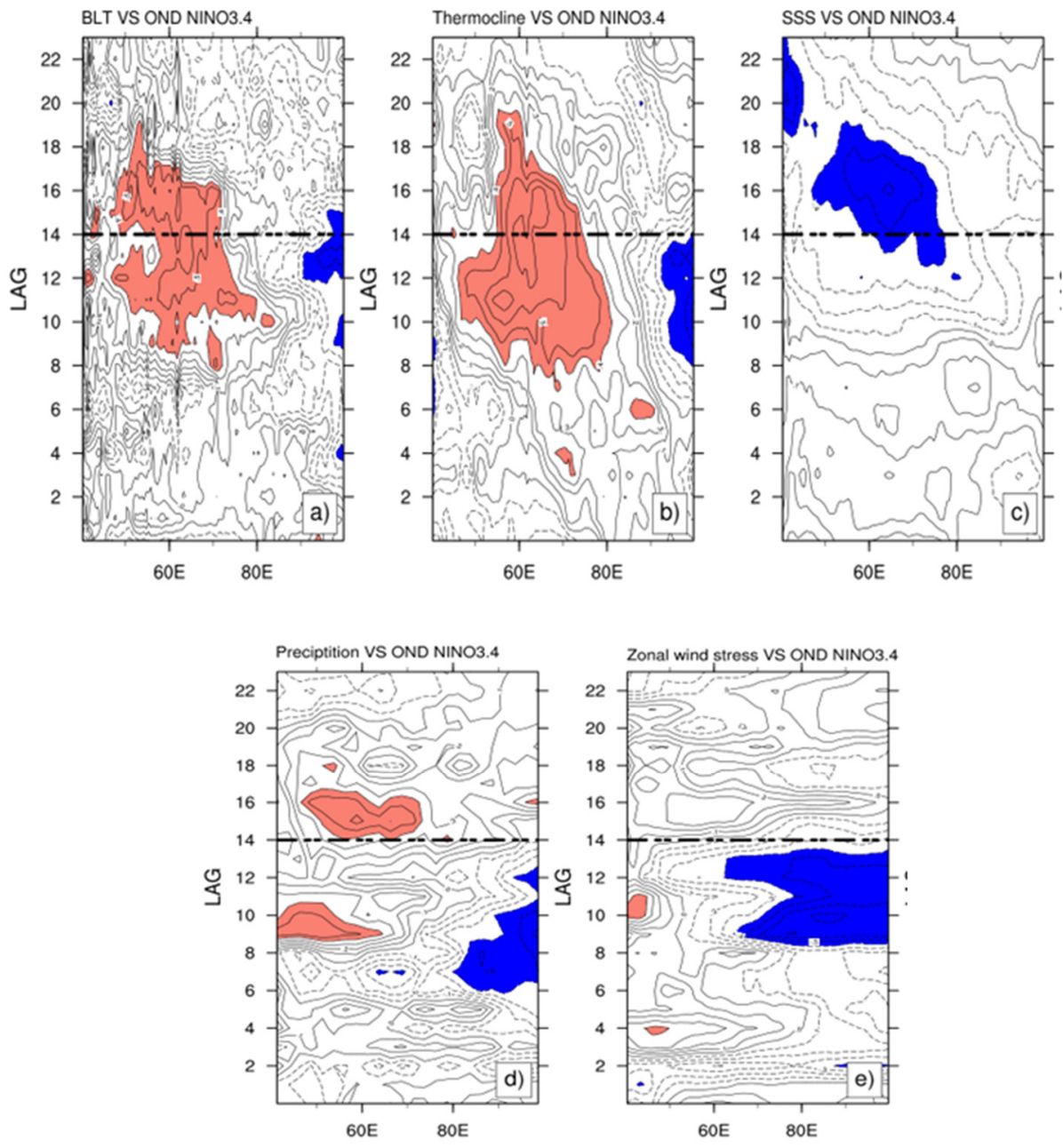

Figure 3. 9. Lagged correlations of (a) BLT, (b) thermocline, (c) SSS anomalies, (d) precipitation anomalies, and (e) zonal wind stress anomalies averaged in $\left(12^{\circ} \mathrm{S}-5^{\circ} \mathrm{N}\right)$, with the Nino3.4 index as a function of longitude and calendar month. Shaded areas exceed a $95 \%$ significance level; positive lagging correlations are shaded in red and negative ones are in blue; the thick black dashed line represents the start of the decaying phase of El Niño.

In conclusion, according to the theory of Xie et al.,(2002), there is warmer water developing in the eastern tropical Pacific Ocean (EI Niño), resulting in the anomalous easterlies and invoking the downwelling Rossby wave along the equatorial TIO. Thereby, thermocline has been deepened in the western TIO associated with the thicker BLT. This thickening BLT hampers the upwelling process and benefits to sustain warmer SST. On the other hand, there is an anomalous ascending branch of the Walker Circulation adjusted during the mature phase of El Niño. Then, abundant precipitation forms over the TIO, 
impacting on SSS. Consequently, fresher surface water helps to thicken BLT, which in turn, prolongs the warmer SST in the western TIO.

\subsection{Summary}

The seasonal and interannual variability of BLT in the TIO was investigated mainly by using SODA version 3 reanalysis dataset from 1980 to 2015 in this study. The distribution of BLT has a difference between the eastern and the western TIO, with thick BLT in the east and thin BLT in the west. Also, the contributors to the seasonal variability of BLT is different between the eastern and western TIO. In eastern TIO, BLT is mainly affected by thermocline change, shown as the deeper thermocline leading to the thicker BLT. This positive correlation between BLT and thermocline is more prominent in autumn. In the western Indian Ocean, the factors affecting the BLT change with the season. During autumn, SSS overwhelming SST has a remarkably negative impact on the BLT. The saltier water is, the thinner BLT is. Both SSS and thermocline anomalies make contributions to the BLT during winter. The positive SSSAs shoal BLT while the positive thermocline anomalies thicken BLT. During spring, BLT anomalies are mainly driven by SSS. Meanwhile, there is a weak BLT feedback on SSSAs, which is intensified in summer.

In terms of the interannual variation, thicker BLT is distinct in the negative IOD and the La Nina years while thinner BLT occurs in the positive IOD and the El Niño years. On the other hand, the prominent BLT shows explicit seasonal phase locking during the IOD and El Niño years. Particularly, in the eastern TIO BLT co-varies with thermocline during the mature phase of both the IOD and El Niño events. Both SSS and thermocline contribute to the change of BLT in the western TIO after the mature phase of the positive IOD events, and their impacts on the BLT variation are enhanced in the El Niño years. In general, the warmer water in the tropical Pacific Ocean deepens thermocline in the western TIO, resulting in thicker BLT. The correlation between thermocline and EI Niño becomes weaker during the decaying phase of El Niño, but the pattern of the correlation between BLT and EI Niño is enlarged attributed to the variation of SSS. Fresher water induced by the abundant precipitation due to El Niño thickens the BLT after the mature phase of EI Niño. 


\section{Chapter 4}

\section{An Observational Perspective of Sea Surface Salinity in the Southwestern Indian Ocean and its Role in the South Asia Summer Monsoon *}

\footnotetext{
* This chapter is based on:

Yuan, X., M. Salama, and Z. Su, 2018: An Observational Perspective of Sea Surface Salinity in the Southwestern Indian Ocean and Its Role in the South Asia Summer Monsoon. Remote Sensing, 10, 1930.
} 


\subsection{Abstract}

The seasonal variability of sea surface salinity anomalies (SSSAs) in the Indian Ocean is investigated for its role in the South Asian Summer Monsoon. We have observed an elongated spatial-feature of the positive SSSAs in the southwestern Indian Ocean before the onset of the South Asian Summer Monsoon (SASM) by using both the Aquarius satellite and the Argo float datasets. The maximum variable areas of SSSAs in the Indian Ocean are along $\left(60^{\circ} \mathrm{E}-80^{\circ} \mathrm{E}\right)$ and symmetrical to the equator, divided into the southern and northern parts. Further, we have found that the annual variability of SSSAs changes earlier than that of sea surface temperature anomalies (SSTAs) in the corresponding areas, due to the change of wind stress and freshwater flux. The change of barrier layer thickness (BLT) anomalies is in phase with that of SSSAs in the southwestern Indian Ocean, which helps to sustain the warming water by prohibiting upwelling. Due to the time delay of SSSAs change between the northern and southern parts, SSSAs, therefore, take part in the seasonal process of the SASM via promoting the SSTAs gradient for the cross-equator currents. 


\subsection{Introduction}

The South Asian Summer Monsoon (SASM) forms a vital source of water for one-sixth of the world's population. The onset and the intensity of the SASM control the occurrence of drought and flood events in South Asia, impacting on agricultural yields, water resources, infrastructure, and humans. According to the monsoon's dynamic theory, the northward shift of the intertropical convergence zone (ITCZ) marks the onset of the SASM whereby the dynamic aspects of the ocean play critical roles in modulating the strength of the monsoon (Webster and Fasullo 2003). It has been found that Sea Surface Temperature (SST) Anomalies (SSTAs) over the Indian Ocean are good indicators of the differential heating between ocean and land and are correlated with both the onset and the intensity of the SASM (Jang and Straus 2013; Minoura et al. 2003; Shenoi et al. 1999).

As water density is controlled by both temperature and salinity, evidence suggests that Sea Surface Salinity (SSS) could be an indicator of abrupt changes in ocean dynamic and air-sea interaction (Hénin et al. 1998). Salinity affects many aspects of ocean stability (Nyadjro et al. 2012; Schiller et al. 1998), dynamic ocean variability (Du and Zhang 2015; Stammer 1997; Sun et al. 2015; Thompson et al. 2006; Vinayachandran and Nanjundiah 2009) and complicates air-sea interactions (Grunseich et al. 2013; Guan et al. 2014; Horii et al. 2015; Simon et al. 2006; Williams et al. 2010). In previous studies (Nyadjro et al. 2012; Rao 2003), the variability of SSS attributes to a series of complex mechanisms, mainly including the freshwater flux, horizontal advection, vertical entrainment as well as some turbulence of mixing and diffusion but the latter in the mixed layer has little influence on the seasonal variability of salinity (Da - Allada et al. 2013; Dong et al. 2009; Zhang and Du 2012a).

Sea Surface Salinity Anomalies (SSSAs) have noticeable changes during SASM. For example, during the SASM season, the extent of SSSAs in the Indian mini warm pool region (Neema et al. 2012) is minimized, and the freshwater belt is formed along the west coast of India (Deshpande et al. 2013). SSS along the equatorial Indian Ocean can also reflect the imprints of Indian winter and summer monsoons via freshwater input and wind-induced mixing (Saraswat et al. 2012). In 2004, minimum SSS was found before the onset of the monsoon (Nyadjro et al. 2012). Many scientific studies have shown that the inter-annual variability of SSSAs is connected to the local vortex of the monsoon onset (Maes and O'Kane 2014; Neema et al. 2012; Nyadjro et al. 2012; Sijikumar and Rajeev 2012) through the Arabian Sea mini warm pool.

Although the annual variance in SSS has been analysed in many studies (Donguy and Meyers 1996; Rao and Sivakumar 2003; Zhang and Du 2012b), 
the annual variance in SSSAs is yet to be analysed. Neema et al. (2012) revealed that the SSSAs in the Arabica Sea signal the onset of SASM by using only one-year simulated data, in this paper, we attempt to study the relationship between SSSA and SASM by providing observational and statistical evidence.

\subsection{Data and Methods}

SSS dataset. The SSS datasets comprised satellite products as well as in situ data. Satellite SSS products were obtained from the Version 5 Aquarius Combined Active-Passive (CAP) archive (Kao et al.) for the period (09/2011-
06/2015)
on
a
grid
of
$0.5^{\circ}$
0.5

(https://aquarius.umaine.edu/cgi/data_v5.htm). In situ measurements of SSS were obtained from the IPRC Array for Real-Time Geotropic Oceanography (Argo) product archive for the period (01/2005-12/2014) (http://apdrc.soest.hawaii.edu/projects/Argo).

Using in situ data obtained from Argo to study the Indian Ocean hold credibility because of the high density of data in the central Arabian Sea and central Bay of Bengal (Bhaskar and Jayaram 2015). The Aquarius data, though limited in the period of coverage, are used for their higher spatial resolution to correct for discrepancies resulting from spatial interpolation of Argo data (Ebuchi and Abe 2014; Qu et al. 2014). Both SSS data are mapped on a $1^{\circ} \times 1^{\circ}$ grid on a monthly timescale.

Ancillary Datasets. The freshwater flux [Evaporation minus Precipitation (E$P)$ ] is calculated using the monthly evaporation dataset obtained from the objectively analysed air-sea fluxes project (OAFLUX) (Yu et al. 2008), and monthly precipitation datasets from the Climate Prediction Centre (CPC) Merged Analysis of Precipitation (CMAP). Monthly MLD is also derived from Argo product provided by French Research Institute for Exploration of the Sea (Ifremer: http://www.ifremer.fr), with the MLD defined as the depth where the density has $0.03 \mathrm{~kg} / \mathrm{m} 3$ difference from that of the surface (de Boyer Montégut et al. 2004).

Monthly SST dataset is used from NOAA Optimum Interpolation (OI) version 2 (Reynolds et al. 2002). The atmospheric circulation is obtained from the monthly wind of ERA-Interim reanalysis data produced by the European Centre for Medium-Range Weather Forecasts (ECMWF) at standard pressure levels (1000 hPa $-100 \mathrm{hPa}$ ). Monthly barrier layer thickness (BLT) is calculated from Argo products provided by Ifremer, by the equation $B L T=T T D_{D T m 02}-$ $M L D_{D R e q D T 02}$, where $T T D_{D T m 02}$ is the isothermal depth defined as the depth at which the surface temperature cools by $0.2{ }^{\circ} \mathrm{C}$ and $M L D_{D R e q D T 02}$ is the mixed layer depth (de Boyer Montégut et al. 2007; Mignot et al. 2007). 
All data used in this study are re-gridded into a $1^{\circ} \times 1^{\circ}$ grid resolution from 2005 to 2014, except for wind stress which is from 2008 to 2014. The anomalies are calculated by the differences between the monthly data and climatological mean, and the tendency of SSSAs and SSTAs are estimated by adopting the finite-difference method.

\subsection{Observed seasonal variability in sea surface salinity anomalies}

The SSS difference between the Arabian Sea and the Bay of Bengal, which is significant in climatological SSS distribution (Rao and Sivakumar 2003), was not found in monthly SSSAs. However, changes are apparent in several SSSAs maxima and minima centres shown by the Aquarius data (Figure 4.1a). For instance, in January, a positive SSSA centre appears in the eastern part (AEIo), a negative SSSA center in the central part ( $\left.B_{\mathrm{cio}}\right)$ and a positive SSSA center in the western part ( $\mathrm{C}_{\text {WIO }}$ ), depicted in Figure 4.1a, respectively. From boreal winter to spring, the BCIO continuously intensifies and expands its area, whereas both the $A_{E I O}$ and $C_{W I O}$ diminish and disappear. In April, negative SSSAs distribute over almost the whole Indian Ocean. A notable change can be seen in May, with positive SSSAs slightly to the south of the equator, which may represent the suddenly intensifying AEIO. This positive SSSA, emerging

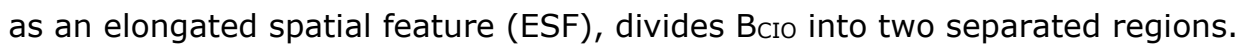
Later, the positive SSSA ESF dominates almost the whole equatorial Indian Ocean and connects up with the intensifying $\mathrm{C}_{w i o}$ in the northern Indian Ocean. Subsequently, the $\mathrm{B}_{\mathrm{cIo}}$ disappears during the boreal summer monsoon period with the positive SSSAs controlling the whole Indian Ocean, except for the equator and the western coast of the Arabian Sea. In the autumn, the positive SSSAs begin to dissipate gradually, and the boreal winter mode is restored in December. This annual cycle of SSSAs also emerges when employing longterm SSS data obtained from Argo data for the period 2005-2014 (Figure 4.1b). Sparse subsampling of Argo data can reproduce the main features of the annual cycle defined by the satellite SSS from Aquarius. 


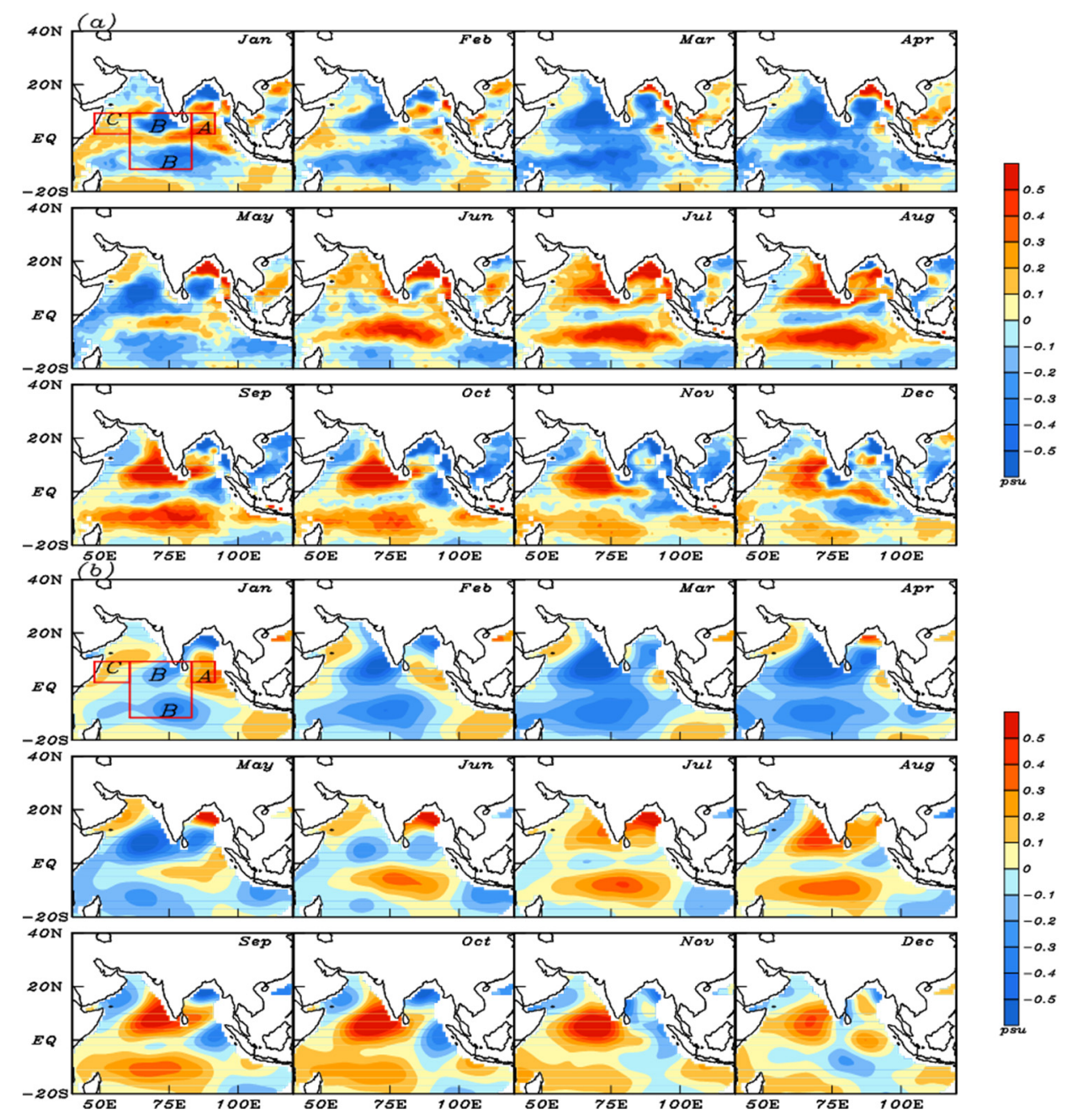

Figure 4. 1. Seasonal variability of sea surface salinity in the Indian Ocean. The annual cycle of sea surface salinity anomalies by (a) Aquarius dataset during 2012-2014 and (b) Argo dataset during 2005-2014. A, B and C (see January) denotes the eastern part $\left(A_{\in I O}\right)$, the central part $\left(B_{C I O}\right)$ and the western part $\left(C_{w I O}\right)$ of the Indian Ocean, respectively. 

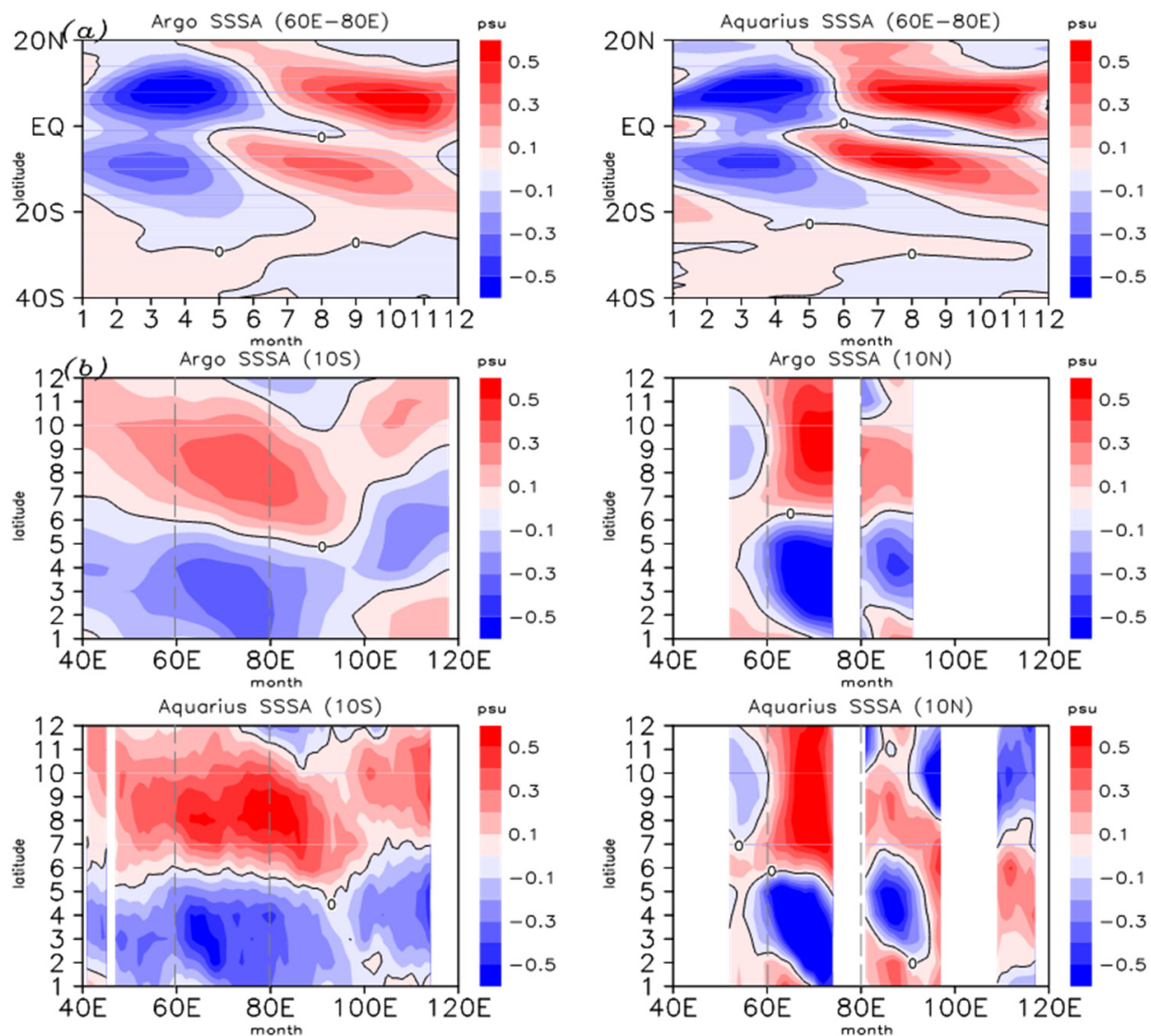

Figure 4. 2. Time-latitude diagrams (a) of SSSAs between $60^{\circ} \mathrm{E}$ and $80^{\circ} \mathrm{E}$ and hovmöller diagrams (b) of SSSAs along the area of $10^{\circ} \mathrm{S}$ and $10^{\circ} \mathrm{N}$ in Argo and Aquarius (Unit: psu, the dashed lines enclose the SSSAs ESF areas).

Figure $4.2 \mathrm{a}$ shows the latitude-time plots of SSSAs averaged over $60^{\circ} \mathrm{E}-80^{\circ} \mathrm{E}$, clearly depicting the positive SSSAs in May. The equator acts as a natural boundary, separating the changes in the SSSAs in the northern and southern Indian Ocean. There is an apparent time lag in these changes occurring across the southern to the northern Indian Ocean, which is consistent with the seasonal variability of the Indian Ocean induced by solar insolation. In this work, the SSSAs ESF area is defined as being the area of $\left(60^{\circ} \mathrm{E}-80^{\circ} \mathrm{E}, 10^{\circ} \mathrm{S}-\right.$ $\left.5^{\circ} \mathrm{S}\right)$ and its corresponding SSSAs in the northern hemisphere $\left(60^{\circ} \mathrm{E}-\right.$ $80^{\circ} \mathrm{E}, 5^{\circ} \mathrm{N}-10^{\circ} \mathrm{N}$ ) is also studied. Moreover, since the thermocline is shallower in the southwestern Indian Ocean and deeper in the eastern Indian Ocean and the easterlies are along the equator, the downwelling Rossby wave acts to suppress the continuous upwelling in the western Indian Ocean (Potemra 2001; Shinoda et al. 2004b). The symmetrical variability of SSSAs mode (Figure 4.2a) probably attributes to this downwelling Rossby wave (Donguy and Meyers 1996; Yuhong et al. 2013; Zhang and Du 2012b). However, there 
are no significant westward SSSAs motions along $10^{\circ} \mathrm{S}$ and $10^{\circ} \mathrm{N}$ in the hovmöller diagrams (Figure 4.2b). The maxima (minima) centers of SSSAs mainly locate in the SSSAs ESF areas. Consequently, the seasonal variability of SSSAs may be influenced by local atmospheric circulations and will be analysed in Section 4.6. But before doing so, we will examine next the relationship between SSSAs and SSTAs.

\subsection{The relationship between SSSAs and SSTAS before the onset of SASM}

The SSSA ESF area corresponds roughly with the Seychelles Dome (SD) which is a remarkable oceanic thermal dome along $\left(60^{\circ} \mathrm{E}-80^{\circ} \mathrm{E}, 5^{\circ} \mathrm{S}-10^{\circ} \mathrm{S}\right.$ ) (Izumo et al. 2008; Yokoi et al. 2008). Due to its unique location, which is under the control of both the monsoon wind and south-easterly trade wind, SD has a semi-annual cycle associated with upwelling in the boreal spring (Izumo et al. 2008; Yokoi et al. 2008). Above the SD, sea surface temperature anomalies (SSTAs) are sensitive to variability in the upwelling, and this is especially so in its seasonal variation (Yokoi et al. 2012).

The seasonal variability of SSSAs is different from that of SSTAs, presenting not only in the trend of changing [when SSSAs increase, corresponding SSTAs decrease (Figure 4.3)] but also in the time of changing. Specifically, in the southern Indian Ocean, the tendency of SSSAs increases in the middle of March and that of SSTAs decreases in early April. In the northern Indian Ocean, the tendency of SSSAs increases in early April and that of SSTAs decreases in early May. In other words, SSSAs have one and a half cycle/yr while SSTAs have one cycle/yr. Thus, SSSAs change faster than SSTAs. To give more convincing evidence of the quick change of SSSAs, we also calculated the seasonal variation in SSSAs and SSTAs for individual years with the Aquarius SSS dataset (Figure 4.4). Remarkably, the change of SSSAs tendency precedes that of SSTAs even in the individual years, except for 2013 (figure not shown), when the MJO (Madden Julian Oscillation) is very active during the onset of the SASM (Pai and Bhan 2014), resulting in heavy precipitation inhibiting SSSAs increase. 

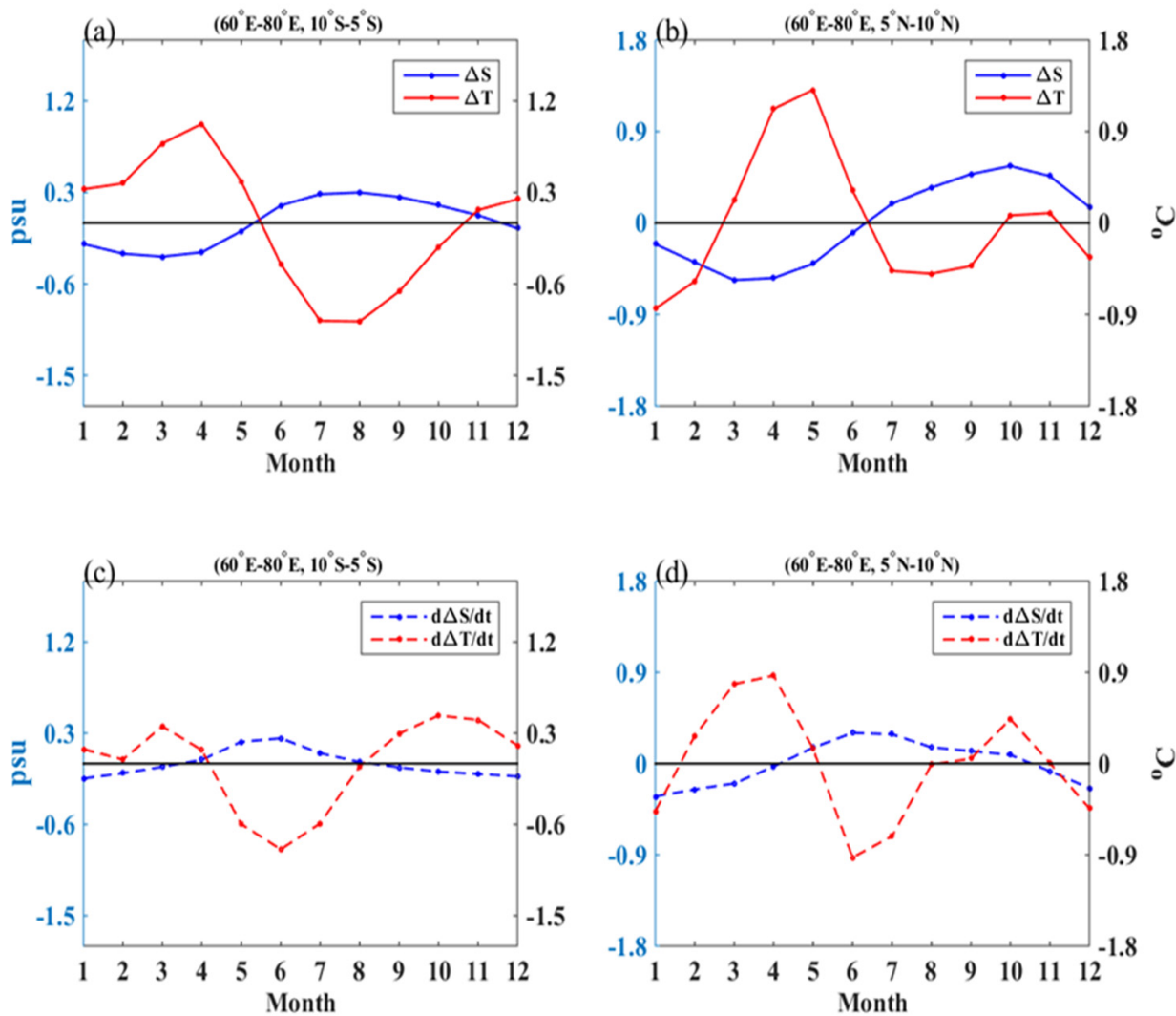

Figure 4. 3. Seasonal variability and tendency for both SSSAs (obtained from Argo, in blue) and SSTAs (obtained from NOAA; in red) in the areas $\left[(\mathrm{a}, \mathrm{c}) ; 60^{\circ} \mathrm{E}-80^{\circ} \mathrm{E}, 10^{\circ}\right.$ $\left.\mathrm{S}-5^{\circ} \mathrm{S}\right]$ and $\left[(\mathrm{b}, \mathrm{d}) ; 60^{\circ} \mathrm{E}-80^{\circ} \mathrm{E}, 5^{\circ} \mathrm{N}-10^{\circ} \mathrm{N}\right]$ for 2005 to 2014. Unit: psu; ${ }^{\circ} \mathrm{C}$.
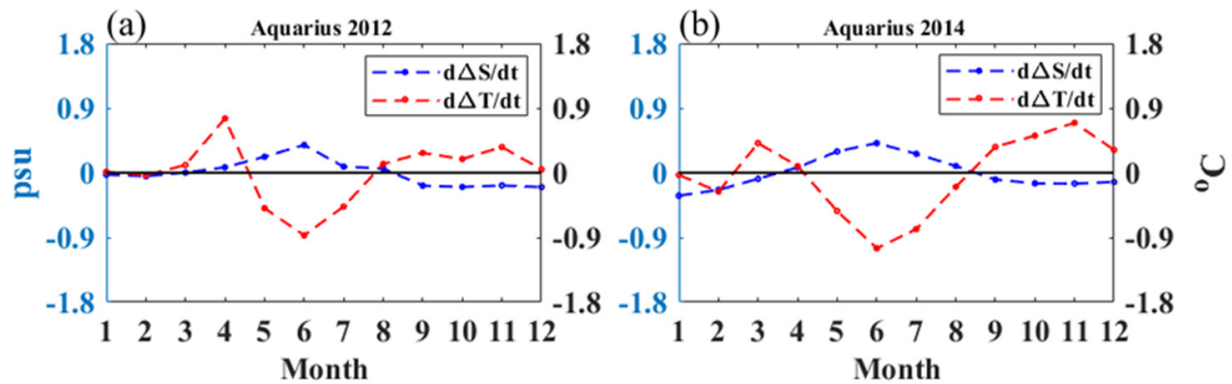

Figure 4. 4. Same as Figure 4.3 but for SSS data obtained from Aquarius. 

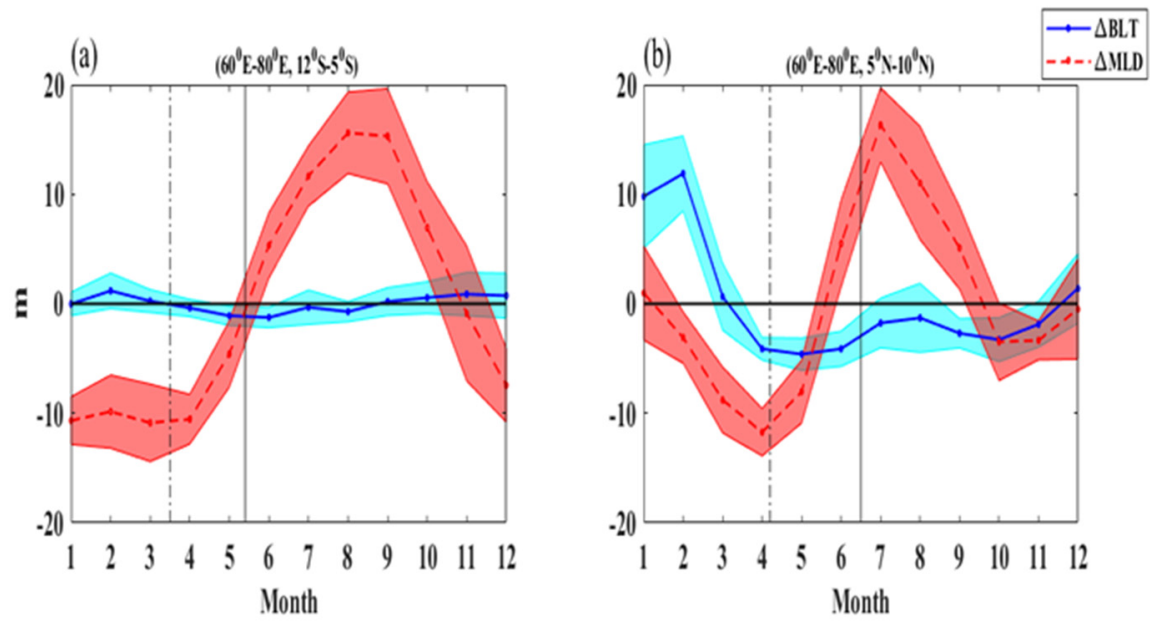

Figure 4. 5. Seasonal variability for both BLT (in blue) and MLD anomalies (in red) in the areas $\left[(\mathrm{a}) ; 60^{\circ} \mathrm{E}-80^{\circ} \mathrm{E}, 10^{\circ} \mathrm{S}-5^{\circ} \mathrm{S}\right]$ and $\left[(\mathrm{b}) ; 60^{\circ} \mathrm{E}-80^{\circ} \mathrm{E}, 5^{\circ} \mathrm{N}-10^{\circ} \mathrm{N}\right]$ for 2005 to 2014 (The shaded areas are the standard deviation, the solid black line represents the time that SSSAs change and dotted black line represents the time that the tendency of SSSAs change.). Unit: $\mathrm{m}$.

The earlier changed SSSAs may affect the oceanic stratification and, in turn, trigger a response in atmospheric circulation. To investigate this process, we show the seasonal variabilities of MLD and BLT anomalies in Figure 4.5. The top layer is the MLD which is defined as the depth that has a density change of $0.03 \mathrm{~kg} / \mathrm{m} 3$ from the surface. In the SD area, the MLD anomalies change in the middle of May and are associated with the change of SSSAs and SSTAs (Figure 4.3a). BLT is the difference between an isothermal layer and the isopycnal MLD, insulating the surface from the deeper layers. Thereby, BLT has influences on the SST by controlling the vertical mixing (Maes et al. 2005; Masson et al. 2005). In the SD area (Figure 4.5a), the change of BLT anomalies is more sensitive to the tendency of SSSAs rather than the seasonal variability of SSSAs (Figure 4.3c). When the tendency of SSSAs increase to positive in early March, the BLD anomalies begin to decrease below zero and vice versa. According to the calculation of BLT (in Section 4.3) and given the slightly decreasing MLD anomalies (Figure 4.5a), in the southern Indian Ocean, decreasing BLT anomalies attribute to upwelling. Then, upwelling eats away at the BLT leading to more cold and salty water entrained into the mixed layer. When MLD anomalies increase in April, SSTAs begin to be affected by this upwelling process (the tendency of the SSTAs decrease below zero, as shown in Figure 4.3c). In the northern Indian Ocean, things respond a little differently (Figure 4.5b). Although BLT and MLD also change in March, the tendency of SSSAs changes in April. We assume that this is because of the strong salty surface water in the Arabian Sea, so it needs more time for the upwelling to affect the SSSAs. With the increasing SSSAs, the significantly decreasing BLT brings more subsurface water into the mixed layer, which, in turn, promotes 
the decrease of SSTAs. As such, SSSAs has the potential ability to affect SSTAs through shoaling the BLT.

\subsection{The external forcing for the SSSAs change}

We analysed next the atmospheric circulation anomalies before and after the SSSAs change to better understand the variability of SSSAs. On the one hand, freshwater flux is stressed to play a crucial role in the seasonal variability of SSS in the Indian Ocean (Vinayachandran and Nanjundiah 2009; Zhang and Du 2012a). Figure 4.6 shows the distributions of freshwater flux anomalies in February and April, respectively. Before the SSSAs change (February), there is more precipitation over the SSSA ESF area, while less freshwater goes into the SSSA ESF area after the SSSAs change (April); instead, strong evaporation anomalies make this area much saltier. On the other hand, the upwelling effect on the variability of SSSAs can be found in the entrainment circulations before and after the increasing SSSAs (Figure 4.7). The wintertime north-westerly wind anomalies intensify in the southern Indian Ocean before SSSAs change and weaken after SSSAs (Figure 4.7a). In the Southern Hemisphere, negative curl corresponds to cyclonic curl and relative upwelling. Thereby, before the SSSAs change, the positive wind stress curl anomalies over the SSSAs ESF area, represent Ekman downwelling. After the SSSAs change, the negative wind stress curl anomalies induce Ekman upwelling in the SSSAs ESF area (Figure 4.7b). Furtherly, due to the negative wind stress curl anomalies in the north of $10^{\circ} \mathrm{S}$ and the positive ones in the south of $10^{\circ} \mathrm{S}$ before the increasing SSSAs (Figure 4.7b), corresponding to anticyclone in the north and cyclone in the south, the easterlies is strengthened (Figure 4.7c), which in turn, provides a favourable environment for upwelling in the eastern Indian Ocean. The mode of wind stress curl change after the SSSAs increasing, with positive anomalies in the north and negative in the south, leading to anomaly westerlies (Figure 4.7c). In March, the SSSAs increase just as the atmospheric circulation pattern begins to change into the SASM pattern and the thermocline in the SD starts to shoal as a result of weakened downwelling (Yokoi et al. 2012).

Therefore, freshwater flux and entrainment circulation anomalies contribute to the increasing SSSAs in the southwestern Indian Ocean. 


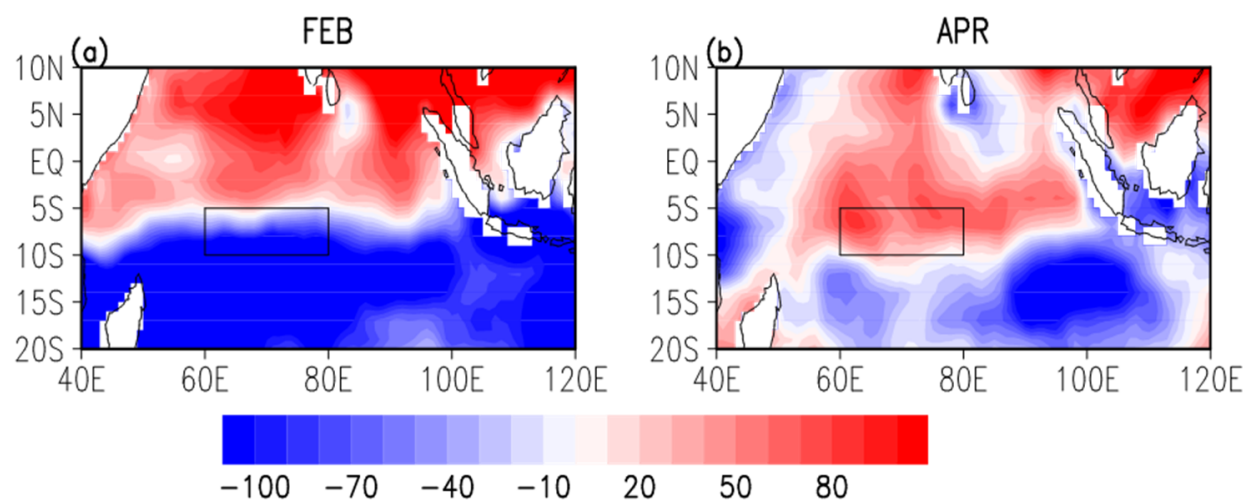

Figure 4. 6. Freshwater flux anomalies. (a) Monthly mean freshwater flux in February (a) and April (b) from 2005 to 2014. (Unit: $\mathrm{cm} / \mathrm{yr}$ ). The box (in black line) denotes the SSSAs ESF area $\left(60^{\circ} \mathrm{E}-80^{\circ} \mathrm{E}, 10^{\circ} \mathrm{S}-5^{\circ} \mathrm{S}\right)$.

In summary (Figure 4.8 ), in the SD $\left(5^{\circ} \mathrm{S}-10^{\circ} \mathrm{S}\right)$ from January to the early April, SSTAs stay in an increasing state (orange rectangle), while SSSAs start to increase in the middle of March (red filled rectangle), which is due to the less freshwater and Ekman upwelling caused by the wind stress. Thus increasing SSSAs, accompanied by the decreasing BLT anomalies, help to create a favourable environment for the SSTAs to decrease in the coming month via strengthening the upwelling. In other words, SSSAs, as one component in the ocean, are more sensitive in responding to the atmospheric influence than SSTAs. This phenomenon can also be found in the symmetrical area of the Northern Hemisphere $\left(5^{\circ} \mathrm{N}-10^{\circ} \mathrm{N}\right)$. One should mention here that there exist time-lags between the southern and northern Hemisphere, which leads to significant SST gradient in May (black rectangle). Thus, this heat contrast promotes the ITCZ to move northward and contributes to the change of vertical circulation. 

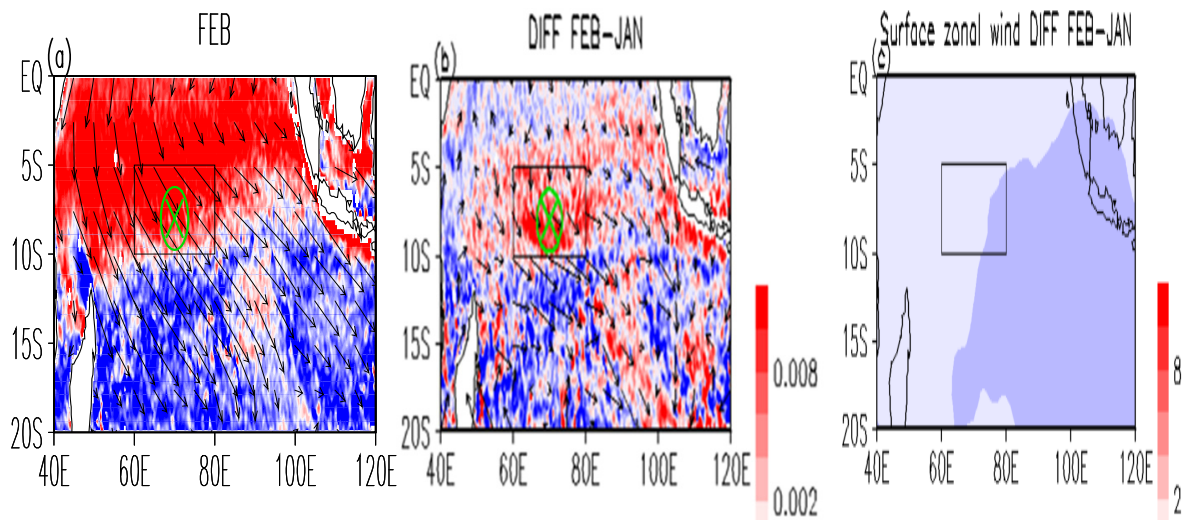

APR

DIFF APR-FEB
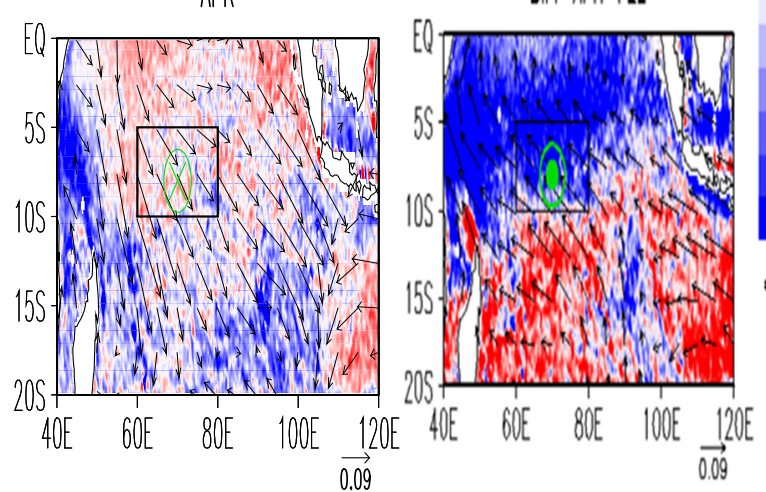

Sulfoce and wind DifF APR FFeB

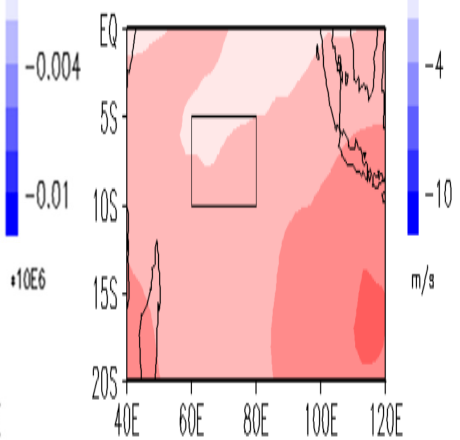

Figure 4. 7. Wind stress and wind stress curl anomalies. (a) Monthly mean wind stress (vector) and wind stress curl anomalies (shaded) in February and April from 2008 to 2014. (b) Differences in wind stress and wind stress curl anomalies as February minus January and April minus February, respectively. (Unit: $\mathrm{N} / \mathrm{m}^{2} ; \mathrm{N} / \mathrm{m}^{3}$ ). (c) Differences in the surface zonal wind $(10 \mathrm{~m})$ obtained from ERA-interim difference as February minus January and for April minus February, respectively (Unit: $\mathrm{m} / \mathrm{s}$ ). [The boxes in black line are the SSSAs ESF area in the southern Indian Ocean $\left(60^{\circ} \mathrm{E}-80^{\circ} \mathrm{E}, 5^{\circ} \mathrm{S}-10^{\circ} \mathrm{S}\right)$; the green plus mark represents downwelling, and the green closed circle represents upwelling ]. 


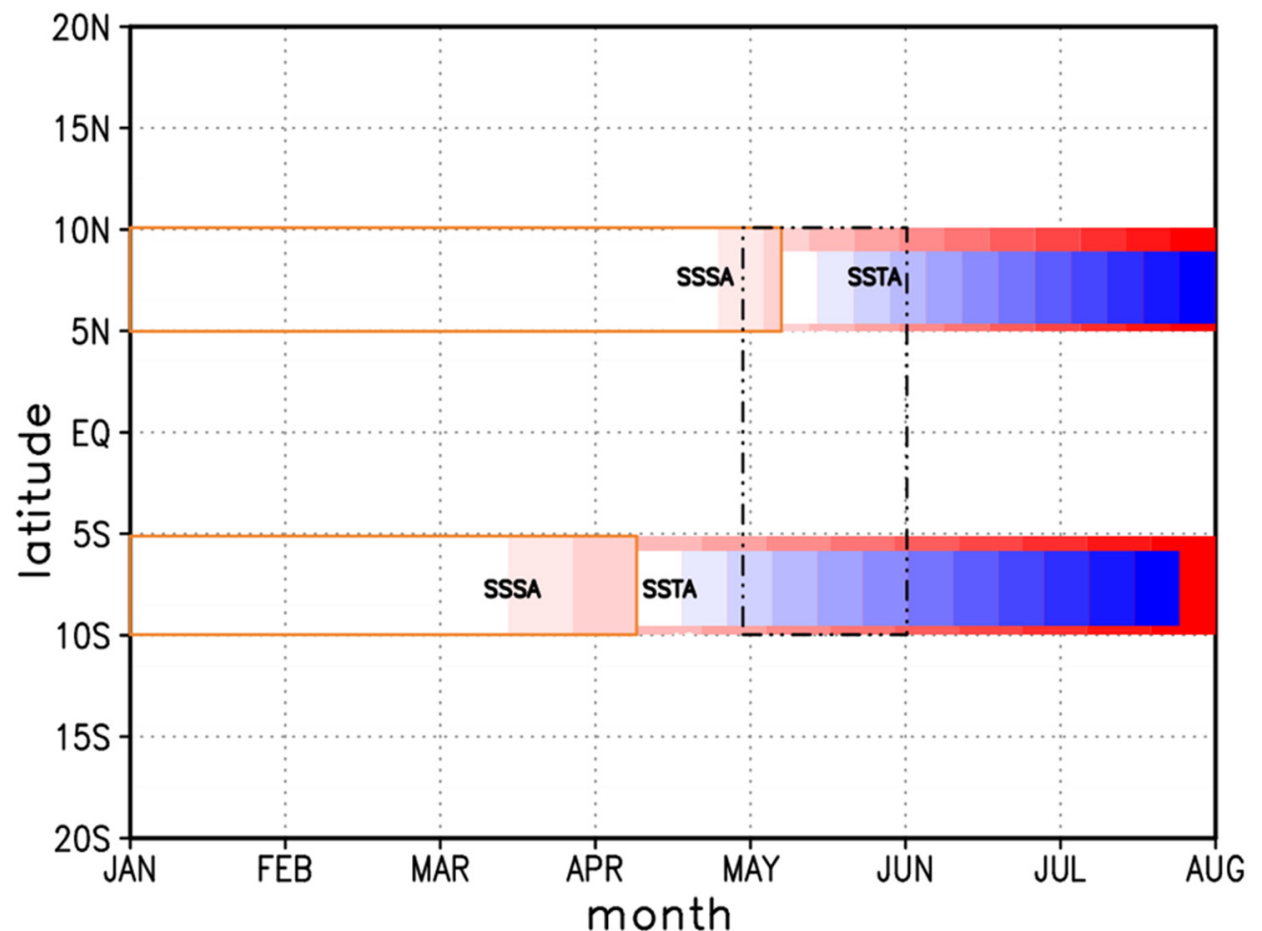

Figure 4. 8. Diagram of the potential mechanism between SSSA and the onset of SASM along $60^{\circ} \mathrm{E}-80^{\circ} \mathrm{E}$ (Gradually increasing red rectangles represent the increasing SSSA, and the blue ones represent the decreasing SSTA; In addition, the orange hollow rectangles represent the increasing SSTA, and the black dot-dashed rectangle indicates the period with large SSTA gradient).

\subsection{Conclusions}

In this study, we analyzed the annual variability in sea surface salinity anomalies (SSSAs) by employing Aquarius satellite datasets from 2012 to 2014 and Argo datasets from 2005 to 2014, as well as the corresponding freshwater fluxes, sea surface temperature anomalies (SSTAs) and also ocean dynamics and atmospheric circulations.

We found that a positive SSSAs as an elongated spatial feature (ESF) along the equator in May with its area roughly coinciding with the Seychelles Dome (SD). The seasonal variability of SSSAs in the SD change from negative to positive and, in contrast, SSTAs change from positive to negative. Although their changes happen in spring, SSSAs change earlier than that of SSTAs, associated with the thinner barrier layer thickness (BLT) anomalies in the corresponding area, which in turn, help to provide favorable circumstances for the decreasing SSTAS. The change of SSSAs is closely related to the atmospheric circulation anomalies, mainly attributing to the freshwater flux anomalies and entrainment anomalies. Moreover, there exists a time delay of 
SSSAs change between the northern and the southern Indian Ocean, resulting in cross-equatorial current by forming the meridional SSTAs gradient. Therefore, SSSAs contribute to the onset of SASM by affecting the SSTAs. 
Chapter 5

Synthesis and Future Work 


\subsection{Contributor to the variability of the TIO}

Since the 1950s, SST in the TIO has increased faster than other oceans, especially in the western TIO, where SST has increased by $1.2{ }^{\circ} \mathrm{C}$. This prominent warming in the TIO could contribute to the increasing trend of global SST (Roxy et al. 2014). Du and Xie (2008) have attributed this warming in the TIO to heat flux. However, Behera et al. (2000) indicated that heat flux could not be used to entirely explain the warming trend of SST in some parts of the TIO.

A dilemma also exists in explaining the main driver for the interannual variability of the TIO. In previous studies (Alexander et al. 2002; Lau and Nath 2003), it has been pointed out the interannual basin-warming in the TIO is due to heat flux induced by EI Niño, which in turn, leads to abnormal rainfall over the near continents ( $\mathrm{Li}$ et al. 2008). However, Yokoi et al. (2012) showed that the interannual variability of SST in the SCTR is induced by wind stress and the Rossby wave. Distinguishing the main contributor to the variability of the TIO is crucial to understand the air-sea interaction in the TIO and improve the prediction of the rainfall over the surrounding areas.

Based on the previous results (Behera et al. 2000; Schott et al. 2009), we mainly focus on two drivers in this study, namely heat flux and wind stress. To distinguish their contributions to the interannual variability of the TIO with respect to its spatial feature and a vertical structure, the simulations from OGCM are employed. The OGCM hindcast could simulate the mean conditions and interannual variability in the upper-ocean temperature structure with good accuracy. Two sensitivity experiments are further designed called HF (only heat flux varying interannually) and WS (only wind stress varying interannually). The results show that heat flux mainly drives the interannual variability of ocean temperature above $30 \mathrm{~m}$ in the TIO, while wind stress contributes to the interannual variability of ocean temperature below $30 \mathrm{~m}$. In other words, the impacts of heat flux and wind stress on the interannual variability of upperocean temperatures are depth-dependent.

Consequently, there is a transition point at a certain depth, which is defined as the "crossing depth" in this study. The crossing depth indicates the specific depth where the dominant driver for the interannual variability of ocean temperature is switching from heat flux to wind stress. Results of this study show that shallower crossing depth could be observed in the southwestern TIO, especially in the SCTR (above the depth of $30 \mathrm{~m}$, Figure 5. 1a) while the larger crossing depth can be found in the eastern TIO (below the depth of $30 \mathrm{~m}$, Figure 5. 2b). 
In conclusion, the relative impacts of heat flux and wind stress on interannual variability of upper-ocean temperature in the TIO has a depth-dependent feature.
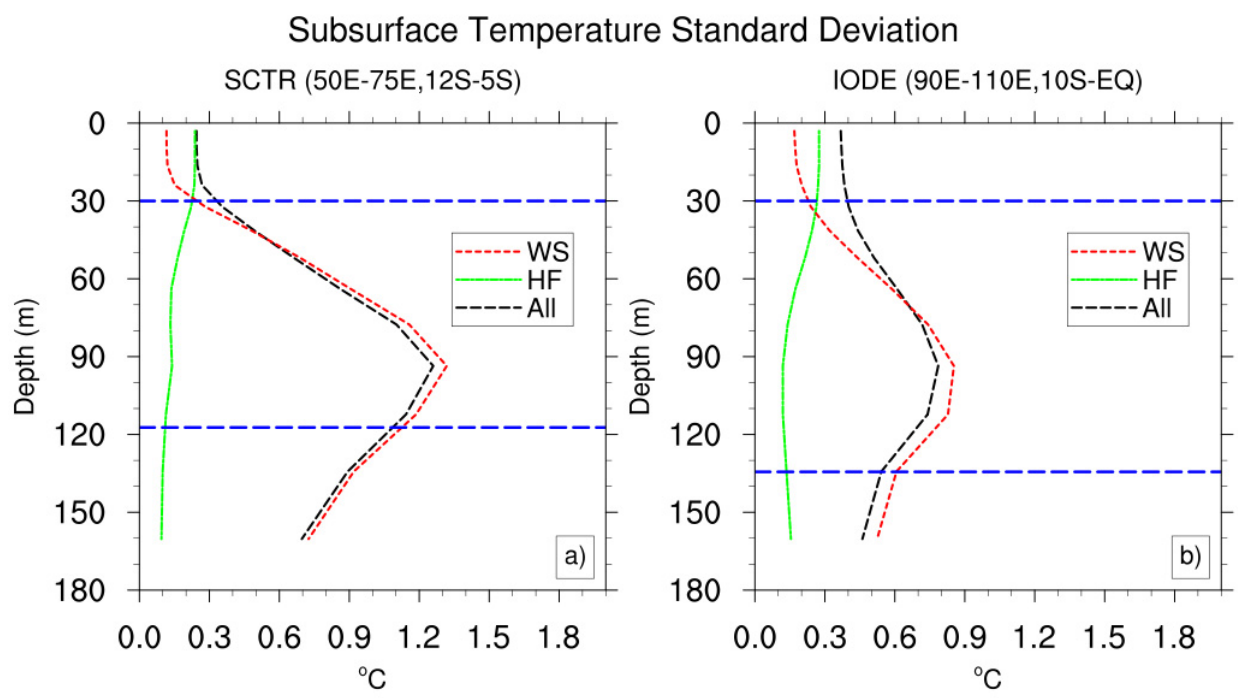

Figure 5. 1. The vertical profiles of the standard deviation of interannual ocean temperatures averaged by the area of SCTR (a) and IODE (b), respectively. Red, green and black lines represent the WS, HF and ALL, separately. The upper blue dashed line represents the depth of $30 \mathrm{~m}$ and the lower one represents thermocline.

\subsection{The variability of the barrier layer in the TIO}

A layer existing between MLD and thermocline, called BLT, is defined as the depth from the bottom of the mixed layer to the top of the thermocline (Lukas and Lindstrom 1991). Although BLT is thinner compared to other ocean layers, it plays an essential role in the ocean dynamic and even affects the atmospheric circulation. For instance, the zonal displacement in the tropical Pacific Ocean is related to the variability of BLT (Picaut et al. 1996), and the correlation coefficient between BLT and the South Oscillation Index passes the significance test (Qu et al. 2014). Further, BLT helps to maintain the heat of the upperocean by prohibiting the upwelling cooling water induced by Ekman pumping, which in turn, promotes the formation of El Niño (Maes et al. 2006).

In the TIO, the distribution of BLT is similar to that of SSS, but in opposite sign: saltier (fresher) water corresponds to thinner (thicker) BLT in the western (eastern) TIO. However, their seasonal variability is not consistent, and the seasonal variability of BLT in the TIO is characterized as having a seasonal and semi-seasonal cycle (Masson et al. 2002; Qu and Meyers 2005). On account of the variability of BLT closely related to a series of complicated oceanic and atmospheric activities, including precipitation, horizontal advection, wind stress and vertical shears (Bosc et al. 2009; Vialard and Delecluse 1998), in 
this study, we mainly adopt the in-phase and lead-lag correlation analysis to understand the seasonal and interannual variability of BLT in the TIO.

In terms of the seasonal variability, a positive correlation between BLT and thermocline anomalies could be detected in the central-eastern TIO during autumn. The shallower thermocline induced by wind stress is, the thinner BLT is, and vice versa. During winter and spring, the positive thermocline-BLT relationship shifts westward to the SCTR. Meanwhile, there also exists a negative SSS-BLT relationship in the SCTR. Both thermocline and SSS have a leading correlation with BLT, which means that the change of thermocline or SSS in the previous month may result in the BLT change in the following month.

At the interannual time scale, a phase-locking mode dominates the variability of the SCTR, mostly attributing to ENSO through adjusting Walker circulation and triggering the Rossby wave. During the mature phase of El Niño (boreal winter), deeper thermocline induced by downwelling Rossby wave and anomalous wind stress curl leads to a thicker BLT in the SCTR. Although the effect of El Niño on the anomalous thermocline weakens in the decaying phase, its influence on the BLT is intensified because of SSS anomalies: abundant precipitation resulted from the anomalous ascending branch of Walker circulation, and warmer ocean surface contributes to more fresher water into the SCTR during the following spring, which in turn, helps to thicken BLT. This thicker BLT sustains the warmer surface by hampering the upwelling cool water, which is consistent with previous studies (Foltz and McPhaden 2009; Maes et al. 2005).

\subsection{The seasonal variability of SSS in the southwestern TIO}

Salinity, as an important parameter in the physical oceanography, not only affects the oceanic dynamic but also has an impact on the atmospheric circulation. In the previous studies (Delcroix and Henin 1991; Dong et al. 2009; Rao and Sivakumar 2003), the tendency of mixed layer salinity equation has been widely used to study the intra-seasonal, seasonal and interannual variabilities of SSS in different ocean areas. In this study, we focus on investigating the seasonal variability of SSS in the TIO.

Recently, with the development of observation technology, more SSS datasets are obtained and could be applied to better investigate the global water cycle and oceanic dynamics. Particularly, the satellite offers a more credible and accurate dataset to improve the understanding of SSS, such as SMOS, SMAP and Aquarius. Due to the bias of SMOS in the northern TIO and short time 
series of SMAP, we mainly use the Aquarius SSS data and verify the results by employing Argo SSS float data.

Through analyzing the monthly distribution of SSSAs in the TIO, an elongated spatial feature (ESF) of the positive SSSAs was observed along the equator before the onset of SASM, especially in the western TIO. The maxima of the positive SSSAs is divided into two parts, being asymmetric in the northern and southern TIO. Through analyzing their seasonal time series and corresponding SSTAs, it is found that the change of SSSAs in the western TIO, due to freshwater and wind-stress-induced Ekman pumping, is earlier than that of SSTAs. Thus, SSSAs are more sensitive and responsive to the change of atmospheric circulation than SSTAs. For instance, during boreal spring, less freshwater and Ekman upwelling results in the positive SSSAs in March within the southwestern TIO. This positive SSSAs associated with the thinning BLT, help to provide a favorable environment for the decreasing SSTAs in April in the corresponding area. The change of SSSAs in the northwestern TIO happens one month later. Then, the SST gradient resulted from the time-lag between the northern and southern TIO enlarges due to these SSSAs induced SSTAs, which in turn, promotes the northward ITCZ and crossing-equatorial current.

\subsection{Outlook}

In this work, we investigated the variability of the structure in the TIO from datasets obtained from field observation and numerical simulation, which reveals the relative contributions of heat flux and wind stress to the variability of the TIO. Also, this study highlights the seasonal and interannual variabilities of BLT in the TIO and the role of the seasonal SSS variability in the onset of the SASM.

Our results are consistent with previous studies and provide more evidence to better explain the special variabilities of the SCTR. For instance, the interannual variability of the SCTR is mainly driven by wind stress associated with the shallowest crossing depth. The seasonal and interannual variabilities of BLT in the SCTR have close relationships with the change of the subsurface and the surface, especially during the El Niño years. The seasonal variability of SSS in the SCTR helps to provide favorable circumstances for enlarging the SST gradient by changing the oceanic stratification, which in turn, promotes the onset of the SASM.

However, there remains a series of complicated dynamical processes to be explored at different time scales. Particularly, the relationship between SSS in the TIO and the monsoon precipitation at the interannual time scale is still unclear. Thereby, whether SSS could become an advanced predictor for the monsoon precipitation still need to be unraveled. 
In this thesis, we have attempted to discover the interannual variability of SSS associated with the SASM by using the SODA ocean reanalysis data from 1900 to 2010. The result shows that the spring-time SSSAs indeed display a unique feature in the SCTR during the extreme monsoon years. Particular, after correlating the first principle mode time series of the SASM rainfall to the SSSAs in the TIO in different seasons, their significant correlation coefficients could be observed in the SCTR during spring, but the remarkable areas are too small to be convinced. In order to avoid the shortage of the correlation analysis, such as the asymmetry of the phenomenon, we, then, used the composition analysis to study the dominant patterns of SSSAs in the extreme drought and flooding monsoon years based on the all Indian rainfall index during the SASM period (JJAS). This index is obtained from the Indian Institute of tropical meteorology. As expected, relatively prominent SSSAs signals merely correlate to the SASM flooding years and are in pre-winter and prespring, while the patterns of SSSAs are still hard to be defined. Subsequently, we attempted to use other monsoon indices to do the same composition for SSSAs in the TIO, such as the Webster-Yang index (Webster and Yang 1992), the South Asian monsoon index (Goswami et al. 1999), and so on. Unfortunately, the predictable areas of SSSAs in the TIO fail to be ascertained. This may be due to lacking of reliable observation data.

Additionally, due to the particularity of the SCTR and the compositing SSSAs signals, the SCTR could be a crucial area for predicting the SASM rainfall, especially by adopting SSSAs. Thus, we used the winter-time Seychelles Dome index (Tozuka et al. 2012) to do the composition analysis again. To remove the impact from ENSO, we have selected the extreme Seychelles Dome years, which are independent of ENSO before compositing the SSSAs in the TIO. A clear SSSAs dipole could be observed in the deeper Seychelles Dome thermocline years during spring. However, there is no significant correlation of SSSAs with the SASM rainfall and corresponding atmospheric circulation anomalies in response to the extreme Seychelles Dome years.

Furthermore, we also tried to find the different SSSAs patterns in the TIO between ENSO and IOD years. Two methods have been employed in this study. The first one is composite analysis in the independent IOD and ENSO events years separately. The other one is to calculate the congruent regression (Ummenhofer et al. 2009a) based on the Nino3.4 and IOD index, respectively. Analysis results show that SSSAs in the TIO displays unique modes during El Niño years, unlike the basin-wide warming in the TIO due to El Niño. In addition to this, SSSAs show some different patterns in the two events, but they do not exceed the significance test. Meanwhile, lacking the important rainfall data over the ocean for this long-term period is not easy for defining the SSS characteristic. 
Therefore, controlled experiments with creditably coupled high-resolution ocean-atmosphere general circulation models should be designed to study the relationship between SSS in the TIO and the SASM in the future work. 


\section{Bibliography}

Agarwal, N., R. Sharma, A. Parekh, S. Basu, A. Sarkar, and V. K. Agarwal, 2012: Argo observations of barrier layer in the tropical Indian Ocean. Advances in Space Research, 50, 642-654.

Alexander, M. A., I. Bladé, M. Newman, J. R. Lanzante, N.-C. Lau, and J. D. Scott, 2002: The atmospheric bridge: The influence of ENSO teleconnections on air-sea interaction over the global oceans. Journal of Climate, 15, 2205-2231.

Alory, G., S. Wijffels, and G. Meyers, 2007: Observed temperature trends in the Indian Ocean over 1960-1999 and associated mechanisms. Geophysical Research Letters, 34. L02606.

Anderson, S. P., R. A. Weller, and R. B. Lukas, 1996: Surface buoyancy forcing and the mixed layer of the western Pacific warm pool: Observations and 1D model results. Journal of Climate, 9, 3056-3085.

Annamalai, H., P. Liu, and S.-P. Xie, 2005: Southwest Indian Ocean SST variability: Its local effect and remote influence on Asian monsoons. Journal of Climate, 18, 4150-4167.

Armi, L., 1978: Some evidence for boundary mixing in the deep ocean. Journal of Geophysical Research: Oceans, 83, 1971-1979.

Ashok, K., Z. Guan, N. Saji, and T. Yamagata, 2004: Individual and combined influences of ENSO and the Indian Ocean dipole on the Indian summer monsoon. Journal of Climate, 17, 3141-3155.

Behera, S., P. Salvekar, and T. Yamagata, 2000: Simulation of interannual SST variability in the tropical Indian Ocean. Journal of Climate, 13, 34873499.

Behera, S. K., and T. Yamagata, 2001: Subtropical SST dipole events in the southern Indian Ocean. Geophysical Research Letters, 28, 327-330.

Bernard, B., and Coauthors, 2006: Impact of partial steps and momentum advection schemes in a global ocean circulation model at eddypermitting resolution. Ocean Dynamics, 56, 543-567.

Bhaskar, T. V., and C. Jayaram, 2015: Evaluation of Aquarius Sea Surface Salinity With Argo Sea Surface Salinity in the Tropical Indian Ocean. IEEE Geoscience and Remote Sensing Letters, 12, 1292-1296.

Blanke, B., and P. Delecluse, 1993: Variability of the tropical Atlantic Ocean simulated by a general circulation model with two different mixed-layer physics. Journal of Physical Oceanography, 23, 1363-1388.

Bosc, C., T. Delcroix, and C. Maes, 2009: Barrier layer variability in the western Pacific warm pool from 2000 to 2007. Journal of Geophysical Research: Oceans, 114. C06023.

Boutin, J., N. Martin, G. Reverdin, X. Yin, and F. Gaillard, 2013: Sea surface freshening inferred from SMOS and ARGO salinity: impact of rain. Ocean Science, 9, 183-192. 
Burns, J. M., and B. Subrahmanyam, 2016: Variability of the SeychellesChagos Thermocline Ridge Dynamics in Connection With ENSO and Indian Ocean Dipole. IEEE Geoscience and Remote Sensing Letters, 13, 2019-2023.

Carton, J. A., and B. S. Giese, 2008: A reanalysis of ocean climate using Simple Ocean Data Assimilation (SODA). Monthly Weather Review, 136, 29993017.

Carton, J. A., G. A. Chepurin, and L. Chen, 2018: SODA3: a new ocean climate reanalysis. Journal of Climate. 31, 6967-6983.

Chen, G., W. Han, Y. Li, and D. Wang, 2016: Interannual variability of equatorial eastern Indian Ocean upwelling: Local versus remote forcing. Journal of Physical Oceanography, 46, 789-807.

Cherchi, A., and A. Navarra, 2013: Influence of ENSO and of the Indian Ocean Dipole on the Indian summer monsoon variability. Climate Dynamics, 41, 81-103.

Clark, C. O., J. E. Cole, and P. J. Webster, 2000: Indian Ocean SST and Indian summer rainfall: Predictive relationships and their decadal variability. Journal of Climate, 13, 2503-2519.

Crétat, J., P. Terray, S. Masson, K. Sooraj, and M. K. Roxy, 2017: Indian Ocean and Indian summer monsoon: relationships without ENSO in oceanatmosphere coupled simulations. Climate Dynamics, 49(4), 1429-1448

Da - Allada, C., G. Alory, Y. Du Penhoat, E. Kestenare, F. Durand, and N. Hounkonnou, 2013: Seasonal mixed - layer salinity balance in the tropical Atlantic Ocean: Mean state and seasonal cycle. Journal of Geophysical Research: Oceans, 118, 332-345.

de Boyer Montégut, C., J. Mignot, A. Lazar, and S. Cravatte, 2007: Control of salinity on the mixed layer depth in the world ocean: 1. General description. Journal of Geophysical Research: Oceans, 112. C06011.

de Boyer Montégut, C., G. Madec, A. S. Fischer, A. Lazar, and D. Iudicone, 2004: Mixed layer depth over the global ocean: An examination of profile data and a profile - based climatology. Journal of Geophysical Research: Oceans, 109. C12003.

Delcroix, T., and C. Henin, 1991: Seasonal and interannual variations of sea surface salinity in the tropical Pacific Ocean. Journal of Geophysical Research: Oceans, 96, 22135-22150.

Delman, A. S., J. Sprintall, J. L. McClean, and L. D. Talley, 2016: Anomalous Java cooling at the initiation of positive Indian Ocean Dipole events. Journal of Geophysical Research: Oceans, 121, 5805-5824.

Deshpande, R., and Coauthors, 2013: Spatio-temporal distributions of $\delta 18 \mathrm{O}$, $\delta D$ and salinity in the Arabian Sea: Identifying processes and controls. Marine Chemistry, 157, 144-161. 
Doi, T., A. Storto, S. K. Behera, A. Navarra, and T. Yamagata, 2017: Improved prediction of the Indian Ocean Dipole Mode by use of subsurface ocean observations. Journal of Climate, 30, 7953-7970.

Dong, S., S. L. Garzoli, and M. Baringer, 2009: An assessment of the seasonal mixed layer salinity budget in the Southern Ocean. Journal of Geophysical Research: Oceans, 114. C12001.

Donguy, J.-R., and G. Meyers, 1996: Seasonal variations of sea-surface salinity and temperature in the tropical Indian Ocean. Deep Sea Research Part I: Oceanographic Research Papers, 43, 117-138.

Drushka, K., J. Sprintall, S. T. Gille, and S. Wijffels, 2012: In situ observations of Madden-Julian oscillation mixed layer dynamics in the Indian and western Pacific Oceans. Journal of Climate, 25, 2306-2328.

Du, Y., and S. P. Xie, 2008: Role of atmospheric adjustments in the tropical Indian Ocean warming during the 20th century in climate models. Geophysical Research Letters, 35. L08712.

Du, Y., and Y. Zhang, 2015: Satellite and Argo observed surface salinity variations in the tropical Indian Ocean and their association with the Indian Ocean Dipole mode. Journal of Climate, 28, 695-713.

Du, Y., W. Cai, and Y. Wu, 2013: A new type of the Indian Ocean Dipole since the mid-1970s. Journal of Climate, 26, 959-972.

Du, Y., S.-P. Xie, G. Huang, and K. Hu, 2009: Role of air-sea interaction in the long persistence of El Niño-induced north Indian Ocean warming. Journal of Climate, 22, 2023-2038.

Durack, P. J., S. E. Wijffels, and R. J. Matear, 2012: Ocean salinities reveal strong global water cycle intensification during 1950 to 2000 . Science, 336, 455-458.

Durand, F., G. Alory, R. Dussin, and N. Reul, 2013: SMOS reveals the signature of Indian Ocean Dipole events. Ocean Dynamics, 63, 1203-1212.

Ebuchi, N., and H. Abe, 2014: Evaluation of sea surface salinity observed by Aquarius. Geoscience and Remote Sensing Symposium (IGARSS), 2014 IEEE International, IEEE, 4427-4430.

Felton, C. S., B. Subrahmanyam, V. Murty, and J. F. Shriver, 2014: Estimation of the barrier layer thickness in the Indian Ocean using Aquarius Salinity. Journal of Geophysical Research: Oceans, 119, 4200-4213.

Feng, J., D. Hu, and L. Yu, 2014: How does the Indian Ocean subtropical dipole trigger the tropical Indian Ocean dipole via the Mascarene high? Acta Oceanologica Sinica, 33, 64-76.

Foltz, G. R., and M. J. McPhaden, 2009: Impact of barrier layer thickness on SST in the central tropical North Atlantic. Journal of Climate, 22, 285299.

Foltz, G. R., S. A. Grodsky, J. A. Carton, and M. J. McPhaden, 2003: Seasonal mixed layer heat budget of the tropical Atlantic Ocean. Journal of Geophysical Research: Oceans, 108. 3146. 
Garrett, C., and W. Munk, 1972: Oceanic mixing by breaking internal waves. Deep Sea Research and Oceanographic Abstracts, Vol. 19, No. 12, pp. 823-832, Elsevier.

Goswami, B., V. Krishnamurthy, and H. Annmalai, 1999: A broad - scale circulation index for the interannual variability of the Indian summer monsoon. Quarterly Journal of the Royal Meteorological Society, 125, 611-633.

Griffies, S. M., and Coauthors, 2009: Coordinated ocean-ice reference experiments (COREs). Ocean Modelling, 26, 1-46.

Grunseich, G., B. Subrahmanyam, and A. Arguez, 2011a: Influence of the Madden - Julian Oscillation on sea surface salinity in the Indian Ocean. Geophysical Research Letters, 38. L17605.

Grunseich, G., B. Subrahmanyam, and B. Wang, 2013: The Madden-Julian oscillation detected in Aquarius salinity observations. Geophysical Research Letters, 40, 5461-5466.

Grunseich, G., B. Subrahmanyam, V. S. N. Murty, and B. S. Giese, 2011b: Sea surface salinity variability during the Indian Ocean Dipole and ENSO events in the tropical Indian Ocean. Journal of Geophysical Research, 116. C11013.

Guan, B., T. Lee, D. J. Halkides, and D. E. Waliser, 2014: Aquarius surface salinity and the Madden-Julian Oscillation: The role of salinity in surface layer density and potential energy. Geophysical Research Letters, 41, 2858-2869.

Guo, F., Q. Liu, X.-T. Zheng, and S. Sun, 2013: The role of barrier layer in southeastern Arabian Sea during the development of positive Indian Ocean Dipole events. Journal of Ocean University of China, 12, 245-252.

Han, W., and J. P. McCreary, 2001: Modeling salinity distributions in the Indian Ocean. Journal of Geophysical Research, 106, 859-877.

Han, W., G. A. Meehl, and A. Hu, 2006: Interpretation of tropical thermocline cooling in the Indian and Pacific oceans during recent decades. Geophysical Research Letters, 33. L23615.

Han, W., J. Vialard, M. J. McPhaden, T. Lee, Y. Masumoto, M. Feng, and W. P. De Ruijter, 2014: Indian Ocean decadal variability: A review. Bulletin of the American Meteorological Society, 95, 1679-1703.

Hénin, C., Y. Du Penhoat, and M. Ioualalen, 1998: Observations of sea surface salinity in the western Pacific fresh pool: Large - scale changes in 1992 1995. Journal of Geophysical Research: Oceans, 103, 7523-7536.

Hermes, J., and C. Reason, 2008: Annual cycle of the South Indian Ocean (Seychelles - Chagos) thermocline ridge in a regional ocean model. Journal of Geophysical Research: Oceans, 113. C04035.

Horii, T., I. Ueki, K. Ando, T. Hasegawa, K. Mizuno, and A. Seiki, 2015: Impact of intraseasonal salinity variations on sea surface temperature in the eastern equatorial Indian Ocean. Journal of Oceanography, 72, 313-326. 
Izumo, T., C. B. Montégut, J.-J. Luo, S. K. Behera, S. Masson, and T. Yamagata, 2008: The role of the western Arabian Sea upwelling in Indian monsoon rainfall variability. Journal of Climate, 21, 5603-5623.

Jang, Y., and D. M. Straus, 2013: Tropical stationary wave response to ENSO: Diabatic heating influence on the Indian summer monsoon. Journal of the Atmospheric Sciences, 70, 193-222.

Jin, X., and Coauthors, 2018: Influences of Pacific climate variability on decadal subsurface ocean heat content variations in the Indian Ocean. Journal of Climate, 31, 4157-4174.

Kao, H., G. Lagerloef, T. Lee, O. Melnichenko, and P. Hacker: Aquarius Salinity Validation Analysis; Data Version 5.0. 2017. Available online at: $\mathrm{ftp}: / /$ podaac-ftp. jpl. nasa. gov/allData/aquarius/docs/v5.

Kerr, Y. H., P. Waldteufel, J.-P. Wigneron, J. Martinuzzi, J. Font, and M. Berger, 2001: Soil moisture retrieval from space: The Soil Moisture and Ocean Salinity (SMOS) mission. IEEE Transactions on Geoscience and Remote Sensing, 39, 1729-1735.

Klein, S. A., B. J. Soden, and N.-C. Lau, 1999: Remote sea surface temperature variations during ENSO: Evidence for a tropical atmospheric bridge. Journal of Climate, 12, 917-932.

Kug, J.-S., and I.-S. Kang, 2006: Interactive feedback between ENSO and the Indian Ocean. Journal of climate, 19, 1784-1801.

Kumari, A., S. P. Kumar, and A. Chakraborty, 2018: Seasonal and interannual variability in the barrier layer of the Bay of Bengal. Journal of Geophysical Research: Oceans, 123, 1001-1015.

Large, W. G., and S. Yeager, 2009: The global climatology of an interannually varying air-sea flux data set. Climate Dynamics, 33, 341-364.

Lau, N.-C., and M. J. Nath, 2003: Atmosphere-ocean variations in the IndoPacific sector during ENSO episodes. Journal of Climate, 16, 3-20.

Lee, T., G. Lagerloef, M. M. Gierach, H. Y. Kao, S. Yueh, and K. Dohan, 2012: Aquarius reveals salinity structure of tropical instability waves. Geophysical Research Letters, 39. L12610.

Levitus, S., J. I. Antonov, T. P. Boyer, R. A. Locarnini, H. E. Garcia, and A. V. Mishonov, 2009: Global ocean heat content 1955-2008 in light of recently revealed instrumentation problems. Geophysical Research Letters, 36. L07608.

Levitus, S., and Coauthors, 1998: NOAA Atlas NESDIS 18, World Ocean Database 1998: vol. 1: Introduction. US Government Printing Office, Washington DC, 346.

Levitus, S., and Coauthors, 2012: World ocean heat content and thermosteric sea level change (0-2000 m), 1955-2010. Geophysical Research Letters, 39, L10603.

Li, S., J. Lu, G. Huang, and K. Hu, 2008: Tropical Indian Ocean basin warming and East Asian summer monsoon: A multiple AGCM study. Journal of Climate, 21, 6080-6088. 
Li, T., B. Wang, C. Chang, and Y. Zhang, 2003: A theory for the Indian Ocean dipole-zonal mode. Journal of the Atmospheric Sciences, 60, 21192135.

Li, Y., W. Han, and T. Lee, 2015: Intraseasonal sea surface salinity variability in the equatorial I ndo - P acific Ocean induced by Madden - Julian oscillations. Journal of Geophysical Research: Oceans, 120, 2233-2258.

Liu, Z., and M. Alexander, 2007: Atmospheric bridge, oceanic tunnel, and global climatic teleconnections. Reviews of Geophysics, 45. RG2005.

Lukas, R., and E. Lindstrom, 1991: The mixed layer of the western equatorial Pacific Ocean. Journal of Geophysical Research: Oceans, 96, 3343-3357.

Madec, G., 2008: NEMO: the OPA ocean engine. IPS Laplace, ed.(France).

Maes, C., 2002: Salinity barrier layer and onset of El Niño in a Pacific coupled model. Geophysical Research Letters, 29. L016029.

Maes, C., and T. J. O'Kane, 2014: Seasonal variations of the upper ocean salinity stratification in the Tropics. Journal of Geophysical Research: Oceans, 119, 1706-1722.

Maes, C., J. Picaut, and S. Belamari, 2005: Importance of the salinity barrier layer for the buildup of El Niño. Journal of Climate, 18, 104-118.

Maes, C., K. Ando, T. Delcroix, W. S. Kessler, M. J. McPhaden, and D. Roemmich, 2006: Observed correlation of surface salinity, temperature and barrier layer at the eastern edge of the western Pacific warm pool. Geophysical Research Letters, 33. L06601.

Maity, R., and D. Nagesh Kumar, 2006: Bayesian dynamic modeling for monthly Indian summer monsoon rainfall using El Nino-Southern Oscillation (ENSO) and Equatorial Indian Ocean Oscillation (EQUINOO). Journal of Geophysical Research: Atmospheres, 111. D07104-D07105.

Masson, S., P. Delecluse, J. P. Boulanger, and C. Menkes, 2002: A model study of the seasonal variability and formation mechanisms of the barrier layer in the eastern equatorial Indian Ocean. Journal of Geophysical Research: Oceans, 107, SRF 18-11-SRF 18-20.

Masson, S., and Coauthors, 2005: Impact of barrier layer on winter - spring variability of the southeastern Arabian Sea. Geophysical Research Letters, 32. L07703.

Matthews, A. J., P. Singhruck, and K. J. Heywood, 2010: Ocean temperature and salinity components of the Madden-Julian oscillation observed by Argo floats. Climate Dynamics, 35, 1149-1168.

McCreary Jr, J. P., P. K. Kundu, and R. L. Molinari, 1993: A numerical investigation of dynamics, thermodynamics and mixed-layer processes in the Indian Ocean. Progress in Oceanography, 31, 181-244.

Menezes, V. V., M. L. Vianna, and H. E. Phillips, 2014: Aquarius sea surface salinity in the South Indian Ocean: Revealing annual - period planetary waves. Journal of Geophysical Research: Oceans, 119, 3883-3908. 
Mignot, J., C. de Boyer Montégut, A. Lazar, and S. Cravatte, 2007: Control of salinity on the mixed layer depth in the world ocean: 2 . Tropical areas. Journal of Geophysical Research: Oceans, 112.

Minoura, D., R. Kawamura, and T. Matsuura, 2003: A mechanism of the onset of the South Asian summer monsoon. Journal of the Meteorological Society of Japan $81,563-580$.

Moisan, J. R., and P. P. Niiler, 1998: The seasonal heat budget of the North Pacific: Net heat flux and heat storage rates (1950-1990). Journal of Physical Oceanography, 28, 401-421.

Murtugudde, R., and A. J. Busalacchi, 1999: Interannual variability of the dynamics and thermodynamics of the tropical Indian Ocean. Journal of Climate, 12, 2300-2326.

Nagura, M., and M. Konda, 2007: The seasonal development of an SST anomaly in the Indian Ocean and its relationship to ENSO. Journal of Climate, 20, 38-52.

Neema, C., P. Hareeshkumar, and C. Babu, 2012: Characteristics of Arabian Sea mini warm pool and Indian summer monsoon. Climate Dynamics, 38, 2073-2087.

Nyadjro, E. S., B. Subrahmanyam, V. Murty, and J. F. Shriver, 2012: The role of salinity on the dynamics of the Arabian Sea mini warm pool. Journal of Geophysical Research: Oceans, 117, C09002:1-12

Nyadjro, E. S., T. G. Jensen, J. G. Richman, and J. F. Shriver, 2017: On the Relationship Between Wind, SST, and the Thermocline in the SeychellesChagos Thermocline Ridge. IEEE Geoscience and Remote Sensing Letters, 14, 2315-2319.

Pai, D., and S. Bhan, 2014: Monsoon 2013: a report (IMD Met. monograph no: ESSO/IMD/SYNOPTIC MET/01-2014/15). India Meteorological Department, National Climate Center, Pune, India.

Pan, L., Y. Zhong, H. Liu, L. Zhou, Z. Zhang, and M. Zhou, 2018: Seasonal variation of barrier layer in the Southern Ocean. Journal of Geophysical Research: Oceans, 123, 2238-2253.

Parthasarathy, B., A. Munot, and D. Kothawale, 1994: All-India monthly and seasonal rainfall series: 1871-1993. Theoretical and Applied Climatology, 49, 217-224.

Picaut, J., M. Ioualalen, C. Menkès, T. Delcroix, and M. McPhaden, 1996: Mechanism of the zonal displacements of the Pacific warm pool: Implications for ENSO. Science, 274, 1486.

Pokhrel, S., and Coauthors, 2012: ENSO, IOD and Indian Summer Monsoon in NCEP climate forecast system. Climate Dynamics, 39, 2143-2165.

Potemra, J. T., 2001: Contribution of equatorial Pacific winds to southern tropical Indian Ocean Rossby waves. Journal of Geophysical Research: Oceans, 106, 2407-2422. 
Prasanna, V., 2016: South Asian Summer Monsoon Rainfall Variability and Trend: Its Links to Indo-Pacific SST Anomalies and Moist Processes. Pure and Applied Geophysics, 173, 2167-2193.

Prodhomme, C., P. Terray, S. Masson, T. Izumo, T. Tozuka, and T. Yamagata, 2014: Impacts of Indian Ocean SST biases on the Indian Monsoon: as simulated in a global coupled model. Climate Dynamics, 42, 271-290.

Qiu, Y., W. Cai, L. Li, and X. Guo, 2012: Argo profiles variability of barrier layer in the tropical Indian Ocean and its relationship with the Indian Ocean Dipole. Geophysical Research Letters, 39. L08605.

Qu, T., and G. Meyers, 2005: Seasonal variation of barrier layer in the southeastern tropical Indian Ocean. Journal of Geophysical Research: Oceans, 110. C11003.

Qu, T., Y. T. Song, and C. Maes, 2014: Sea surface salinity and barrier layer variability in the equatorial Pacific as seen from Aquarius and Argo. Journal of Geophysical Research: Oceans, 119, 15-29.

Rao, R., and R. Sivakumar, 2000: Seasonal variability of near - surface thermal structure and heat budget of the mixed layer of the tropical Indian Ocean from a new global ocean temperature climatology. Journal of Geophysical Research: Oceans, 105, 995-1015.

Rao, R., and R. Sivakumar, 2003: Seasonal variability of sea surface salinity and salt budget of the mixed layer of the north Indian Ocean. Journal of Geophysical Research: Oceans, 108(C1), 9-1-9-14.

Rao, S. A., and S. K. Behera, 2005: Subsurface influence on SST in the tropical Indian Ocean: Structure and interannual variability. Dynamics of Atmospheres and Oceans, 39, 103-135.

Reason, C., 1999: Interannual warm and cool events in the subtropical/mid latitude South Indian Ocean Region. Geophysical Research Letters, 26, 215-218.

_- , 2001: Subtropical Indian Ocean SST dipole events and southern African rainfall. Geophysical Research Letters, 28, 2225-2227.

Reynolds, R. W., N. A. Rayner, T. M. Smith, D. C. Stokes, and W. Wang, 2002: An improved in situ and satellite SST analysis for climate. Journal of Climate, 15, 1609-1625.

Roemmich, D., and J. Gilson, 2009: The 2004-2008 mean and annual cycle of temperature, salinity, and steric height in the global ocean from the Argo Program. Progress in Oceanography, 82, 81-100.

Roxy, M. K., K. Ritika, P. Terray, and S. Masson, 2014: The curious case of Indian Ocean warming. Journal of Climate, 27, 8501-8509.

Roxy, M. K., K. Ritika, P. Terray, R. Murtugudde, K. Ashok, and B. Goswami, 2015: Drying of Indian subcontinent by rapid Indian Ocean warming and a weakening land-sea thermal gradient. Nature communications, 6. 7423.

Saji, N., B. N. Goswami, P. Vinayachandran, and T. Yamagata, 1999: A dipole mode in the tropical Indian Ocean. Nature, 401, 360-363. 
Saraswat, R., R. Nigam, A. Mackensen, and S. Weldeab, 2012: Linkage between seasonal insolation gradient in the tropical northern hemisphere and the sea surface salinity of the equatorial Indian Ocean during the last glacial period. Acta Geologica Sinica, 86, 1265-1275.

Sayantani, O., and C. Gnanaseelan, 2015: Tropical Indian Ocean subsurface temperature variability and the forcing mechanisms. Climate Dynamics, 44, 2447-2462.

Schiller, A., and P. R. Oke, 2015: Dynamics of ocean surface mixed layer variability in the Indian Ocean. Journal of Geophysical Research: Oceans, $120,4162-4186$.

Schiller, A., U. Mikolajewicz, and R. Voss, 1998: The stability of the North Atlantic thermohaline circulation in a coupled ocean-atmosphere general circulation model. Oceanographic Literature Review, 1, 41-42.

Schott, F. A., S. P. Xie, and J. P. McCreary, 2009: Indian Ocean circulation and climate variability. Reviews of Geophysics, 47. RG1002.

Schwarzkopf, F. U., and C. W. Böning, 2011: Contribution of Pacific wind stress to multi - decadal variations in upper - ocean heat content and sea level in the tropical south Indian Ocean. Geophysical Research Letters, 38. L12602.

Shenoi, S., D. Shankar, and S. Shetye, 1999: On the sea surface temperature high in the Lakshadweep Sea before the onset of the southwest monsoon. Journal of Geophysical Research, 104, 15703-15712.

Shinoda, T., M. A. Alexander, and H. H. Hendon, 2004a: Remote response of the Indian Ocean to interannual SST variations in the tropical Pacific. Journal of Climate, 17, 362-372.

Shinoda, T., H. H. Hendon, and M. A. Alexander, 2004b: Surface and subsurface dipole variability in the Indian Ocean and its relation with ENSO. Deep Sea Research Part I: Oceanographic Research Papers, 51, 619-635.

Sijikumar, S., and K. Rajeev, 2012: Role of the Arabian Sea warm pool on the precipitation characteristics during the monsoon onset period. Journal of Climate, 25, 1890-1899.

Simon, B., S. Rahman, and P. Joshi, 2006: Conditions leading to the onset of the Indian monsoon: a satellite perspective. Meteorology and Atmospheric Physics, 93, 201-210.

Stammer, D., 1997: Global characteristics of ocean variability estimated from regional TOPEX/POSEIDON altimeter measurements. Journal of Physical Oceanography, 27, 1743-1769.

Subrahmanyam, B., V. Murty, and D. M. Heffner, 2011a: Sea surface salinity variability in the tropical Indian Ocean. Remote Sensing of Environment, $115,944-956$.

Subrahmanyam, B., V. S. N. Murty, and D. M. Heffner, 2011b: Sea surface salinity variability in the tropical Indian Ocean. Remote Sensing of Environment, 115, 944-956. 
Sun, S., J. Lan, Y. Fang, and X. Gao, 2015: A triggering mechanism for the Indian Ocean Dipoles independent of ENSO. Journal of Climate. 28,5063-5076

Tang, W., and Coauthors, 2017: Validating SMAP SSS with in situ measurements. Remote Sensing of Environment, 200, 326-340.

Tanizaki, C., T. Tozuka, T. Doi, and T. Yamagata, 2017: Relative importance of the processes contributing to the development of SST anomalies in the eastern pole of the Indian Ocean Dipole and its implication for predictability. Climate Dynamics, 49, 1289-1304.

Thadathil, P., P. Muraleedharan, R. Rao, Y. Somayajulu, G. Reddy, and C. Revichandran, 2007: Observed seasonal variability of barrier layer in the Bay of Bengal. Journal of Geophysical Research: Oceans, 112.

Thadathil, P., and Coauthors, 2008: Seasonal variability of the observed barrier layer in the Arabian Sea. Journal of Physical Oceanography, 38, 624638.

Thompson, B., C. Gnanaseelan, and P. Salvekar, 2006: Variability in the Indian Ocean circulation and salinity and its impact on SST anomalies during dipole events. Journal of Marine Research, 64, 853-880.

Tozuka, T., T. Yokoi, and T. Yamagata, 2010: A modeling study of interannual variations of the Seychelles Dome. Journal of Geophysical Research: Oceans, 115. C04005.

- - 2012: Variability of the Seychelles Dome and its possible connection to the Madden-Julian Oscillation. AGU Fall Meeting Abstracts.

Trenary, L. L., and W. Han, 2012: Intraseasonal-to-interannual variability of South Indian Ocean sea level and thermocline: remote versus local forcing. Journal of Physical Oceanography, 42, 602-627.

Ummenhofer, C. C., A. Sen Gupta, and M. H. England, 2009a: Causes of late twentieth-century trends in New Zealand precipitation. Journal of Climate, 22, 3-19.

Ummenhofer, C. C., A. Biastoch, and C. W. Böning, 2017: Multidecadal Indian Ocean variability linked to the Pacific and implications for preconditioning Indian Ocean dipole events. Journal of Climate, 30, 1739-1751.

Ummenhofer, C. C., A. Sen Gupta, M. J. Pook, and M. H. England, 2008: Anomalous rainfall over southwest Western Australia forced by Indian Ocean sea surface temperatures. Journal of Climate, 21, 5113-5134.

Ummenhofer, C. C., A. Sen Gupta, M. H. England, and C. J. Reason, 2009b: Contributions of Indian Ocean sea surface temperatures to enhanced East African rainfall. Journal of Climate, 22, 993-1013.

Vialard, J., and P. Delecluse, 1998: An OGCM study for the TOGA decade. Part II: Barrier-layer formation and variability. Journal of Physical Oceanography, 28, 1089-1106.

Vialard, J., and Coauthors, 2009: Cirene: Air-sea interactions in the Seychelles-Chagos thermocline ridge region. Bulletin of the American Meteorological Society, 90, 45-62 
Vinayachandran, P. N., and R. S. Nanjundiah, 2009: Indian Ocean sea surface salinity variations in a coupled model. Climate Dynamics, 33, 245-263.

Webster, P., and J. Fasullo, 2003: Monsoon: dynamical theory. Encyclopedia of Atmospheric Sciences, 3, 1370-1391.

Webster, P. J., and S. Yang, 1992: Monsoon and ENSO: Selectively interactive systems. Quarterly Journal of the Royal Meteorological Society, 118, 877-926.

Williams, P. D., E. Guilyardi, G. Madec, S. Gualdi, and E. Scoccimarro, 2010: The role of mean ocean salinity in climate. Dynamics of Atmospheres and Oceans, 49, 108-123.

Xie, S.-P., H. Annamalai, F. A. Schott, and J. P. McCreary Jr, 2002: Structure and mechanisms of South Indian Ocean climate variability. Journal of Climate, 15, 864-878.

Xie, F., J. Li, W. Tian, Y. Li, and J. Feng, 2014: Indo-Pacific warm pool area expansion, Modoki activity, and tropical cold-point tropopause temperature variations. Sci Rep, 4, 4552.

Yamagata, T., S. K. Behera, J.-J. Luo, S. Masson, M. R. Jury, and S. A. Rao, 2004: Coupled ocean-atmosphere variability in the tropical Indian Ocean. Earth's Climate: The Ocean-Atmosphere Interaction, Geophys. Monogr, 147, 189-212.

Yang, J., Q. Liu, and Z. Liu, 2010: Linking observations of the Asian monsoon to the Indian Ocean SST: Possible roles of Indian Ocean basin mode and dipole mode. Journal of Climate, 23, 5889-5902.

Yang, J., Q. Liu, S. P. Xie, Z. Liu, and L. Wu, 2007: Impact of the Indian Ocean SST basin mode on the Asian summer monsoon. Geophysical Research Letters, 34. L02708.

Yang, J., Q. Liu, Z. Liu, L. Wu, and F. Huang, 2009: Basin mode of Indian Ocean sea surface temperature and Northern Hemisphere circumglobal teleconnection. Geophysical Research Letters, 36. L19705.

Yokoi, T., T. Tozuka, and T. Yamagata, 2008: Seasonal variation of the Seychelles Dome. Journal of Climate, 21, 3740-3754.

-, 2009 : Seasonal variations of the Seychelles Dome simulated in the CMIP3 models. Journal of Physical Oceanography, 39, 449-457.

- - 2012: Seasonal and interannual variations of the SST above the Seychelles Dome. Journal of Climate, 25, 800-814.

Yu, L., X. Jin, and R. Weller, 2008: Multidecade Global Flux Datasets from the Objectively Analyzed Air-sea Fluxes (OAFlux) Project: Latent and sensible heat fluxes, ocean evaporation, and related surface meteorological variables. OAFlux Project Technical Report. OA-2008-01, pp 64.

Yu, W., B. Xiang, L. Liu, and N. Liu, 2005: Understanding the origins of interannual thermocline variations in the tropical Indian Ocean. Geophysical Research Letters, 32. L24706. 
Yuan, X., M. Salama, and Z. Su, 2018: An Observational Perspective of Sea Surface Salinity in the Southwestern Indian Ocean and Its Role in the South Asia Summer Monsoon. Remote Sensing, 10, 1930.

Yuhong, Z., D. Yan, Z. Shaojun, Y. Yali, and C. Xuhua, 2013: Impact of Indian Ocean Dipole on the salinity budget in the equatorial Indian Ocean. Journal of Geophysical Research: Oceans, 118, 4911-4923.

Zhang, Y. and Y. Du, 2012a: Seasonal variability of salinity budget and water exchange in the northern Indian Ocean from HYCOM assimilation. Chin J Oceanol Limn, 30, 1082-1092.

Zhang, Y. H. and Y. Du, 2012b: Seasonal variability of salinity budget and water exchange in the northern Indian Ocean from HYCOM assimilation. Chin J Oceanol Limn, 30, 1082-1092.

Zhong, A., H. H. Hendon, and O. Alves, 2005: Indian Ocean variability and its association with ENSO in a global coupled model. Journal of Climate, 18 , 3634-3649.

Zhou, L., R. Murtugudde, and M. Jochum, 2008: Seasonal influence of Indonesian Throughflow in the southwestern Indian Ocean. Journal of Physical Oceanography, 38, 1529-1541. 


\section{Acronyms}

\begin{tabular}{|l|l|}
\hline APDRC & Asian-Pacific Data-Research Center \\
\hline Argo & $\begin{array}{l}\text { Array for Real-Time Geotropic } \\
\text { Oceanography }\end{array}$ \\
\hline AS & Arabian Sea \\
\hline BLT & Barrier Layer Thickness \\
\hline BOB & Bay of Bengal \\
\hline CAP & Combined Active-Passive \\
\hline CMAP & CPC Merged Analysis of Precipitation \\
\hline CORE & $\begin{array}{l}\text { Common Ocean-ice Reference } \\
\text { Experiments }\end{array}$ \\
\hline CPC & Climate Prediction Center \\
\hline DJF & December-January-February \\
\hline ECMWF & $\begin{array}{l}\text { European Centre for Medium-Range } \\
\text { Weather Forecasts }\end{array}$ \\
\hline ENSO & El Niño South Oscillation \\
\hline E-P & Evaporation minus Precipitation \\
\hline ESF & Elongated Spatial Feature \\
\hline HYCOM & Hybrid Coordinate Ocean Model \\
\hline ILD & Isothermal Layer Depth \\
\hline IOB & Basin Warming Mode \\
\hline IOD & Indian Ocean Dipole \\
\hline ITCZ & Intertropical Convergence Zone \\
\hline ITF & Indonesian Throughflow \\
\hline JJA & June-July-August \\
\hline MAM & March-April-May \\
\hline MJO & Madden Julian Oscillation \\
\hline MLD & Mixed Layer Depth \\
\hline NCAR & $\begin{array}{l}\text { National Center for Atmospheric } \\
\text { Research }\end{array}$ \\
\hline NCEP & $\begin{array}{l}\text { National Center for Environmental } \\
\text { Prediction }\end{array}$ \\
\hline NEMO & $\begin{array}{l}\text { Nucleus for European Modelling of the } \\
\text { Ocean }\end{array}$ \\
\hline NOAA & $\begin{array}{l}\text { National Oceanic and Atmospheric } \\
\text { Association }\end{array}$ \\
\hline OAFLUX & $\begin{array}{l}\text { Objectively Analyzed Air-sea Fluxes } \\
\text { Project }\end{array}$ \\
\hline OGCM & Ocean General Circulation Model \\
\hline PDF & Probability Density Function \\
\hline SASM & South Asian Summer monsoon \\
\hline SD & Seychelles Dome \\
\hline & \\
\hline &
\end{tabular}




\begin{tabular}{|l|l|}
\hline SMOS & Soil Moisture Ocean Salinity \\
\hline SSH & Sea Surface Height \\
\hline SSS & Sea surface salinity \\
\hline SSSAS & Sea surface salinity anomalies \\
\hline SST & Sea surface temperature \\
\hline SSTAs & Sea surface temperature anomalies \\
\hline SODA & Simple ocean data assimilation \\
\hline SON & September-October-November \\
\hline SWIO & Southwestern Indian Ocean \\
\hline TRIO & $\begin{array}{l}\text { Thermocline Ridge of the Indian } \\
\text { Ocean }\end{array}$ \\
\hline TTD & Top of the thermocline depth \\
\hline TIO & The tropical Indian Ocean \\
\hline
\end{tabular}




\section{Summary}

The variability of the tropical Indian Ocean (TIO) is crucial to the global water cycle and heat transportation. At the seasonal time scale, the variability of the TIO is closely related to the monsoon circulation. Interannually, on the one hand, it is influenced remotely by the variability of the Pacific Ocean through atmospheric bridge and Rossby wave. On the other hand, the variability of TIO is independent of El Niño-Southern Oscillation (ENSO) and varies as a dipole pattern along the equator, known as the Indian Ocean dipole (IOD). In addition, the unique distribution of the TIO with shallower thermocline in the west, due to the unstable easterlies along the equator, makes the variability of the TIO differ from that in the Pacific and the Atlantic Ocean with deeper thermocline in the west. However, the TIO variability is still hard to precisely predict and the difficulty is well acknowledged nowadays.

To this end, the main aim of this dissertation is to better understand the seasonal and interannual variability of the TIO. Specifically, the first objective is to distinguish the relative impacts of heat flux and wind stress on the interannual variability of upper-ocean temperature in the TIO. The second objective focuses on studying the relationships among the parameters in the mixed layer and thermocline with the barrier layer thickness (BLT) in the TIO. The last objective of this dissertation is to investigate the role of sea surface salinity (SSS) in the onset of South Asian Summer Monsoon (SASM). To achieve this aim, the observation datasets including float and satellite data, reanalysis data, and simulations from a high-resolution model, are employed.

In Chapter 2, we compared the ocean general circulation model (OGCM) hindcast with the reanalysis and observation data and found that they were consistent in the simulation of the climatological mean and interannual variability of the upper-ocean temperature vertical structure in the TIO. Therefore, OGCM was adopted in this study to study the variability of the TIO. Two sensitivity simulations were designed to study the relative contribution of heat flux and wind stress to the variability of TIO: one was set with only heat flux varying interannually, and another one assumed only wind stress varying interannually. The results show that the impacts of heat flux and wind stress on the interannual variability of ocean temperature in the TIO have a depthdependent feature. Specifically, heat flux mainly dominates the interannual variability of ocean temperature above the depth of approximately $30 \mathrm{~m}$ in the TIO, while wind stress contributes most to the interannual variability of ocean temperature below the depth of $30 \mathrm{~m}$. This depth-dependent feature has also been observed for sub-areas and different seasons in the TIO. Therefore, we define the depth where the dominant force switches from heat flux to wind stress in the TIO as the "crossing depth". Shallower crossing depth indicates that heat flux only controls the interannual variability of ocean temperature 
near the surface while wind stress is the dominant driving force for the interannual temperature variability in the upper-ocean, such as the SeychellesChagos Thermocline Ridge (SCTR) and the eastern part of the Indian Ocean Dipole (IODE).

In chapter 3, we assessed the driving forces for the variability of the barrier layer thickness (BLT) in TIO. The barrier layer is defined as a thinner layer between the bottom of the mixed layer and the top of the thermocline. The BLT in the TIO has significant seasonal and interannual variabilities. The results of this study show that the sea surface temperature (SST) barely contributes to the variability of BLT but the main forcing on the BLT from the mixed layer can be explained by the variability of SSS. At the seasonal time scale, the dominating drivers of the BLT variability are different in the western and eastern TIO. In the western TIO, SSS exerts a negative correlation with the BLT variability during boreal autumn, winter, and spring while shows minimal impacts on the BLT variability in summer. In the eastern TIO, the thermocline is the dominant driver for the BLT variability, and it has positive correlations with BLT in all four seasons. At the interannual time scale, the variability of BLT in the TIO is affected by the IOD and ENSO events. Particularly, in the eastern TIO, thinner BLT could be detected mainly induced by the anomalous thermocline during the positive IOD and El Niño years. In the western TIO, deepening thermocline due to El Niño induced anomalous wind stress results in thicker BLT. But the correlation between BLT and El Niño does not become weaker with the weakening relationship between thermocline and El Niño. This is because of the variation of SSS.

In Chapter 4, we investigated the role of sea surface salinity anomalies (SSSAs) in the onset of the SASM. Positive SSSAs appears in the western TIO before the onset of SASM. This SSSAs has two maxima in the symmetry of the equator with one in the southern TIO and another one in the northern TIO. The location of the southern maxima corresponds to the SCTR. It is found that the SSSAs respond more sensitively to the change of the atmospheric circulation than sea surface temperature anomalies (SSTAs). The positive SSSAs in the SCTR, induced by the anomalous wind stress curl and associated with thinner BLT anomalies, provides a favorable environment for the decreasing SSTAs during spring. Meanwhile, this SSSAs-BLT-SSTAs process also develops in the SSSAs maxima of the northern TIO but happens later than that in the southern TIO. Therefore, this time-lag between the northern and southern TIO strengthened the north-to-south SST gradient, which in turn, promotes the northward crossing current for the onset of SASM.

To conclude, this Ph.D. research primarily investigates the variability of the TIO by distinguishing the main driver of the interannual upper-ocean temperature variability, studying the relationships between SSS and 
thermocline with BLT at seasonal and interannual scales and discovering the role of SSS in the onset of SASM. However, more efforts are highly demanded in the near future to investigate more sophisticated air-sea interaction mechanism within the TIO. For example, the theory of crossing depth is only adapted in the area of $\left(15^{\circ} \mathrm{S}-20^{\circ} \mathrm{N}\right)$. Thus, how to distinguish the relative impacts of heat flux and wind stress on the upper-ocean variability in the area to the south of $15^{\circ} \mathrm{S}$ is still to be unraveled. In addition, the role of SSS in the interannual variability of the TIO needs more precise datasets to investigate and the numerical modeling with more sophisticated air-sea interactions should be taken into consideration. 


\section{Samenvatting}

De variabiliteit van de tropische Indische Oceaan (TIO) is van cruciaal belang voor de globale watercyclus en warmtetransport. Op niveau van seizoenen hangt de variabiliteit van de TIO nauw samen met de moessoncirculatie. Op meerjarige tijdschaal echter, wordt het op afstand beïnvloed door de variabiliteit van de Stille Oceaan via een atmosferische brug en de Rossbygolven. Aan de andere kant blijkt de variabiliteit van de TIO onafhankelijk van de El Niño-Southern Oscillation (ENSO) en de variatie van een dipoolpatroon langs de evenaar, beter bekend als de Indische Oceaan dipool (IOD). Bovendien maakt de unieke verdeling van de TIO met een ondiepere thermocline in het westen en onstabiele oostelijke delen langs de evenaar, de variabiliteit van de TIO anders dan die van de Stille Oceaan en de Atlantische Oceaan, met beide diepere thermoclines in het westen. De TIO-variabiliteit is nog steeds moeilijk te voorspellen en dit probleem wordt tegenwoordig ook goed onderkend.

Het hoofddoel van dit proefschrift was om de seizoensgebonden en meerjarige variabiliteit van de TIO beter te begrijpen. Het eerste doel was een onderscheid maken tussen de relatieve effecten van warmteflux en windstress op de meerjarige variabiliteit van de temperatuur boven de oceaan in de TIO. De tweede doelstelling richtte zich op het bestuderen van de relaties tussen de parameters van de gemengde laag en thermocline, met de barrièrelaagdikte (BLT) in de TIO. Het laatste doel van dit proefschrift was om de rol te onderzoeken van het zoutgehalte aan het zeeoppervlak (SSS) bij het begin van de Zuid-Aziatische Zomer Moesson (SASM). Om dit doel te bereiken, werden de observatiegegevens, inclusief "buoy-" en satellietgegevens, her analysegegevens en simulaties van een model met hoge resolutie gebruikt.

In hoofdstuk 2 hebben we "hintcast" simulaties van een algemeen oceaan circulatiemodel (OGCM) vergeleken met de her analyse- en observatiegegevens en geconstateerd dat ze consistent waren in de simulatie van het klimatologische gemiddelde en de meerjarige variabiliteit van de verticale structuur van de temperatuur boven de oceaan in de TIO. Twee gevoeligheidsanalyses werden ontworpen om de relatieve bijdrage van warmteflux en windstress aan de variabiliteit van TIO te bestuderen: één werd ingesteld met enkel een variabele warmteflux, en een andere veronderstelde enkel een variabele windbelasting. De resultaten laten zien dat de effecten van warmteflux en windstress op de meerjarige variabiliteit van de oceaan watertemperaturen in de TIO diepteafhankelijk zijn. In het bijzonder domineert de warmteflux voornamelijk de meerjarige variabiliteit van de oceaantemperatuur boven de diepte van $30 \mathrm{~m}$ in de TIO, terwijl windstress het meest bijdraagt aan de meerjarige variabiliteit van de oceaantemperatuur beneden de diepte van $30 \mathrm{~m}$. Deze diepte-afhankelijke relatie is ook 
waargenomen voor deelgebieden en de verschillende seizoenen in de TIO. Daarom definiëren we de diepte waar de dominante kracht van warmteflux naar windstress in de TIO overschakelt als de "kruisingsdiepte". Ondiepere kruisdiepte geeft aan dat warmteflux alleen de meerjarige variabiliteit van de oceaantemperatuur in de buurt van het oppervlak regelt, terwijl windstress de dominante drijvende kracht is voor de meerjarige temperatuurvariabiliteit in de boven-oceaan, zoals de Seychelles-Chagos Thermocline Ridge (SCTR) en de oostelijk deel van de Indische Oceaan Dipool (IODE).

In hoofdstuk 3 hebben we de drijvende krachten beoordeeld op de variabiliteit van de barrièrelaagdikte (BLT) in de TIO. De barrière laag werd gedefinieerd als een dunnere laag tussen de onderkant van de gemengde laag en de bovenkant van de thermocline. De BLT in de TIO vertoonde significante seizoensgebonden en meerjarige variabiliteit. De resultaten van dit onderzoek tonen aan dat de watertemperatuur van het zeeoppervlak (SST) nauwelijks bijdraagt aan de variabiliteit van BLT, en de belangrijkste kracht op de BLT vanuit de gemengde laag kan worden verklaard door de variabiliteit van het zoutgehalte aan het oppervlak (SSS). Op seizoen niveau zijn de dominante sturingen van de BLT-variabiliteit verschillend in de westelijke en oostelijke TIO. In de westerse TIO oefent het zoutgehalte (SSS) een negatieve correlatie uit op de BLT-variabiliteit tijdens herfst, winter en lente, terwijl het minimale effecten op de BLT-variabiliteit in de zomer vertoont. In de oostelijke TIO is de thermocline de dominante driver voor BLT-variabiliteit en het heeft positieve correlaties met BLT in alle vier seizoenen. Op de meerjarige tijdschaal wordt de variabiliteit van BLT in de TIO beïnvloed door de IOD- en ENSOgebeurtenissen. In het bijzonder in de oostelijke TIO kon een dunnere BLT worden gedetecteerd, voornamelijk veroorzaakt door de abnormale thermocline tijdens de positieve IOD- en El Niño-jaren. In de westelijke TIO resulteerde de verdieping van de thermocline door El Niño in abnormale windstress in een dikkere BLT. Maar de correlatie tussen BLT en El Niño wordt niet zwakker vanwege de weefverhouding tussen thermocline en El Niño. Dit komt door de variatie van het zoutgehalte (SSS).

In hoofdstuk 4 onderzochten we de rol van de afwijkingen van het zeeoppervlak zoutgehalte (SSSAs) bij het ontstaan van de SASM. Een positieve SSSA verschijnt in de westelijke TIO vóór het begin van SASM. Deze SSSA heeft twee maxima in symmetrie van de evenaar met een in de zuidelijke TIO en een andere in de noordelijke TIO. De locatie van de zuidelijke maxima komt overeen met de SCTR. Het is gebleken dat de SSSAs gevoeliger reageren op de verandering van de luchtcirculatie dan anomalieën van de zee oppervlaktetemperatuur (SSTAs). De positieve SSSAs in de SCTR, veroorzaakt door de abnormale windstresskrul en geassocieerd met dunnere BLTafwijkingen, bieden een gunstige omgeving voor de afnemende SSTAs tijdens de lente. Ondertussen ontwikkelt dit SSSAs-BLT-proces zich ook in de SSSAs 
maxima van de noordelijke TIO, maar gebeurt later dan deze in de zuidelijke TIO. Daarom versterkte deze tijdsvertraging tussen de noordelijke en zuidelijke TIO de noord-naar-zuid SST-gradiënt, die op zijn beurt de noordelijke kruisingsstroom voor het begin van SASM bevordert.

Om te besluiten, dit PhD onderzoek onderzocht in de eerste plaats de variabiliteit van de TIO door onderscheid te maken tussen de belangrijkste oorzaken van de meerjarige temperatuurschommeling van het bovenste deel van deze oceaan, het bestuderen van de relaties tussen SSS en de thermocline met de BLT op seizoens- en meerjarige tijdschalen en de rol van het zoutgehalte (SSS) bij het ontstaan van SASM. In de nabije toekomst zijn er echter meer inspanningen nodig om een meer geavanceerde lucht-zee interactiemechanismes binnen de TIO te onderzoeken. De theorie van kruisingsdiepte is bijvoorbeeld alleen aangepast in het gebied van ( $15^{\circ} \mathrm{S}-20^{\circ}$ $\mathrm{N})$. Dus, hoe de relatieve effecten van warmteflux en windstress op de variabiliteit van de bovenste oceaan in het gebied ten zuiden van $15^{\circ} \mathrm{S}$ te onderscheiden is, is nog steeds niet duidelijk. Bovendien moet de rol van de SSS op de meerjarige variabiliteit van de TIO meer precieze datasets onderzoeken en moet ook gewerkt worden aan de numerieke modellering van meer geavanceerde lucht-zee-interacties. 